US Army Corps of Engineers ${ }_{\circledast}$

Engineer Research and

Development Center

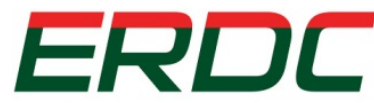

INNOVATIVE SOLUTIONS for a safer, better world

Department of Defense Legacy Resource Management Program

\title{
Guidance on the Use of Historic Human Remains Detection Dogs for Locating Unmarked Cemeteries
}

Carey L. Baxter and Michael L. Hargrave

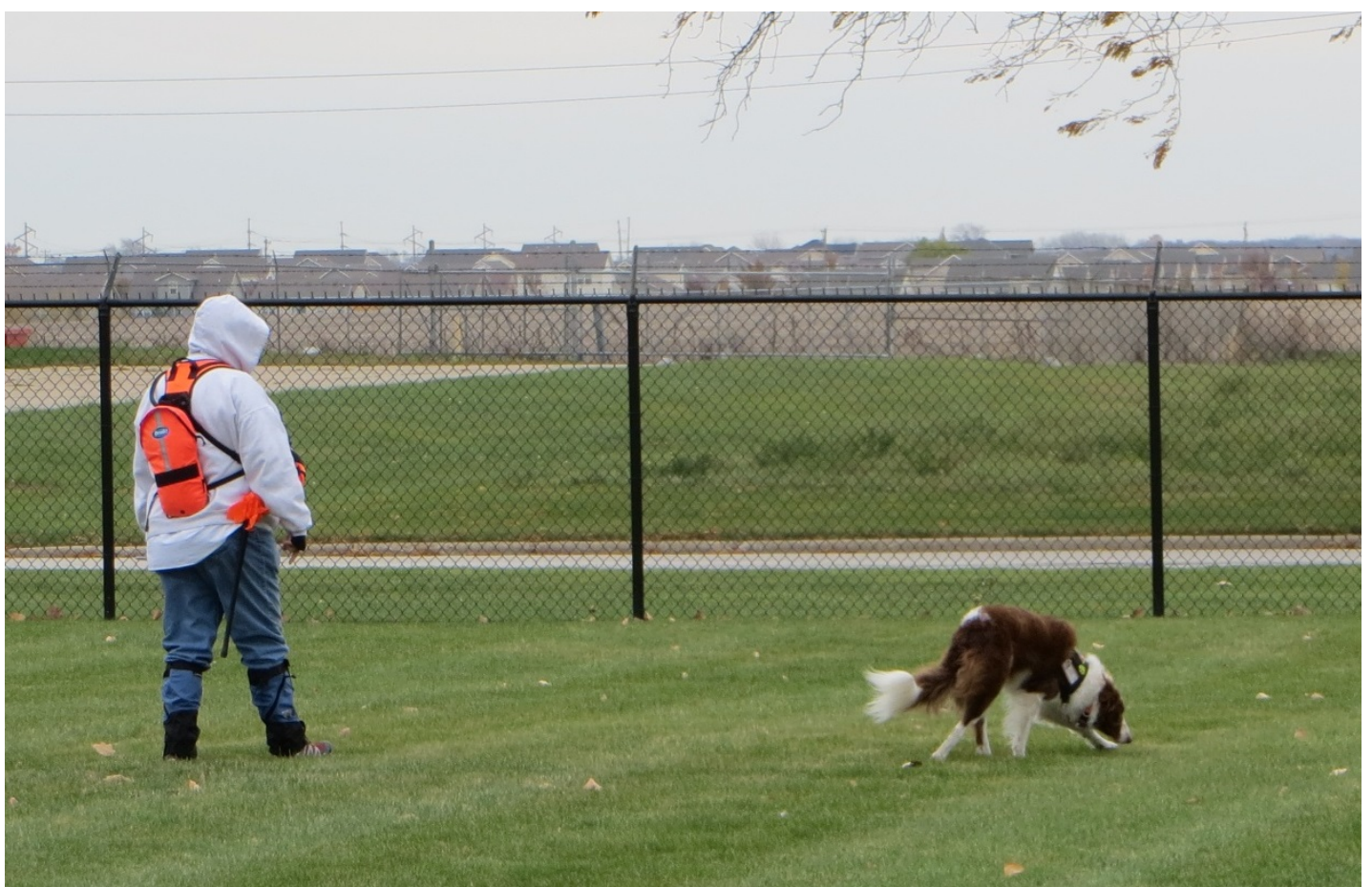


The US Army Engineer Research and Development Center (ERDC) solves the nation's toughest engineering and environmental challenges. ERDC develops innovative solutions in civil and military engineering, geospatial sciences, water resources, and environmental sciences for the Army, the Department of Defense, civilian agencies, and our nation's public good. Find out more at www.erdc.usace.army.mil.

To search for other technical reports published by ERDC, visit the ERDC online library at http://acwc.sdp.sirsi.net/client/default. 


\section{Guidance on the Use of Historic Human Remains Detection Dogs for Locating Unmarked Cemeteries.}

Carey L. Baxter and Michael L. Hargrave

Construction Engineering Research Laboratory

US Army Engineer Research and Development Center

2902 Newmark Drive

Champaign, IL 61822

Final report

Approved for public release; distribution is unlimited.

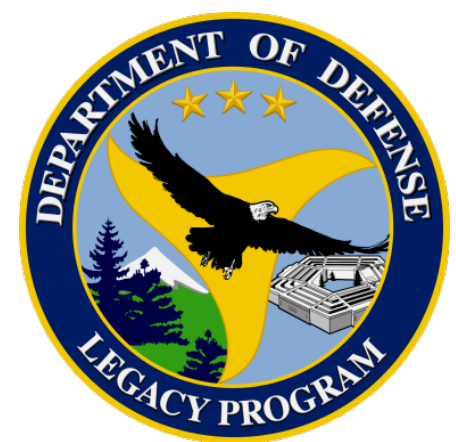

Prepared for DoD Legacy Program

Alexandria, VA 20314

Under Project 12-510, "Guidance on the Use of Historic Human Remains Detection Dogs for Locating Unmarked Cemeteries" 


\section{Abstract}

Human burial sites form a unique class of archeological site. Local civilian populations tend to have strong emotional ties to historic cemeteries, and Native American cemeteries are given special protection under federal law. Standard operating procedures on most (if not all) government installations is to identify and protect (in situ) all known locations of human burials. The location of many cemeteries, however, is unknown due to a lack of recognizable visual cues such as grave markers. Because the sites must be investigated without excavation, archaeologists have traditionally used geophysical survey as a noninvasive technique to locate lost cemeteries.

A recent development in noninvasive grave location techniques is the use of Historic Human Remains Detection (HHRD) dogs. These dogs are specially trained to detect the scent of buried human bones. Proponents of this techniques claim the dogs can differentiate between human and animal bones and can detect graves exceeding 100 years of age and located up to 6 feet beneath the surface. Determining the effectiveness of HHRD dog surveys is problematic because ground truthing is rarely allowed. This report describes a scientific study testing the effectiveness of HHRD dogs and comparing HHRD dog results against geophysical survey results at multiple, unmarked, burial sites.

DISCLAIMER: The contents of this report are not to be used for advertising, publication, or promotional purposes. Citation of trade names does not constitute an official endorsement or approval of the use of such commercial products. All product names and trademarks cited are the property of their respective owners. The findings of this report are not to be construed as an official Department of the Army position unless so designated by other authorized documents. 


\section{Contents}

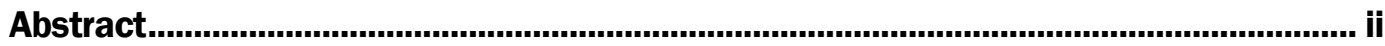

Figures and Tables...........................................................................................................

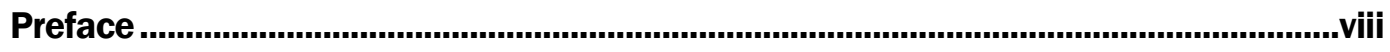

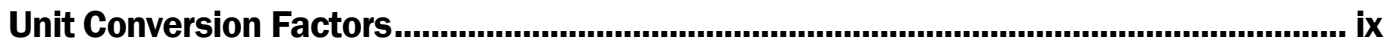

Abbreviations.................................................................................................. X

1 Introduction .......................................................................................................................... 1

1.1 Background and previous work ............................................................ 1

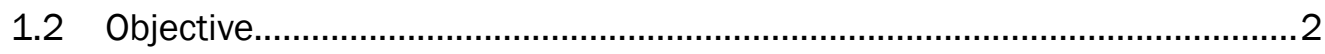

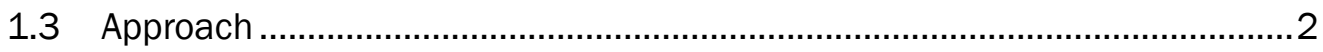

1.3.1 Field site selection ............................................................................................ 2

2 Historic Human Remains Detection Dogs ................................................. 4

2.1 Principles of canine scent detection .........................................................

2.2 The Institute of Canine Forensics (ICF) practice and procedures...................8

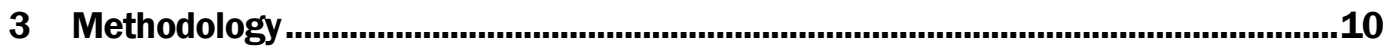

3.1 Geophysical techniques ....................................................................

3.1.1 General background …………................................................................. 10

3.1.2 Data collection and analysis ..................................................................... 14

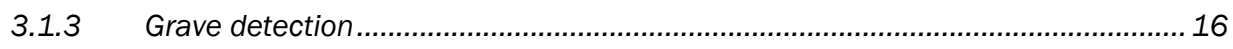

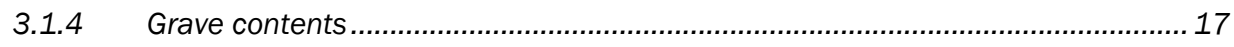

3.1.5 Assumptions and interpretive criteria.......................................................... 18

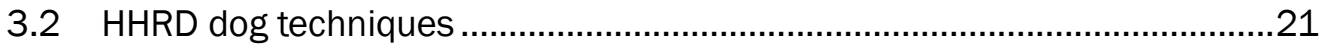

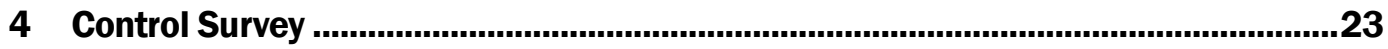

4.1 Survey area creation .......................................................................... 23

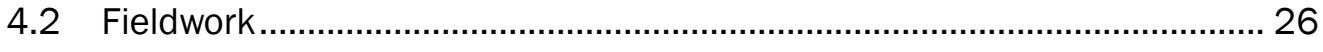

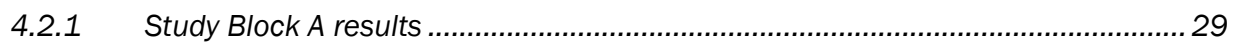

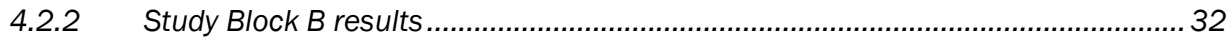

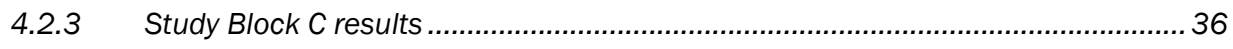

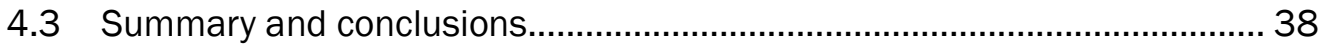

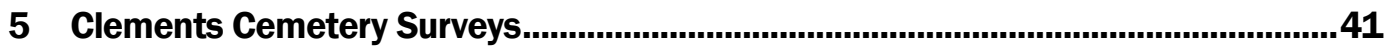

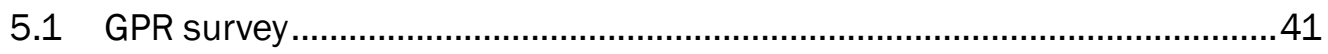

5.1.1 Summary and conclusions ........................................................................... 50

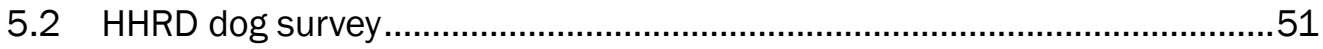

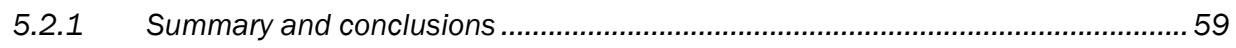




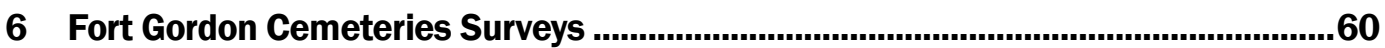

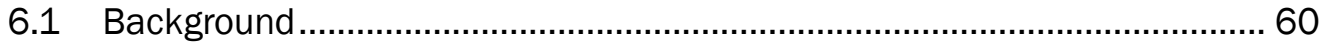

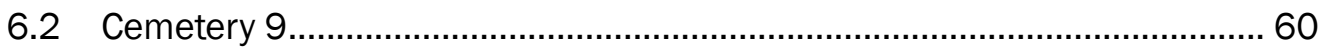

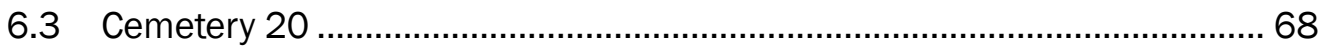

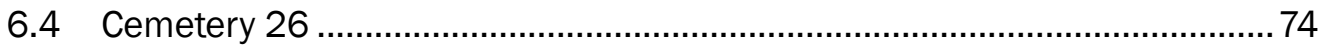

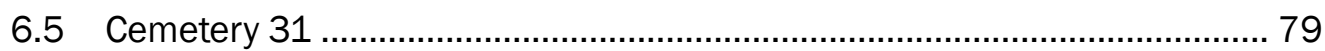

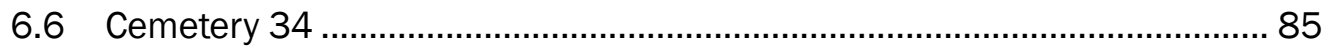

6.7 Cost benefits comparison of HHRD and geophysical surveys.....................91

6.8 Summary and conclusions on Fort Gordon cemetery surveys .................... 92

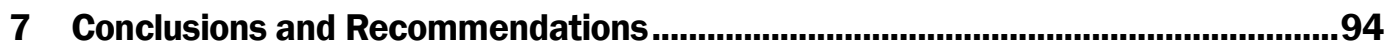

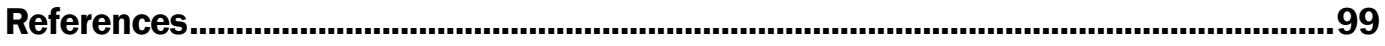

\section{Report Documentation Page}




\section{Figures and Tables}

\section{Figures}

Figure 1. Use of a GSSI $400 \mathrm{MHz}$ antenna detached from the SIR3000 cart (left) and use of a Bartington Grad601 dual gradiometer (right) (neither photo taken during this study).

Figure 2. Bricks outlining a presumed grave location at Fort Gordon Cemetery 30 (cemetery not included in the geophysical survey).

Figure 3. Aligned bricks near footstone and along retaining wall at Fort Gordon Cemetery 30 (cemetery not included in the geophysical survey).

Figure 4. Concrete retaining wall surrounding a family section in Fort Gordon Cemetery 30 (cemetery not included in the geophysical survey).

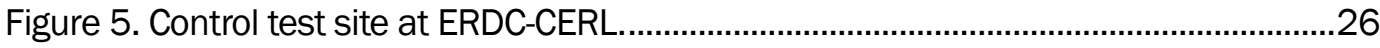

Figure 6. Control test site with human and animal buffers depicted. ................................28

Figure 7. Results of Team AM dog survey of Control Area, Study Block A...........................29

Figure 8. Results of Team BP dog survey of Control Area, Study Block A...........................30

Figure 9. Results of Team JG dog survey of Control Area, Study Block A............................30

Figure 10. Results of Team LA dog survey of Control Area, Study Block A........................31

Figure 11. Results of Team AM dog survey of Control Area, Study Block B.......................32

Figure 12. Results of Team BP dog survey of Control Area, Study Block B. ......................33

Figure 13. Results of Team JG dog survey of Control Area, Study Block B..........................34

Figure 14. Results of Team LA dog survey of Control Area, Study Block B. ........................35

Figure 15. Results of Team AM dog survey of Control Area, Study Block C........................36

Figure 16. Results of Team JG dog survey of Control Area, Study Block C. .........................37

Figure 17. Results of Team LA dog survey of Control Area, Study Block C..........................37

Figure 18. Selected GPR hyperbolas detected in the southwest survey area, Clements Cemetery (Grid 52; $x=0.51 ; y=4.00$ ).

Figure 19. Selected GPR hyperbolas detected in the northeast survey area,

Clements Cemetery (Grid 51; $x=12.00 ; y=4.02$ ).

Figure 20. Selected GPR hyperbolas detected in the northeast survey area, Clements Cemetery (Grid 51; $x=6.78 ; y=9.58$ ).

Figure 21. Selected GPR hyperbolas detected in the northeast survey area, Clements Cemetery (Grid 50; $x=7.47 ; y=12.02$ ).

Figure 22. Selected GPR hyperbolas detected in the southeast survey area, Clements Cemetery (Grid 49; $x=8.72 ; y=1.44$ ).

Figure 23. Selected GPR hyperbolas detected in the southeast survey area, Clements Cemetery (Grid 49; $x=9.74 ; y=4.86$ ).

Figure 24. GPR survey at Clements Cemetery, looking west. Note that inscriptions are on the east side of some markers. 
Figure 25. GPR survey at Clements Cemetery, looking east. Note that inscriptions are on the west side of many markers.

Figure 26. Amplitude slices of west survey area, Clements Cemetery. North-south linear patterns are clearly visible.

Figure 27. Locations of GPR hyperbolas possibly associated with graves and observed grave marker stones, Clements Cemetery.

Figure 28. Alignments of observed grave marker stones and GPR hyperbolas possibly associated with graves, Clements Cemetery.

Figure 29. Cases where hyperbolas occur within one meter of a marker stone (green circles), Clements Cemetery.

Figure 30. Clements Cemetery showing GPR (black outline) and HHRD dog (red outline) survey blocks.

Figure 31. Results of Team AM dog survey for Clements Cemetery, Blocks A and D.

Figure 32. Results of Team JG dog survey for Clements Cemetery, Blocks A and D.

Figure 33. Results of Team LA dog survey for Clements Cemetery, Blocks A and D...

Figure 34. Results of Team AM dog survey for Clements Cemetery, Blocks B and C.

Figure 35. Results of Team BP dog survey for Clements Cemetery, Blocks B and C.

Figure 36. Results of Team JG dog survey for Clements Cemetery, Blocks B and C.

Figure 37. View to north of Cemetery 9 at Fort Gordon.

Figure 38. Overlay of magnetic data onto GPR data showing two rows of possible graves. Coordinates in meters. (Hargrave 2011, Figure 3-7).

Figure 39. Results of Team AM dog survey of Cemetery 9 at Fort Gordon .64

Figure 40. Results of Team BP dog survey of Cemetery 9, Fort Gordon. 65

Figure 41. Results of Team JG dog survey of Cemetery 9, Fort Gordon. .66

Figure 42. Results of Team LA dog survey of Cemetery 9, Fort Gordon. .67

Figure 43. Possible graves based on all GPR slices, Cemetery 20, Fort Gordon (Hargrave 2011, Figure 3-11). 69

Figure 44. Results of Team AM dog survey, Cemetery 20, Fort Gordon.............................70

Figure 45. Results of Team BP, Cemetery 20, Fort Gordon. ................................................. 71

Figure 46. Results of Team JG, Cemetery 20, Fort Gordon. ................................................. 72

Figure 47. Results of Team LA, Cemetery 20, Fort Gordon...............................................73

Figure 48. View to northwest of possible grave stones, Cemetery 26, Fort Gordon. ......... 74

Figure 49. possible graves at Cemetery 26, Fort Gordon, based on all GPR slices (top), all magnetic data (center), and overlay of magnetic anomalies on possible graves (bottom) (Hargrave 2011, Figure 3-15) ...................................................................... 76

Figure 50. Results of Team JG dog survey, Cemetery 26, Fort Gordon................................77

Figure 51. Results of Team LA dog survey, Cemetery 26, Fort Gordon...............................78 
Figure 52. Possible graves in Cemetery 31 at Fort Gordon. Strong magnetic anomalies (red and blue) atop possible graves, based on all GPR slices. There is some correlation of magnetic and GPR indications of graves. All coordinates given in meters, and north is at top of figure. (Hargrave 2011, Figure 3-22).

Figure 53. Results of Team AM dog survey, Cemetery 31, Fort Gordon. ............................81

Figure 54. Results of Team BP, Cemetery 31, Fort Gordon. ..............................................82

Figure 55. Results of Team JG, Cemetery 31, Fort Gordon...............................................83

Figure 56. Results of Team LA, Cemetery 31, Fort Gordon. ............................................84

Figure 57. Possible graves at Cemetery 34, Fort Gordon. All magnetic data (top) and magnetic anomalies atop all possible graves (below). (Hargrave 2011, Figure 3-29)

Figure 58. Results for Team AM survey of Cemetery 34, Fort Gordon..............................87

Figure 59. Results for Team BP survey of Cemetery 34, Fort Gordon.................................88

Figure 60. Results of Team JG survey of Cemetery 34, Fort Gordon...................................89

Figure 61. Results of Team LA survey of Cemetery 34, Fort Gordon...................................90

\section{Tables}

Table 1. Bone order composition among common mammals (Vass et al. 2008)................ 6

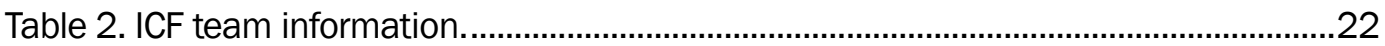

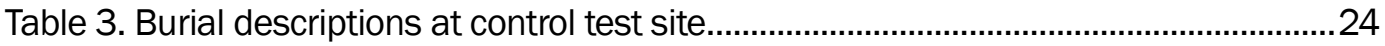

Table 4. Summary for dog surveys Control Area, Study Block A. ..........................................31

Table 5. Summary of dog surveys for Control Study, Block B..........................................35

Table 6. Summary of dog surveys for Control Area, Study Block C......................................38

Table 7. Summary of HHRD dog surveys, Cemetery 9, Fort Gordon....................................67

Table 8. Summary of HHRD dog surveys, Cemetery 20, Fort Gordon...................................73

Table 9. Summary of HHRD dog survey, Cemetery 26, Fort Gordon.....................................78

Table 10. Summary of HHRD dog survey, Cemetery 31, Fort Gordon..................................84

Table 11. Summary of HHRD dog survey, Cemetery 34, Fort Gordon. ................................90

Table 12. Summary of all HHRD dog alerts at Fort Gordon cemeteries. ............................92 


\section{Preface}

This study was conducted for the Department of Defense Legacy Resource Management Program under Project 12-510, "Guidance on the Use of Historic Human Remains Detection Dogs for Locating Unmarked Cemeteries.” The sponsor's technical monitor was Kelly Merrifield, Cultural Resources Specialist.

The authors would like to thank the following for the assistance provided to the researchers during the fieldwork at Fort Gordon, Georgia: Mr. Robert Drumm, Chief, Natural Resources Branch DPW and Ms. Renee Lewis, Archaeologist. The authors would also like to thank the staff of the Institute of Canine Forensics including Ms. Lynne Angeloro, Ms. Adela Morris, Ms. Barbara Pence, Mr. John Grebenkemper and Mr. Jerrold Christensen. The authors would also like to thank Mr. Cecil McCormick, Clements Cemetery Association Trustee for allowing the cemetery to be used as a test location.

This work was performed by the Land and Heritage Conservation Branch (CN-C) of the Installations Division (CN), US Army Engineer Research and Development Center - Construction Engineering Research Laboratory (ERDC-CERL). At the time fieldwork was performed, Dr. Christopher White was Chief, CEERD-CN-C. At the time of publication, Dr. Michael Hargrave was Chief, CEERD-CN-C, and Ms. Michelle Hanson was Chief, CEERD-CN. The Deputy Director of ERDC-CERL was Dr. Kirankumar Topudurti, and the Director was Dr. Ilker Adiguzel.

COL Bruce S. Green was the Commander of ERDC, and Dr. Jeffery P. Holland was the Director. 


\section{Unit Conversion Factors}

\begin{tabular}{|l|l|l|}
\hline Multiply & By & To Obtain \\
\hline degrees (angle) & 0.01745329 & radians \\
\hline degrees Fahrenheit & $(\mathrm{F}-32) / 1.8$ & degrees Celsius \\
\hline hectares & $1.0 \mathrm{E}+04$ & square meters \\
\hline miles per hour & 0.44704 & meters per second \\
\hline
\end{tabular}




\section{Abbreviations}

$\begin{array}{ll}\text { Term } & \text { Spell-out } \\ \text { 3D } & \text { three-dimensional } \\ \text { CRM } & \text { Cultural Resource Management } \\ \text { DOAD } & \text { Decompositional Odor Analysis Database } \\ \text { DRI } & \text { Desert Research Institute } \\ \text { ERDC-CERL } & \text { Engineer Research and Development Center-Construction } \\ & \text { Engineering Research Laboratory } \\ \text { GPR } & \text { ground penetrating radar } \\ \text { HRD } & \text { Human Remains Detection } \\ \text { HHRD } & \text { Historic Human Remains Detection } \\ \text { ICF } & \text { Institute of Canine Forensics } \\ \text { MHz } & \text { megahertz }\end{array}$




\section{Introduction}

\subsection{Background and previous work}

Human burial sites form a unique class of archeological site. Local civilian populations tend to have strong emotional ties to historic cemeteries, and Native American cemeteries are deemed places of religious significance and given special protection under federal law (Native American Graves Protection and Repatriation Act of 1990). Standard operating procedures on most (if not all) government installations will identify and protect (in situ) all known locations of human burials. The location of many cemeteries, however, is unknown due to a lack of recognizable visual cues such as grave markers. Identification and verification of historic and prehistoric cemeteries through standard archeological techniques is problematic because the sites must be investigated without excavation. Traditionally, archaeologists have used geophysical survey as a noninvasive technique to locate lost cemeteries.

In 2009, archaeologists at US Army Engineer Research and Development Center-Construction Engineering Research Laboratory (ERDC-CERL) in Champaign, Illinois, were approached by the Cultural Resource Management Office for Fort Leavenworth, Kansas, to conduct a geophysical survey to locate a historic, unmarked cemetery within the installation. Anecdotal evidence and a historic newspaper account indicated that during the Nez Perce confinement on Fort Leavenworth (1877-1879), approximately two dozen tribe members died and were buried near the Nez Perce encampment. The burial area was believed to be near the current airfield. At the request of the Nez Perce Nation, Fort Leavenworth included historic human remains detection (HHRD) dog teams as one of the methodologies to be deployed in the search for the cemetery.

At the Fort Leavenworth site, ERDC-CERL archaeologists deployed electric resistance and magnetic gradiometer geophysical survey techniques. Ground penetrating radar (GPR) was not utilized, as the survey area was located on a floodplain and water saturation of the soil precluded good results from that technique. The presence of the remains of a World War II cinder runway and the underground infrastructure associated with the modern airfield prevented ERDC-CERL archaeologists from obtaining good results with the survey techniques available to them. 
During this work, the archaeology team and the HHRD dog teams were working simultaneously. It was observed that the dogs were able to: (a) cover significantly more ground than the archaeologists, (b) did not alert on the remains of wild animals that were observed on the ground surface, and (c) were alerting on the measuring tapes that ERDC-CERL had used in previous cemetery surveys. The HHRD dog teams had alerted at several locations in the project area, but ground truthing of any suspect areasboth those identified by archaeologists and dog teams-was prohibited. As a result, it was not possible to verify the accuracy of those HHRD alerts.

\subsection{Objective}

The study reported here was conceived as a result of the previous experience described above. The objective was to verify the accuracy of HHRD alerts by designing and conducting a scientific study.

\subsection{Approach}

The study consisted of three stages. The first stage was a controlled survey, where human and animal bones were buried at known depths in a field. After several months had passed during which the scent had dispersed through the soil, the dogs were tested to determine if they could locate the human bones. The study's second stage was a survey conducted at a known cemetery with standing headstones in portions of the cemetery and open spaces that were known to contain unmarked graves (although the exact location of individual graves was not known). At this site, the dogs were tested while Dr. Michael Hargrave conducted a GPR survey to compare the results of traditional geophysical survey methods to the HHRD dog results. The third stage was a survey that tested the dogs and geophysical techniques at homestead sites with small cemeteries (or suspected cemeteries) and compared the results. More details of methodology and techniques are outlined in Chapter 3.

\subsubsection{Field site selection}

The control survey (stage 1) was sited at ERDC-CERL (details in Chapter 4). Original plans called for stages two and three to be conducted at Fort Gordon, Georgia. After the Legacy grant for this project was awarded but prior to the commencement of fieldwork, a Memorandum for Record was issued on 11 September 2012 by Ms. Kathryn Condon, Executive Director of Army National Military Cemeteries. This memorandum instituted a 
moratorium on the use of GPR and geophysical survey techniques to locate unmarked graves at cemeteries on US Army installations. In order to comply with the terms of the moratorium, the second two portions of this study had to be modified. The second survey was conducted at a privately owned cemetery in Champaign County, Illinois. The third phase utilized geophysical data from Fort Gordon that was collected by Dr. Michael Hargrave in 2011, prior to the issuance of the moratorium (Hargrave 2011). Thus, the fieldwork conducted at Fort Gordon in 2013 consisted of dog teams only. 


\section{Historic Human Remains Detection Dogs}

\subsection{Principles of canine scent detection}

Human remains detection (HRD) dogs are dogs specifically trained to detect decomposing human remains. A subset of HRD dog teams are HHRD dogs that are specifically trained to locate human bones at the surface of the ground and buried remains of some age. HHRD dogs are not trained to alert on soft-tissue decomposition. Dogs trained to scent soft-tissue decomposition are often referred to as "cadaver dogs" and are typically deployed by search and rescue teams and police agencies.

The science behind the dog's scent detection ability is not fully understood, but the successes of some dog teams have been noted in recent years.

\footnotetext{
The ability of HRD canines to detect these sites, while poorly understood, uncharacterized, and unstandardized, is nevertheless impressive. Their ability to locate as little as 5-15 mg of human tissue, blood, or bone, either buried, on the surface, or elevated above the ground, still exceeds the ability of our best instrumentation. Additional verbal reports of their ability to identify cremains, graves over 100 years old, and minute amounts of human material (even when masked) nearly defy explanation. (Vass et al. 2008, 384).
}

A study conducted by Desert Research Institute (DRI) in 2011 noted that HRD dogs were able to locate individual human teeth with accuracy and false positive rates at $20 \%-70 \%$ (variation by dog) (Cablk and Sagebiel 2011). Lasseter et al. (2003) examined the use of dogs trained to detect the generic scent of human decomposition. This study found that despite not being trained to alert specifically on dry human skeletal remains, all dog teams involved in the study were able to narrow the search area for this material buried at $1 \mathrm{ft}$ depth for at least one sample, with the overall success rate of $15 \%$. One dog was able to locate, through alert, a single human vertebra buried at $2 \mathrm{ft}$ depth for only two months. A Canadian study (Komar 1999) used eight dog teams to locate dried human bones and fabric soaked in human decompositional fluid to simulate the scent patterns of human remains that had experienced extended postmortem intervals and animal scavenging. In training sessions, 
where the handlers knew how many items were present, the success rate was $77 \%-100 \%$ in locating all of the dry human bones. In field trials, where the handlers were unaware of the sample size, the dog teams still had a $63 \%-95 \%$ success rate.

Despite reports of HRD dog team success rates, there is ongoing debate and research about what chemicals the dogs are detecting that allows for grave detection and differentiation between human and animal remains. Scientist at the Oak Ridge National Laboratory conducted a two-part study to create a Decompositional Odor Analysis Database (DOAD) to attempt to isolate the volatile chemical signature of the decomposing remains of humans and various animals. The goal was to provide HRD dog teams with the information required to focus dog training on the specific chemical compounds that would indicate the presence of decomposing remains and differentiate human remains from those of other animals. The first study (Vass et al. 2004) focused on the first $1.5 \mathrm{yr}$ of human burial decomposition by utilizing remains buried at depth ranges of 1.5-3.5 $\mathrm{ft}$ below the surface and causes of death ranging from accidental to various ailments including cancer (treated with radiation and chemotherapy). Sampling tubes and hoods were place in and over the graves to collect the escaping gasses. The results indicated that the processes of decomposition are not straightforward and can be affected by a variety of environmental conditions. The study identified 424 specific chemicals released from the decomposing human remains. These chemicals were divided into eight classes: (1) cyclic hydrocarbons, (2) noncyclic hydrocarbons, (3) nitrogen compounds, (4) oxygen compounds, (5) acids/esters, (6) halogen compounds, (7) sulfur compounds, and (8) other compounds. With the exception of the halogen compound, environmental factors such as barometric pressure, air temperature, humidity, soil temperature, soil type, and/or soil water content affected not only the dissemination of the scents but the production of the chemicals as well. The depth of the burial, which influenced the oxygen content and microflora content of the soil, also caused significant variation in the amount and relative abundance of odoriferous chemicals produce by decaying human remains. Finally, perimortem weight and diet also affected the amount and range of chemicals escaping from the grave.

The follow-up study (Vass et al. 2008) continued the study of human remains from 1.5-4 yr after burial and included data obtained from a burial 16 years old, where only skeletal remains were present. In this work, 478 
unique chemical compounds were identified to be radiating from the remains; of these, only 30 were identified as "key markers of human decomposition which were detectable at the soil surface" (Vass et al. 2008, 387). There were 11 compounds that were only detected in the early stages of decomposition, 5 additional compounds persisted until all soft tissue was fully decomposed, and 14 compounds were detected throughout the decomposition process, including the 16-yr-old burial. A second part of the study examined the chemical vapors released from unburied long bones of human, pig, dog, and deer that had been defleshed 5-9 yr prior to the study. There were 72 compounds detected, and 12 of these were determined to be significant markers of burial decomposition. These compounds were then divided into four classes of compounds, and the differences in composition of these classes among species are described in Table 1.

Table 1. Bone odor composition among common mammals (Vass et al. 2008).

\begin{tabular}{|l|l|l|l|l|}
\hline Compound & Human & Dog & Pig & Deer \\
\hline Aldehydes & $4 \%$ & $7 \%$ & $50 \%$ & $39 \%$ \\
\hline Amides & $0 \%$ & $46 \%$ & $31 \%$ & $23 \%$ \\
\hline Alcohols & $5 \%$ & $44 \%$ & $42 \%$ & $9 \%$ \\
\hline Ketones & $28 \%$ & $3 \%$ & $27 \%$ & $42 \%$ \\
\hline
\end{tabular}

A final study (Cablk et al. 2012) looked at chemical compounds released by separate tissue types from different species of animals and compared them to published results of human decomposition odors. The study focused on eight classes of chemical compounds (acids, aldehydes, ketones, alkanes, alcohols, sulfides, amines, and aromatics) and looked at how the frequency of these compound classes varied in different tissue types (bone, fat, muscle, and skin), instead of looking at whole-body decomposition as previous studies did. The results indicated that not only did the amount of tissue (as a percentage of total body mass) vary from species to species, but the compound class percentages had distinct profiles for each tissue type by species. For example, about $25 \%$ of the compounds released from a decomposing pig emanate from the decaying bone, while in chickens the amount is only $20 \%$. Half of all chemicals released from the decaying pig bones are classed as aldehyde compounds, while only $8 \%$ of chicken bone compounds fall into the same class. 
These studies demonstrate there are distinct sets of chemicals that are emitted from decaying remains throughout the decomposition process, even after soft tissue is completely gone, and that the total chemical composition of odiferous compounds generated by skeletal remains varied between species of mammals. This finding indicates there is a scientific basis for HRD dog's ability, by scent alone, to detect graves and differentiate species. It should be noted, however, that all animal remains from the Cablk et al. (2012) study were derived from animals that were raised as free-range, pasture-fed animals, and not from animals fed massproduced corn and soy-based products. Vass et al. (2008) did not state the kind of diet that the domesticated animals in their study were raised on, although Vass does raise the possibility of human diet affecting the range and abundance of some compounds detected during decomposition. It is possible, therefore, that domesticated animals raised on man-made feed may have a chemical decomposition profile more similar to humans than would wild or free-range specimens.

In addition to attempts to isolate what the dogs are smelling, studies also have been conducted on which environmental conditions aid or inhibit scent detection by dogs. In 1999, Debra Komar looked at dogs' ability to detect various scattered decomposition scents in a temperature range of $-22^{\circ} \mathrm{F}$ to $50^{\circ} \mathrm{F}$, with various ground covers including $25 \mathrm{~cm}$ of snow and scattered water puddles. She noted that in extreme cold temperatures and deep snow, some dogs either could not or would not work, but the dogs that did work in those conditions did not appear to have lower success rates than they did in better conditions. Other studies have suggested that the effectiveness of the dogs starts to drop off at temperatures exceeding $85^{\circ} \mathrm{F}$ (Killam 1990; France et al. 1997). As the temperature increases, the dogs tire quickly and pant to cool off. As they then are breathing through their mouths and not their noses, their ability to detect scent drops dramatically. A study conducted during July and August in Tuscaloosa, Georgia, found that half the dogs in the trial stopped alerting after the temperatures rose above $90^{\circ} \mathrm{F}$ (Lasseter et al. 2003).Scent vapor radiates away from the decomposing remains through diffusion (Killam 1990; ICF 2013b). Volatile compounds will follow the path of least resistance, and conditions such as bioturbation, variation in vegetation, erosion, water seepage, and man-made ground-disturbing events can create paths where the scent will disseminate farther away from the burial site. As a result, HHRD dogs do not necessarily alert immediately over a burial site but may alert within a few meters of a burial site. 


\subsection{The Institute of Canine Forensics (ICF) practice and procedures}

The dog teams used in this study were provided by the Institute of Canine Forensics (ICF) located in Woodside, California. This corporation was established in 1998 and works exclusively on the training, certification, and deployment of HHRD dogs (ICF 2013a). Former customers of ICF include, but are not limited to (ICF 2013a):

- Lolo National Forest, Montana

- NASA Moffett Field, California

- University of Santa Clara, California

- Indiana Department of Homeland Security, Muscatatuk Urban Training Center, Indiana

- Vandenberg Air Force Base, California

- Equipo Peruano de Antropología Forense (EPAF), Peru

- San Diego State University and State Parks, California

- Bodie State Park, California

- City of Port Angeles, Washington

- California Park Service, California

- Fort Leavenworth and Nez Perce Nation, Kansas

- The Presidio at Santa Barbara, California

- Feather Falls National Forest, California

- Schofield Army Base, Hawaii

- Donner Memorial State Park, California

- Veteran's Affairs, Palo Alto, California

Each handler is responsible for the upkeep and training of their dogs (IFC 2013b). The dogs used in this study are not cross-trained. In other words, the dogs are trained to detect on the scent of bones and burials, with a focus on burials that are no longer in the active stages of decay. They are not trained to alert on living persons or contraband. IFC dog teams typically train a minimum of $40 \mathrm{hr}$ per month in a variety of conditions and terrains. Additionally training includes common distraction factors such as loud noises, pin flags in the survey area, and the presence of other dogs in the survey area.

The dogs are trained to notify their handler to a scent through passive alerts (ICF 2013b). This type of alert typically consists of the dog moving to a sit or down position while maintaining direct eye contact with their handler at the location where the scent is the strongest. The dogs are trained not to dig, scratch, mouth, urinate, or defecate in alert areas or 
while working. When the dog detects a scent that they cannot access directly, due to vegetation or fences for example, they must try to communicate the information to their handlers through body language that must then be interpreted by their handler.

Certification is conducted by a panel of preapproved evaluators, one of which cannot be affiliated with ICF (ICF 2013b). The tests are scored on success criteria developed for scent detection, and an efficacy score above $75 \%$ is required to be certified. The certification is specific to dog and handler as a team. Once certified, teams must recertify annually. 


\section{Methodology}

\subsection{Geophysical techniques}

\subsubsection{General background}

Geophysical techniques are gradually being more widely used by archaeologists in the United States, including US Army installations (Baxter et al. 2010; Hargrave and Dunn 2010; Hargrave et al. 2010). Previous investigations have demonstrated that all of the widely used geophysical methods (including electrical resistance, magnetic gradiometry, GPR, conductivity, and magnetic susceptibility) can-when properly used at suitable sites-be useful in detecting subsurface archaeological features and other deposits (Bevan 1991; Clark 2001; Conyers 2004; Hargrave 2010; Johnson 2006; Witten 2006). Researchers in both academic and cultural resource management (CRM) settings now focus on enhanced applications (often in the area of improved data processing and display) and integrating geophysics into archaeology in a manner that will optimize information return, reliability, and cost effectiveness (Ernenwein and Hargrave 2009; Johnson 2006).

Television programs have made the public aware of the contributions of geophysics to forensics, history, and archaeology. Radar seems to be the technique that has most captured the public's imagination, perhaps because the technology's role in aviation and military applications is familiar to many (Conyers 2004). While GPR is not effective in many settings, the sandy soil conditions at Fort Gordon, Georgia, made GPR the most promising technique (Ernenwein and Hargrave 2009). Magnetic field gradient surveys were also conducted at four of the five cemeteries (Kvamme 2006). Use of a second technique increases the likelihood of detecting graves and other cultural features (Clay 2001). Some consideration was given to using electrical resistance instead of magnetometry (Somers 2006). It was decided, however, that the wide range of natural variability in the resistance characteristics of the local sandy soils would make electrical resistance less promising than magnetometry.

All geophysical techniques used in archaeology rely on the (geophysical) contrast between a subsurface target (in this case, historic graves) and the surrounding soil (Clark 2001; Gaffney and Gater 2003; Kvamme 2003). 
Target features can contrast with their surroundings in a variety of ways. When archaeologists excavate, for example, they identify subsurface features (e.g., house remains, storage pits, hearths, graves) based on contrasts in soil color, texture, and artifact contents. Geophysical instruments are designed to measure extremely subtle contrasts between a target and its surroundings by using properties such as magnetism, a soil's resistance to the passage of an electrical current, and dielectric permittivity. Factors that contribute to these geophysical contrasts include soil's moisture, texture (e.g., silt, clay, sand, or loam), iron oxide content, and presence of fired clay (e.g., pottery, brick) objects or ferrous metal artifacts (Clark 2001; Conyers 2006a; Gaffney and Gater 2003). GPR is particularly effective for identifying interfaces between materials that differ in terms of their absorption and/or reflectance of electromagnetic energy.

Geophysical surveys typically involve systematically moving the sensor across the survey area, collecting data at regular intervals along closely spaced (.5-1.0 m) traverses. Grids comprised of parallel traverses are marked in the field using nonmagnetic plastic tapes and tent pegs. The data are transferred to a computer where specialized software is used to process the data and to produce plan and (in the case of GPR) profile maps. A fundamental goal is to identify and interpret geophysical anomalieslocalized areas that exhibit data values distinct from their immediate surroundings. Some anomalies may be associated with (or caused by) subsurface archaeological features such as graves, whereas many others are associated with other cultural or natural phenomena (e.g., tree roots, rocks, rodent burrows, localized areas of deeper or more shallow soils, architectural debris, mechanized earthmoving) (Ernenwein and Hargrave 2009).

Radar is the only geophysical instrument widely used in archaeology that can measure a target's depth below surface, based on the speed at which the energy moves through the soil. In a GPR survey, a radar antenna transmits electromagnetic energy into the ground, receiving and measuring the amplitude and travel time of that portion of the energy that is reflected back to the antenna by subsurface deposits (Conyers 2004; Witten 2006).

The amplitude of radar energy reflected back to the surface is influenced by many objects and materials including tree roots, animal burrows, rocks, soil strata interfaces, architectural remains, pipes, other archaeological 
features and deposits (e.g., prehistoric pits; historic wells, cisterns, and privies), and graves. Moist soils tend to absorb radar energy rather than allowing it to pass. Soil moisture reduces the depth to which the energy penetrates and thus, the maximum depth at which graves or other features can be detected. Thus, clayey soils are often poor candidates for GPR survey, whereas sandy soils that do not retain as much moisture are good candidates. Metal pipes and other large metal objects are excellent reflectors and are easily detected but can obscure objects and deposits below them. Ultimately, the depth of the radar signal penetration and the depth to which objects can be detected depends on the frequency of the antenna being used and the conductivity of the ground.

Antenna frequency is also an important consideration. Archaeologists typically use antennas with a frequency ranging from 50-1,000 megahertz $(\mathrm{MHz})$. The higher-frequency antennas within this range allow detection of smaller objects but are only effective at shallow depths. Lowerfrequency antennas can penetrate much deeper but can only detect larger things. Archaeologists typically use antennas in the 400-500 $\mathrm{MHz}$ range, providing a reasonable capability for most situations, particularly most historic cemeteries (Ernenwein and Hargrave 2009; Hargrave et al. 2010).

A number of instrument parameters are set by the operator prior to beginning a GPR survey. These parameters pertain to the data collection strategy (e.g., length and spacing of transects), local ground characteristics, and the type of default processing that will influence the real-time display of data as the survey proceeds. Radar systems are typically used to collect at least 20 traces per meter (essentially, a data value or "trace" recorded every $5 \mathrm{~cm}$ ) along transects spaced $50 \mathrm{~cm}$ apart. When all of the traces are arranged side by side along their collection transect, they form a profile image that shows the locations and shapes of the radar reflections. Specialized GPR processing software interpolates data between transects, creating a three-dimensional (3D) data "cube." Software allows the data cube to be examined from any perspective and bisected or "sliced" in any manner. Archaeologists familiar with GPR are now used to seeing survey results presented in plan as one or more amplitude or time slices (e.g., Chapter 5, Figure 26). During data processing, the surveyor typically considers many possible slices and then chooses depths and thickness ranges that reveal patterns that may be associated with subsurface features. 
Raw GPR data are often characterized by several types of noise that can obfuscate indications of subsurface features. Removal of noise is therefore a primary objective of data processing. Sources include noise generated by the system's own operation, inconsistencies in the antenna's coupling (contact) with the ground surface, antenna ringing that occurs when energy is repeatedly reflected back and forth between the antenna and a subsurface object (Conyers 2004, 127), and sometimes (particularly in urban and industrial areas) radio and other energy introduced into the air and ground by modern infrastructure and communication systems (including cell phones). Viewed in profile, noise often appears in unprocessed data as a series of horizontal layers of varying amplitude that span all or much of the survey transect. Ringing may also resemble a narrow stack or column of alternating high- and low-amplitude bands. The surveyor often uses the range gain amplification technique (i.e., applies gain) to increase visual contrast, particularly as depth increases and the signal transmitted by the GPR antenna diminishes at an exponential rate, and in the presence of soil moisture.

Effective interpretations of GPR data require some understanding of how energy moves through the soil and is reflected back to the antenna. While data processing is underway, GPR data are examined in profiles associated with each transect. In some ways, a GPR profile is analogous to a soil profile, but one does not expect objects and features to be recognizable based on their actual shape. For example, in GPR profiles, caskets, metal storage drums, rocks, and similar discrete objects (described as point sources) are often detected based on the presence of hyperbolas (i.e., inverted $\mathrm{V}$-shapes). Conyers (2006b) explains the occurrence of hyperbolas by indicating that point source reflection hyperbolas are generated because most GPR antennas produce a transmitted radar beam that propagates downward from the surface in a conical pattern, radiating outward as energy travels to depth. The pattern of energy dispersal therefore spreads out and is reflected from buried features that are often not located directly below the transmitting antenna. The GPR records the location of the source of the reflected energy as if it was directly below the antenna, and this fact accounts for the hyperbola's "wings" being plotted at greater depth as the antenna moves away from the actual point source.

Hyperbolas are important for several reasons. Their geometry provides the basis for estimating velocity and depth. A hyperbola's apex indicates the position of the object or portion of an object that is the source of reflected 
energy. Hyperbolas can complicate the interpretation of patterns seen in horizontal slices, because the hyperbola wings are in part the result of how the GPR system records the location of a reflective source. The hyperbola wings are therefore typically removed prior to the creation of time slices by using a two-dimensional image processing technique called migration.

While some GPR surveys of cemeteries (and other archaeological sites) yield stunning results, many are less successful. Successful GPR surveys are far more likely to be published than those that are unsuccessful. Factors that can limit survey success include: unfavorable surface conditions (e.g., vegetation, uneven ground, obstacles such as trees and grave markers), soil moisture, and clutter in the data associated with rocks, tree roots, rodent burrows, bedrock, etc. (Bevan 1991; Conyers 2006a; Ernenwein and Hargrave 2009). GPR can detect graves or other features that contrast with their immediate surroundings in terms of the extent to which they reflect electromagnetic energy. Contrast between grave contents (coffins, partial voids) and the soil characteristics of grave shafts (compared to intact soil) is highly variable and interacts with the other factors just described to influence survey outcome.

\subsubsection{Data collection and analysis}

In 2011, ERDC-CERL conducted GPR and magnetic field gradient surveys at each of the cemeteries on Fort Gordon (details in Chapter 6; Hargrave 2011). GPR survey alone was conducted at the Clements Cemetery in Champaign, Illinois. The GPR surveys were conducted using a GSSI SIR 3000 unit equipped with a $400 \mathrm{MHz}$ antenna. Dense vegetation made it inefficient to use the SIR 3000's three-wheeled cart at Fort Gordon. There, the antenna was pulled by one person while a second surveyor carried the CPU (Figure 1, left). The open space at Clements Cemetery allowed for use of the survey cart to collect that data. At both locations, data were collected in $20 \times 20 \mathrm{~m}$ grids (and in some cases, smaller) along traverses spaced at $50 \mathrm{~cm}$ intervals. At all survey locations, it was often necessary to dodge around trees, and this practice introduced some spatial noise into the data. Overall, data quality at Fort Gordon was good but not optimal. Data quality at the Clements Cemetery was poor. GPR data collection and analysis issues specific to Clements Cemetery are discussed in more detail in Chapter 5 . 
Data were processed using Radan. ${ }^{\mathrm{TM}_{1}}$ The data (one file per transect) were assembled into 3D files, filtered to reduce background noise using thresholds of 200 and $800 \mathrm{MHz}$, and migrated. The 3D data cubes were examined, and those combinations of slice midpoint depth and thickness were selected that best displayed anomalies resembling possible graves, saved as .cvs files, exported to Surfer 8.0, ${ }^{2}$ gridded, and Gaussian filtered. The resultant slice maps were then examined, interpreted, and labeled. While Radan and Surfer 8.o both offer the capability for color displays, we view the use of grayscale image maps as best for interpretation. One exception to this practice is the use of red and blue to differentiate strong magnetic anomalies from GPR anomalies whenever the two data are shown on a single map. In all GPR maps, darker colors indicate higher amplitudes.

The magnetic survey was conducted using a Bartington Grad601 dual gradiometer (Figure 1, right). This system consists of a light weight frame that supports two gradiometers separated by a horizontal distance of one meter. The fluxgate gradiometers can measure exceedingly subtle disruptions in the earth's magnetic field that can be associated with prehistoric or historic cultural features as well as a wide range of natural phenomena. Each of the gradiometers records the difference between the values measured by its upper and lower sensors that are separated by a vertical distance of one meter. To collect data, the surveyor carries the instrument along a traverse marked by a nonmagnetic plastic tape. A sound emitted by the instrument's automatic trigger allows the surveyor to distribute the data collection points at regular intervals.

The system was set for its maximum resolution (.1 nanotesla). Data values were collected at $.125 \mathrm{~m}$ intervals as the surveyor moved slowly along each transect. This strategy resulted in a relatively high-density survey (8 data values per $\mathrm{m}^{2}$ ) and reasonably high-resolution maps. The data were downloaded to a laptop computer and processed using Geoplot 3.o. Maps produced in Geoplot were later entered into Surfer 7.0 (and later, 8.0), which offers a wider range of options for data presentation.

\footnotetext{
1 Radan is a specialized GPR software distributed by GSSI of Salem, New Hampshire

2 Visualization, contouring, and surface modeling software distributed by Golden Software, Inc. of Golden, Colorado.
} 
Figure 1. Use of a GSSI $400 \mathrm{MHz}$ antenna detached from the SIR 3000 cart (left), and use of a Bartington Grad601 dual gradiometer (right). (Neither photo was taken during this study.)

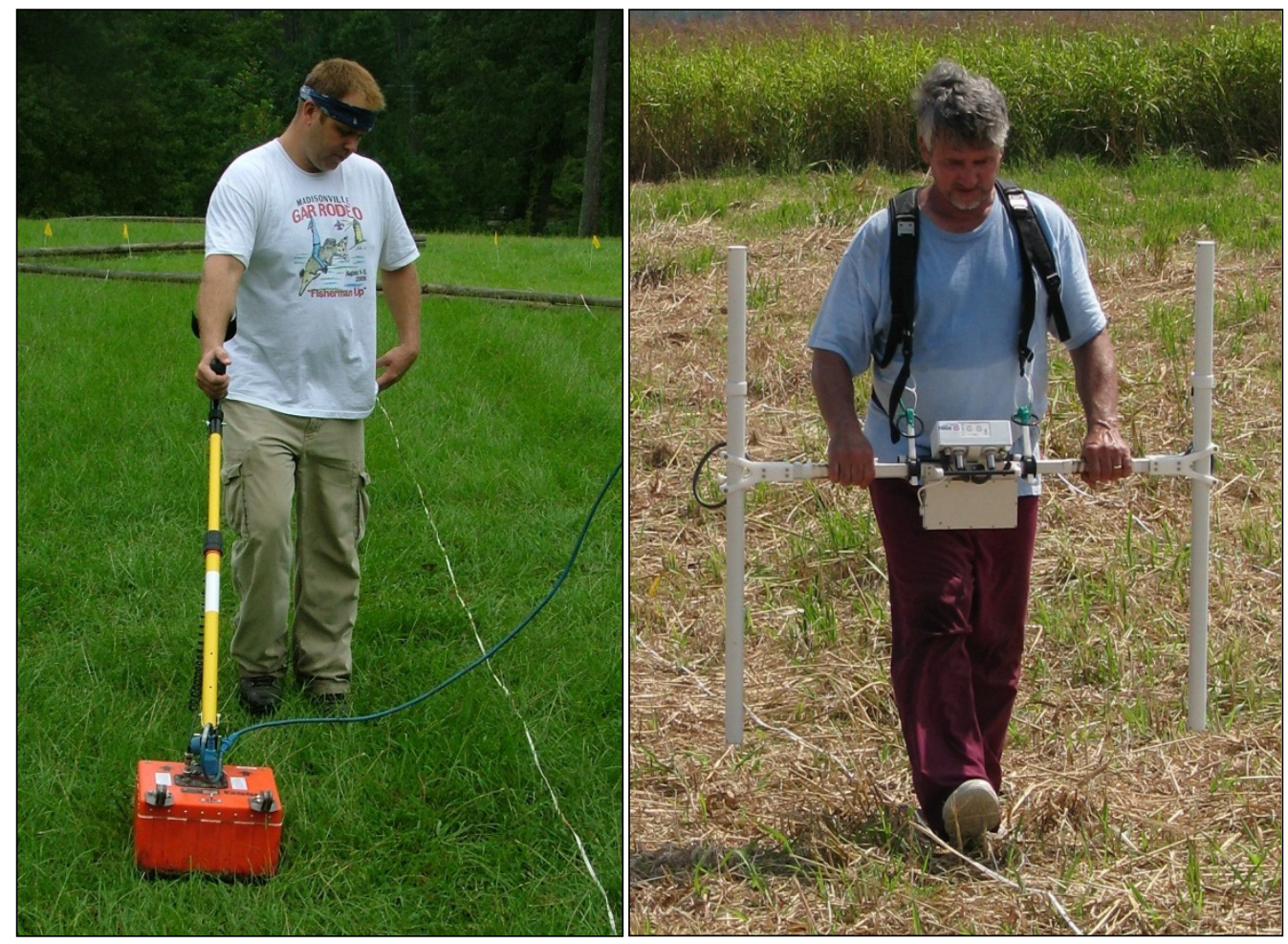

\subsubsection{Grave detection}

Historic graves can be detected based on their shaft, soil fill, or other contents (typically the casket and/or vault) (Burks 2009a, 2009b). The grave shaft and its fill are the most important factors in detecting historic graves, since the casket and body may have decomposed, and no vault may have been used (Bevan 1991). Grave shafts where the body is in a prone position are (in plan) oval to rectangular holes that range from 2-6 ft in depth below the surface. Their plan dimensions vary based on the size of the individual buried and the use of a coffin and/or a burial vault. Larger grave shafts associated with adult burials are more likely to be detected by geophysical instruments than are smaller graves associated with children. Historic adult graves are typically expected to be about 6-8 ft (1.8-2.4 m) long and 1.5-2.5 ft wide (approximately .46-76 m) (Burks 2009a, 6). Prehistoric graves may have more variable dimensions, given a wider range of burial practices in the past. Variations in grave shape and size may result from flexed, recumbent fetal, upright fetal, sitting, or standing burial position or multiple or secondary burial practices (Prowse 2008). A burial with an individual in a fetal position, for example, will have a more circular or 
square grave shaft. Orientation, location, and relative position of graves will also vary across cultures. It is important, therefore, to become familiar with the range of possible burial practices in the study location to predict what the grave shape will be.

Soil type plays an important role in grave detection. A grave is typically filled by using the soil removed when it was excavated. The grave shaft fill is more mixed and less compact than the surrounding, in-situ soil and will have different moisture-retention properties. Graves dug into soil characterized by multiple, distinct strata are more likely to be detected than those dug into a homogeneous soil, since each stratum offers an opportunity for contrast with the fill. Older graves are characterized by greater settling as a result of natural processes as well as the eventual collapse of a wood coffin. In some cases, old graves may be "topped off" by using soil from a different location, increasing the likelihood that the shaft fill will differ markedly from the intact surrounding soil (Burks 2009a, 6-7).

\subsubsection{Grave contents}

In addition to human remains, graves may contain a coffin and a vault. Burial vaults, made of reinforced concrete or fiberglass, have come to be widely used throughout the United States. Vaults are now required by many cemeteries to prevent the formation of depressions as the grave shaft's fill soil gradually settles and for when the coffin eventually collapses. Vaults that contain brick, concrete, and/or iron rebar; that represent a void; or that retain moisture differently than the surrounding soils are likely to be detected by a GPR survey, and they also may be detected by electrical resistance, conductivity, or magnetometry. Use of vaults was rare until well into the 2oth century, particularly among lower-income families and in rural areas (Burks 2009a). Graves that do not incorporate vaults or coffins will have a more subtle anomaly pattern in the geophysical data, while graves where these features have collapsed will fall somewhere in the middle of the spectrum of anomaly strength.

In addition to vault use, coffin material influences the likelihood that a grave will be detected by a GPR survey. Intact wood coffins may be detected that include a void or are associated with a sharp difference in soil moisture within versus outside the coffin; however, most wooden coffins have rotted and collapsed a few decades after burial (depending on soil conditions). Metal is an excellent reflector, meaning that metal coffins are very likely to be detected by GPR. Iron coffins came into use after 1850 , 
although they were probably never widely used in nonurban settings. (Burks 2009a, 7; Crane, Breed, and Company 1858).

\subsubsection{Assumptions and interpretive criteria}

No specific information is available as to when the five cemeteries on Fort Gordon were established, although all of the cemeteries were associated with nearby historic farmstead sites. It is assumed (but not certain) that no graves were excavated at the cemeteries under consideration here after the Army purchased the land in 1940, and that most of the graves are associated with relatively rural families of modest means. Given these assumptions, most of the graves probably contained wood coffins (some may have had no coffin), and few (if any) included vaults. The graves may well be characterized by low contrasts with the surrounding soil. Anomaly detection indicating a potential grave may be complicated by the presence of tree roots, given that four of the five cemeteries were located in areas that are or recently had been heavily overgrown. Several of the cemeteries showed at least some indications of surface disturbances (e.g., uneven ground surface, displaced stones and bricks that may have been grave markers) associated with activities such as military training, timbering, and vehicle traffic.

Fort Gordon CRM staff indicated that the $19^{\text {th }}$ and early $20^{\text {th }}$ century population in the region was dominated by people of the Protestant and Catholic religions. A visual inspection was conducted at other historic cemeteries on the installation that are still well maintained. Commonalties of burial practices at these cemeteries were observed that correspond to a historic Christian burial pattern. These common practices include: (1) graves tend to be oriented east to west, (2) multiple graves are often arranged in rows or other family clusters, and (3) variability in the nature of grave markers and other cemetery features (e.g., retaining or decorative walls and fences) may reflect socioeconomic status of the deceased.

A brief inspection of Fort Gordon Cemetery 30 (which was not included in this study) demonstrated that loose bricks are sometimes used to outline graves (Figure 2), and that bricks are sometimes used in conjunction with concrete in retaining, enclosing, or decorative walls (Figure 3 and Figure 4). Bricks, concrete, and flat thin stones (suitable for service as grave markers) were observed at Cemeteries 26, 31, and 34. None of these were definitely associated with graves or other cemetery features. Only at Cemetery 26 is there evidence that a broken stone slab may be an in-situ grave 
marker. A scatter of bricks was present at Cemetery 31, and several bricks set into concrete may be the remains of a wall at Cemetery 34. The paucity of these materials suggests that they may well be evidence of a cemetery rather than the remains of domestic structures.

Figure 2. Bricks outlining a presumed grave location at Fort Gordon Cemetery 30 (cemetery not included in the geophysical survey).

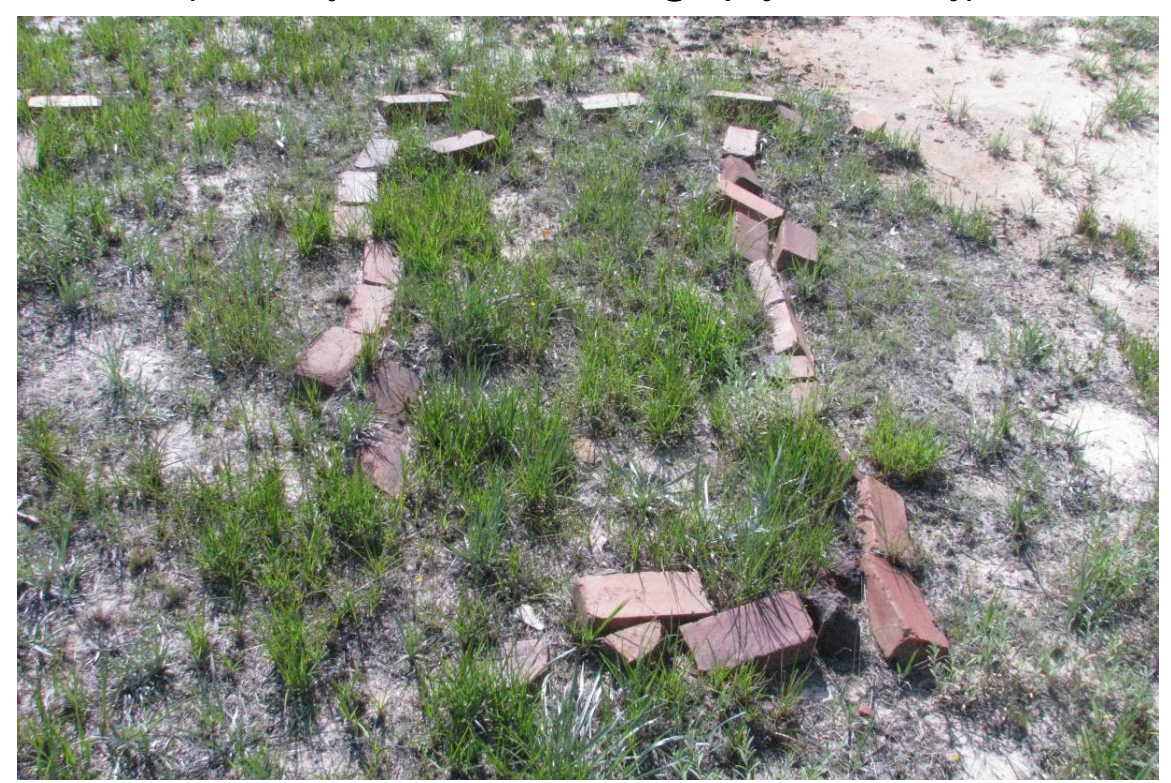

Figure 3. Aligned bricks near footstone and along retaining wall at Fort Gordon Cemetery 30 (cemetery not included in the geophysical survey).

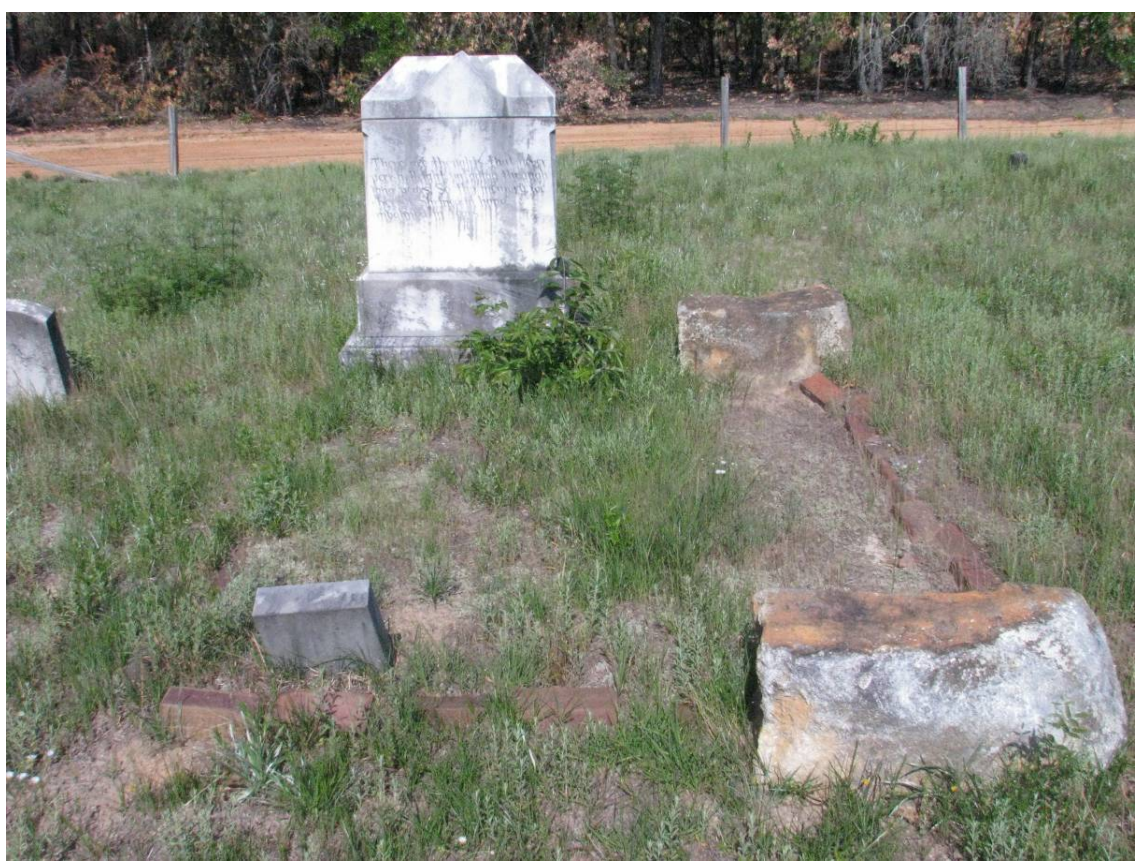


Figure 4. Concrete retaining wall surrounding a family section in Fort Gordon Cemetery 30 (cemetery not included in the geophysical survey).

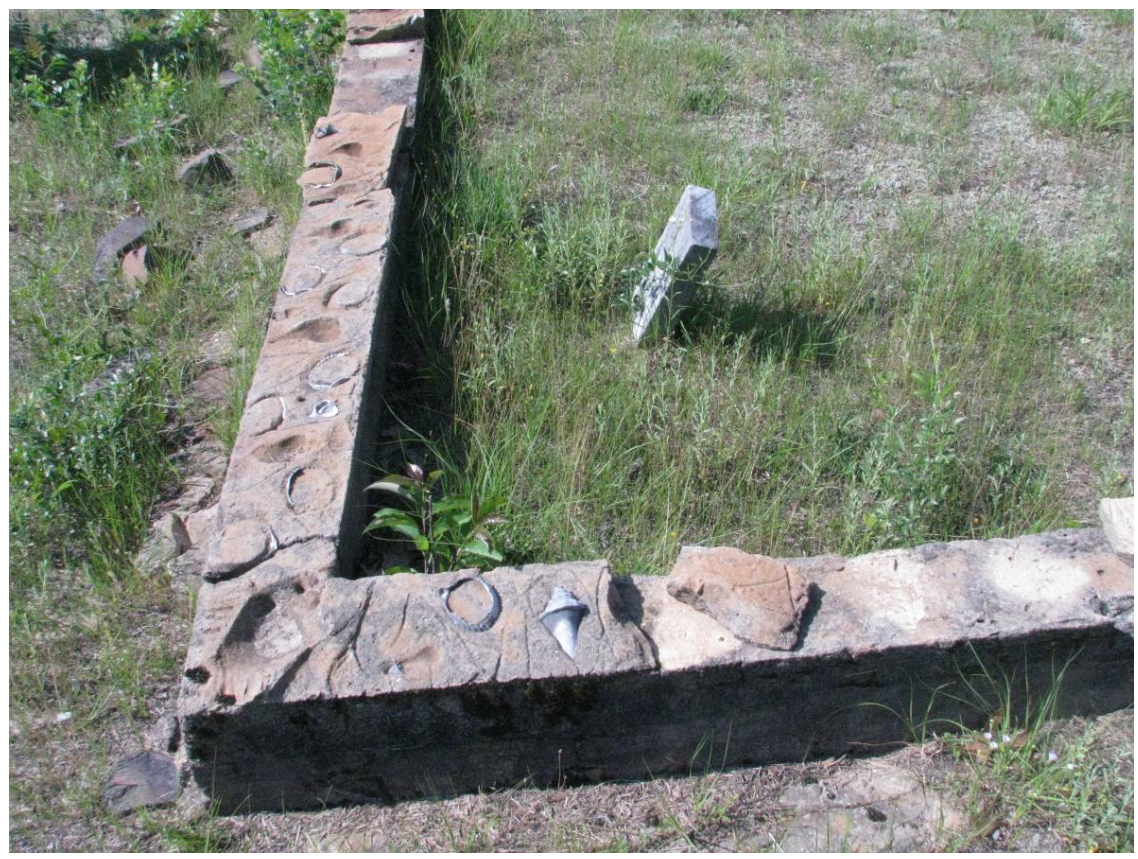

Several challenges and ironies accompany the use geophysical techniques to detect unmarked graves. There is a great deal of inter-site and sometimes seasonal variation in how soil texture, moisture, rock and bedrock, tree roots, military or other ground disturbances, and grave contents cause graves to contrast with their immediate surroundings. In the absence of historical records, reliable informants, or archaeological ground truthing, interpreting geophysical anomalies as graves has a strong subjective component. Despite one's use of the most sophisticated sensors and rigorous field methods, one ultimately must decide if a particular anomaly "looks like" a grave. In some cases, two equally competent analysts might arrive at different decisions. Perhaps the best way to reduce the element of subjectivity and to convincingly convey one's interpretations to nonspecialists, is to be explicit about the criteria used to differentiate possible graves from other anomalies.

The following is a summary of expectations for historic graves and cemeteries that were used in this study.

Graves are/were:

- Oval or rectangular in plan

- $\quad 6-8 \mathrm{ft}$ long (children's graves can be smaller) 
- $1.5^{-2.5} \mathrm{ft}$ wide (children's graves can be smaller)

- Oriented (long axis) east to west

- Arranged in rows or clusters (based on family groups)

- Marked using wood or stone (often now absent or displaced)

- Sometimes outlined using bricks (often now absent or displaced)

- Sometimes surrounded or otherwise marked by fences or walls (often now absent or displaced)

- Can be characterized by shallow depressions (from natural settling)

It should be noted that on surveys to locate unmarked cemeteries, the goal is almost always to protect the graves from disturbances. As a result, standard practice is to be very conservative in interpreting the data. It is considered preferable to over report the possibility of the presence of graves and to include any anomaly that has "grave-like" characteristics.

\subsection{HHRD dog techniques}

ICF provided four dog teams and a team coordinator to participate in this study (Table 2). Each team searched each study block independently, both in Champaign and Fort Gordon. Each team systematically covered the search area in a grid pattern, marking the location of dog alerts with pin flags. Occasionally, the team handler would repeatedly visit areas of the study block to get a distracted dog to refocus or to retest an area where the dog's body language was ambiguous. Each alert was marked with a pin flag by the dog handler, and the handler noted the quality of the alert. ERDCCERL researchers then mapped each alert location with a GPS handheld data recorder (Trimble GeoXH 600o, with decimeter accuracy) and removed the pin flag. Only then would the next dog team be allowed into the study area. Pin flags were only used once and then discarded to insure that scent contamination did not occur through reuse of flags. The team coordinator facilitated the coordination of the team members with the ERDCCERL archaeologists to guarantee that the study was completely blind and that the archaeologist could not comment on any dog trial as it was taking place.

In addition to team coordination, the coordinator also recorded air and surface temperatures as well as wind speed and direction at various times during the testing to ensure that each dog team was working under similar conditions to each other. Additionally, volatile organic chemicals will dissipate differently as air and soil temperature change, affecting the accuracy of the dog alert results. The percentage of the search area where the dogs 
could get access to the soil surface was determined and recorded as the percentage of accessible terrain. This measurement is equivalent to, and serves the same purpose as, surface visibility observations that archaeologists routinely make during Phase I surface surveys.

Each dog handler recorded the quality of each dog alert on a scale of 1-3. A Quality 1 alert indicated a strongly committed alert-where the dog alerted immediately to a specific location. A Quality 2 alert indicated the dog is committed to an area but needed to work the area to determine the alert location. A Quality 3 alert indicated the presence of a scent pool. This type of alert is where the dog is indicating by their body language that they are detecting the scent of human decomposition, but they cannot determine the source of the scent to the degree needed to trigger a higherquality alert. Therefore, the handler's experience with their dog and their ability to communicate effectively with the animal plays more of a role in Quality 3 alerts.

Table 2 gives information on the human and canine team members. Throughout the remainder of the report, the teams are referenced by the initials of the team handler (column 1 of Table 2).

Table 2. ICF team information.

\begin{tabular}{|l|l|l|l|l|}
\hline Team & Handler & Dog & Breed & $\begin{array}{l}\text { Certification } \\
\text { Year }\end{array}$ \\
\hline AM & Adela Morris & Jasper & Border Collie & 2012 \\
\hline BP & Barbara Pence & Bailey & Labrador Retriever & 2013 \\
\hline JG & John Grebenkemper & Kayle & Border Collie & 2011 \\
\hline LA & Lynne Angeloro & Berkeley & Border Collie & 2011 \\
\hline Field Coordinator: John Christensen & & \\
\hline
\end{tabular}




\section{Control Survey}

The control survey area was created as a test to determine the rate of false positive alerts as well as the ability of the dogs to differentiate between human and animal bones within the same search area. This site consisted primarily of bones that had been buried after soft-tissue decomposition had ended. The dogs are trained to locate graves where decomposition had once occurred or where human bones are scattered on the surface. Personal communications with the ICF staff indicated that while they had participated in these kinds of artificially generated sites in the past, the elapsed time between burial and study was usually $8-12$ weeks. It was recognized, therefore, that the nature of the burials themselves would be a struggle for the dogs, but it was hoped that having multiple bones buried at each location and a long burial period of 11 months would help mitigate these potential problems.

\subsection{Survey area creation}

Skeletonized human (homo sapien sapien) and coyote (canis latrans) bones were purchased from The Bone Room in Berkley, California. This store sells human skeletal remains that were legally exported from the People's Republic of China between 1987 and 2008 (The Bone Room 2014). None of the human remains used in this study derived from Native American populations, either domestically or abroad. Bare whitetail deer (odocoileus virginianus) bones of recent origin were obtained from a local taxidermist. The study area also incorporated an experimental archaeological site where three domesticated pig (sus scrofa domestica) carcasses were buried in 1998 and have been decomposing undisturbed in situ since that time. ERDC-CERL's Director of Public Works and ERDC-CERL's legal counsel were consulted, and their approval was obtained prior to the burial of all the bones in this study. All burial locations, regardless of species (with the exception of the pig burials), will be removed from the site after completion of the study.

The control test site was located in an enclosed, mowed grass field near the ERDC-CERL laboratory (Figure 5). The field was divided into three survey blocks. Wood posts from a preexisting rope fence provided the separation boundaries between the three study blocks. Study Block A was south of the 
fence posts and contained five human burials, five deer burials, and three coyote burials. Study Block B contained the preexisting experimental archaeological site. This area had seen substantial ground disturbance activities more than $10 \mathrm{yr}$ ago, and simulated historic and prehistoric architectural features are still located below the surface. Additionally, all three of the domestic pig burials were located within this block. No human, deer, or coyote were buried with this block. It was intended that Study Block B would provide the best opportunity to test false positive alerts. Study Block $\mathrm{C}$ was the northern area. It contained five human burials (including three burials in close proximity), five coyote burials, and one deer burial. ICF dog handlers were not informed how many burials were present, that both animal and human bones had been buried, or that a preexisting experimental site was situated within the study areas.

Bones were buried from 10-12 December 2012. Locations were selected to create single burials as well as clusters of single species. Each location contained multiple bones spread out in a horizontal layer at the bottom of each excavation (Table 3). Depth of the burials varied from 6-100 $\mathrm{cm}$ below surface. Topsoil depths were recorded at $14-18 \mathrm{~cm}$ below surface with the topsoil consisting of silty clay loam with clay loam subsoil. Small rocks were found infrequently in the excavations. As each excavation was backfilled, the soil was slightly compressed and left slightly mounded so that settling would not produce depressions or divots. All soil not used to backfill the hole was removed completely from the site. Each location was mapped to decimeter accuracy with a Trimble GeoXH 6000 GPS device. After burials were completed, no further ground disturbance occurred with the testing locations. Periodic visits and visual inspections were made to ensure that the disturbed grass had reseeded and visible signs of the burial locations were obscured by the vegetation growth. The only other visitors to the site were periodic groundskeepers who mowed the grass with riding lawnmowers.

Table 3. Burial descriptions at control test site.

\begin{tabular}{|l|l|l|l|}
\hline Burial Number & Species & Bones & Depth \\
\hline 1 & Human & 3 Scapula & $50 \mathrm{~cm}$ \\
\hline 2 & Human & 3 Scapula & $50 \mathrm{~cm}$ \\
\hline 3 & Human & 3 Scapula & $50 \mathrm{~cm}$ \\
\hline 4 & Coyote & 3 Ulna & $6 \mathrm{~cm}$ \\
\hline
\end{tabular}




\begin{tabular}{|c|c|c|c|}
\hline Burial Number & Species & Bones & Depth \\
\hline 5 & Human & 3 Scapula & $80 \mathrm{~cm}$ \\
\hline 6 & Human & 5 Ribs & $30 \mathrm{~cm}$ \\
\hline 7 & Human & 13 Carpal/Tarsal & $15 \mathrm{~cm}$ \\
\hline 8 & Human & 4 Vertebra & $30 \mathrm{~cm}$ \\
\hline 9 & Human & 3 Scapula & $25 \mathrm{~cm}$ \\
\hline 10 & Human & 3 Ribs & $70 \mathrm{~cm}$ \\
\hline 11 & Human & 4 Ribs & $20 \mathrm{~cm}$ \\
\hline 12 & Human & 4 Vertebra & $50 \mathrm{~cm}$ \\
\hline 13 & Deer & 4 Ribs & $50 \mathrm{~cm}$ \\
\hline 14 & Deer & $\begin{array}{l}3 \text { Lower Limb } \\
\text { Bone }\end{array}$ & $50 \mathrm{~cm}$ \\
\hline 15 & Deer & 4 Ribs & $50 \mathrm{~cm}$ \\
\hline 16 & Pig & Entire Carcass & $100 \mathrm{~cm}$ \\
\hline 17 & Pig & Entire Carcass & $100 \mathrm{~cm}$ \\
\hline 18 & Deer & $\begin{array}{l}3 \text { Lower Limb } \\
\text { Bone }\end{array}$ & $70 \mathrm{~cm}$ \\
\hline 19 & Deer & 4 Ribs & $10 \mathrm{~cm}$ \\
\hline 20 & Deer & 4 Ribs & $50 \mathrm{~cm}$ \\
\hline 21 & Coyote & 3 Ulna & $10 \mathrm{~cm}$ \\
\hline 22 & Coyote & 3 UIna & $30 \mathrm{~cm}$ \\
\hline 23 & Coyote & 3 UIna & $120 \mathrm{~cm}$ \\
\hline 24 & Coyote & 3 UIna & $50 \mathrm{~cm}$ \\
\hline 25 & Coyote & 3 UIna & $20 \mathrm{~cm}$ \\
\hline 26 & Coyote & 3 UIna & $40 \mathrm{~cm}$ \\
\hline 27 & Pig & Entire Carcass & $100 \mathrm{~cm}$ \\
\hline
\end{tabular}


Figure 5. Control test site at ERDC-CERL.

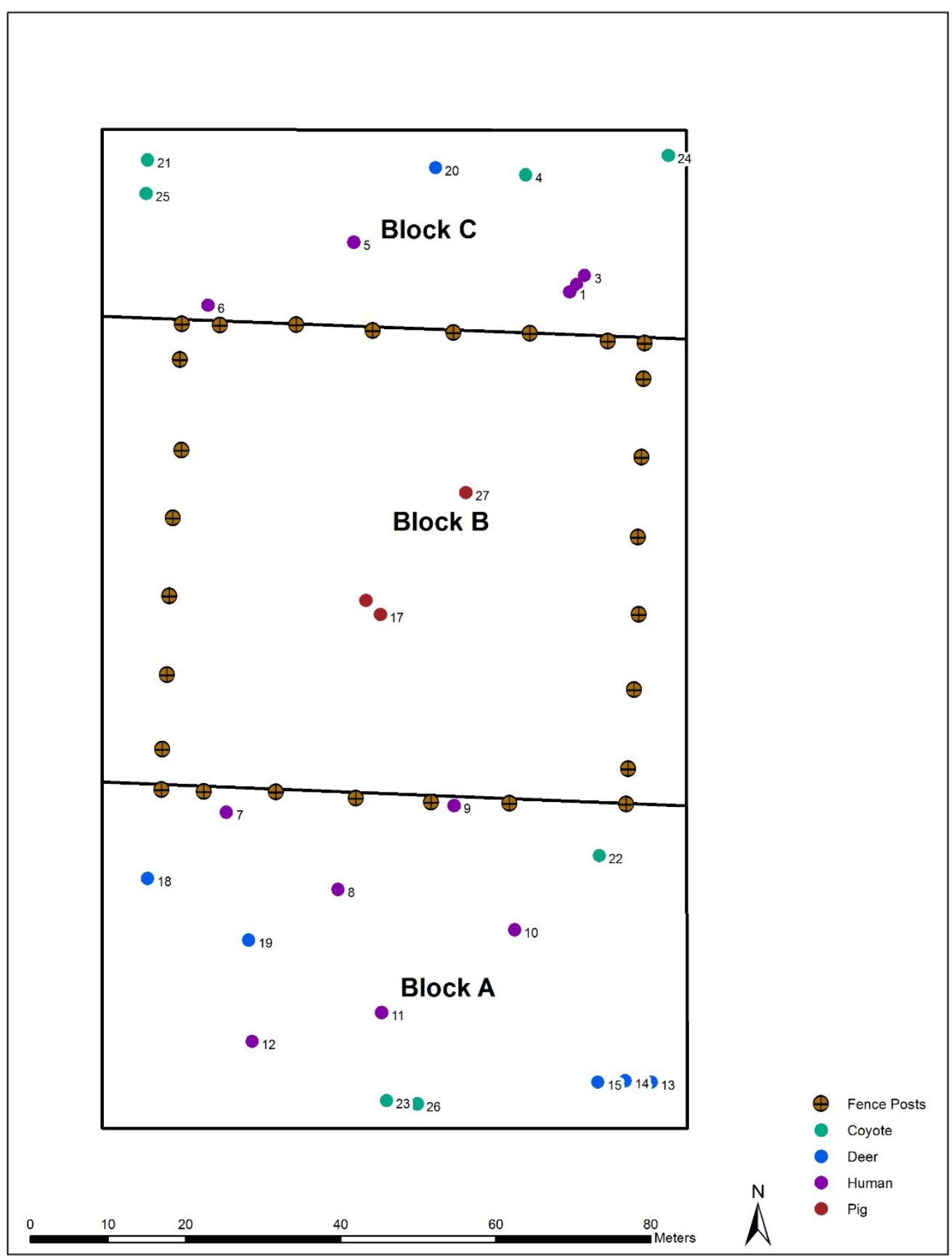

\subsection{Fieldwork}

HHRD dog team survey was the only data collection done at this testing location. GPR survey was not conducted at this site for two reasons.

ERDC-CERL archaeologists had created this site. As a result, the exact location of each burial site and depth of burial was known to them. Thus, the results of the HHRD dog alerts did not need to be verified through geo- 
physical survey. Additionally, the sizes of the excavations were kept as small as possible to minimize the appearance of ground disturbance activities that might tip off the dog handlers to the location of burial sites. The size and shape of the anomalies the excavations would produce in GPR data would not resemble in any way the size and shape of the anomalies generated by full-size grave shafts. Additionally, analysis of the data by using the same criteria of grave detection utilized in the Fort Gordon and Clements Cemetery data sets would have been extremely problematic.

HHRD dog testing at this site occurred on 11 November 2013. Testing began at 09:30 and continued until 13:55. The dog teams interspersed working study blocks with resting periods for the dogs, so that most of the time there were only two study blocks being worked at the same time. Team members did not necessarily work the study blocks in any particular order. At no time were two dog teams working any individual block simultaneously. The ICF team coordinator determined the soil surface $80 \%-100 \%$ accessible to the dogs at the time of the survey. Temperature ranged from $49.2{ }^{\circ} \mathrm{F}$ to $53.7^{\circ} \mathrm{F}$ during testing. Ground temperature ranged from $56.1{ }^{0} \mathrm{~F}$ to $55.1{ }^{0} \mathrm{~F}$ throughout the testing day. Humidity ranged from $53.7 \%$ to $61.3 \%$. The wind ranged from 3.8-11.1 mph. At the beginning of the day, the wind was blowing on an azimuth of 235 degrees and then switched direction around noon to a direction of 346 degrees. The day was overcast, and rain moved into the area immediately after testing concluded.

GIS software was utilized to generate circular buffer zones around each burial location (Figure 6). Radiuses of $1 \mathrm{~m}$ and $2 \mathrm{~m}$ were chosen to approximate the size of typical grave and grave shaft excavations. Larger buffer zones of $5 \mathrm{~m}$ and $10 \mathrm{~m}$ radiuses were chosen to demonstrate far field dispersal of the scent. The results from the teams for each zone are presented individually in Figure 7-Figure 17 and Table 4-Table 6. The size symbol used for each alert represents the quality of the alert, with the larger symbols assigned to Quality 1 alerts and the smallest symbol used for Quality 3 scent pool alerts. In their notes, the handlers numbered each of their alerts sequentially throughout the project. The authors of this report chose to keep the same numbering system. As a result, on some of the maps higher ordinals may be used to designate specific alerts, even though lower ordinal numbers are not utilized in the same map. 
Figure 6. Control test site with human and animal buffers depicted.

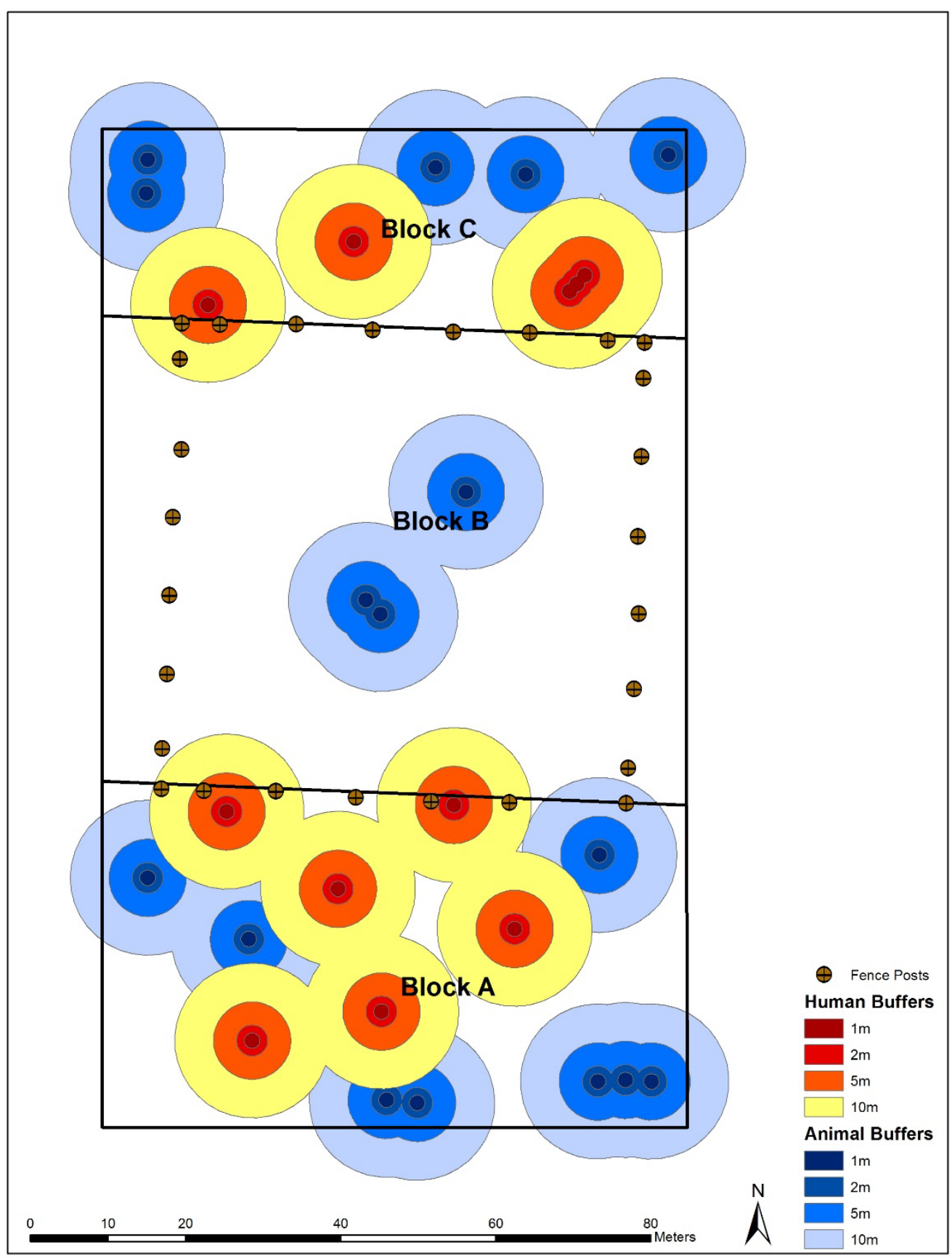




\subsubsection{Study Block $A$ results}

Figure 7. Results of Team AM dog survey of Control Area, Study Block A.

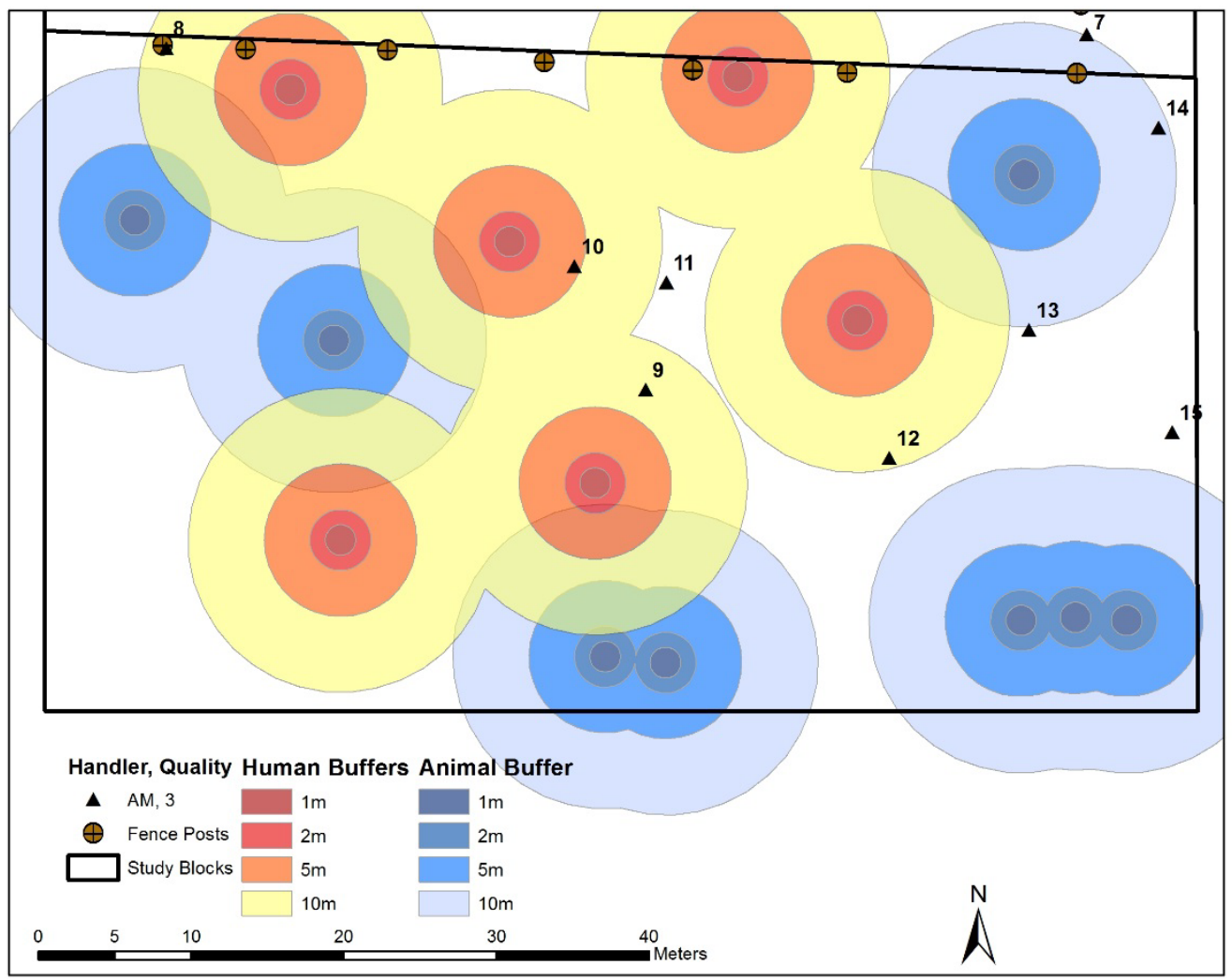


Figure 8. Results of Team BP dog survey of Control Area, Study Block A.

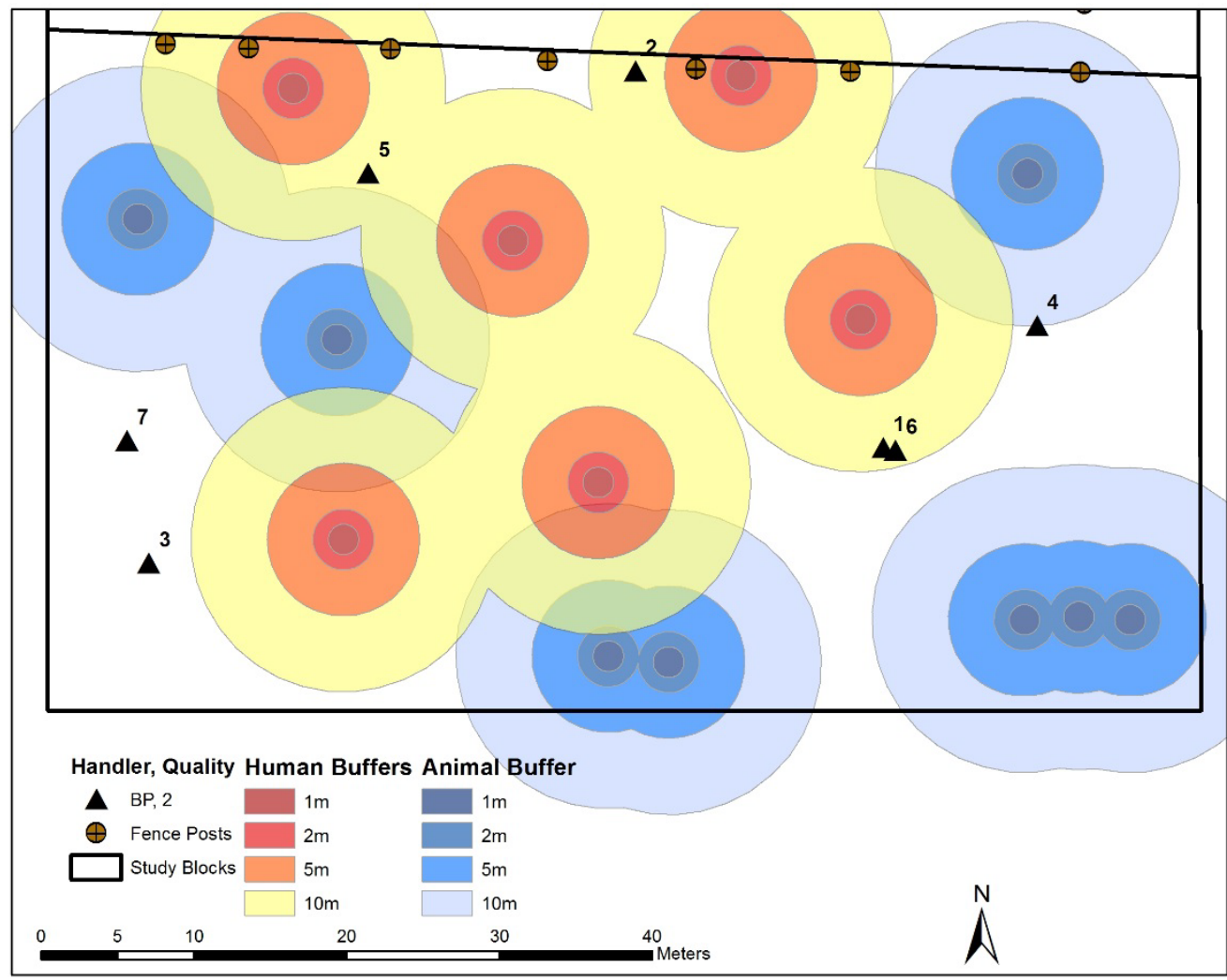

Figure 9. Results of Team JG dog survey of Control Area, Study Block A.

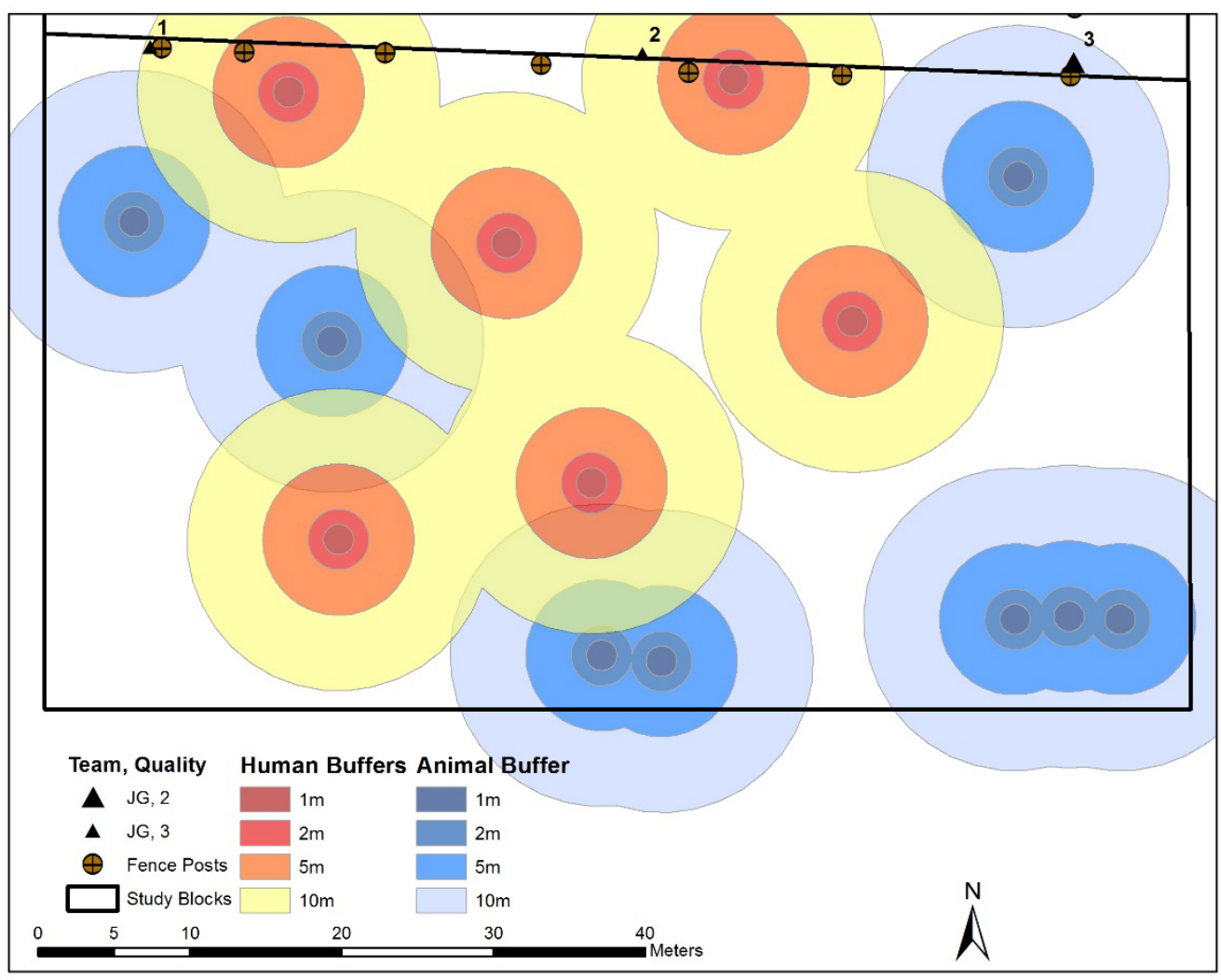


Figure 10. Results of Team LA dog survey of Control Area, Study Block A.

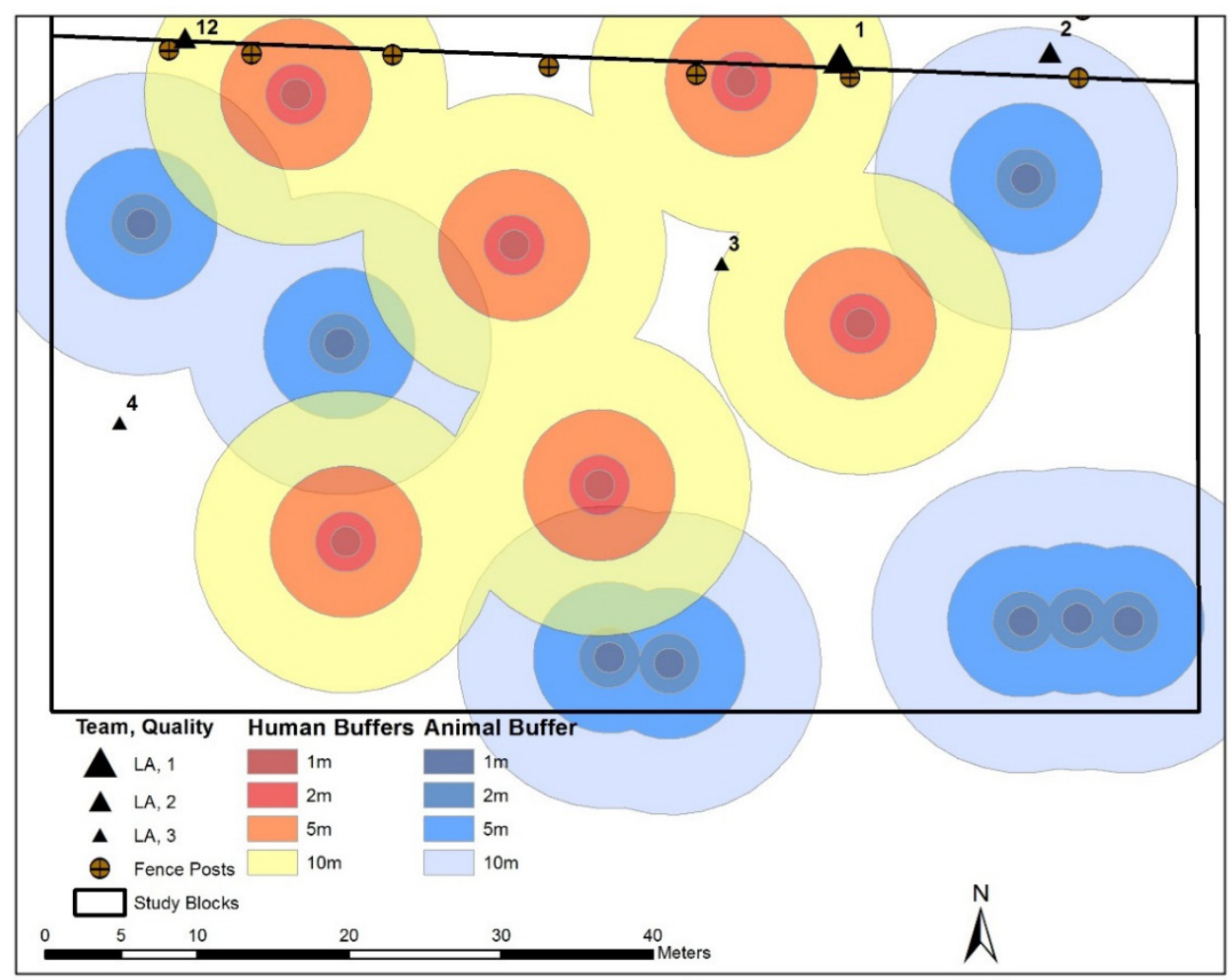

Table 4. Summary for dog surveys Control Area, Study Block A.

\begin{tabular}{|l|c|c|c|c|}
\hline \multirow{2}{*}{ Results } & \multicolumn{3}{|c|}{ Team } \\
\cline { 2 - 5 } & AM & BP & JG & LA \\
\hline \# of alerts less than1 $m$ from human burial & & & & \\
\hline \# of alerts 1-2 $m$ from human burial & & & & \\
\hline \# of alerts 2-5 $m$ from human burial & 1 & & & \\
\hline \# of alerts 5-10 $m$ from human burial & 3 & 4 & 2 & 3 \\
\hline \# of alerts less than 1 $m$ from animal burial & & & & \\
\hline \# of alerts 1-2 $m$ from animal burial & & & & \\
\hline \# of alerts 2-5 $m$ from animal burial & & & & \\
\hline \# of alerts 5-10 $m$ from animal burial & 1 & & 1 & 1 \\
\hline \# of alerts not in any buffer zone & 3 & 3 & & 1 \\
\hline
\end{tabular}




\subsubsection{Study Block B results}

Figure 11. Results of Team AM dog survey of Control Area, Study Block B.

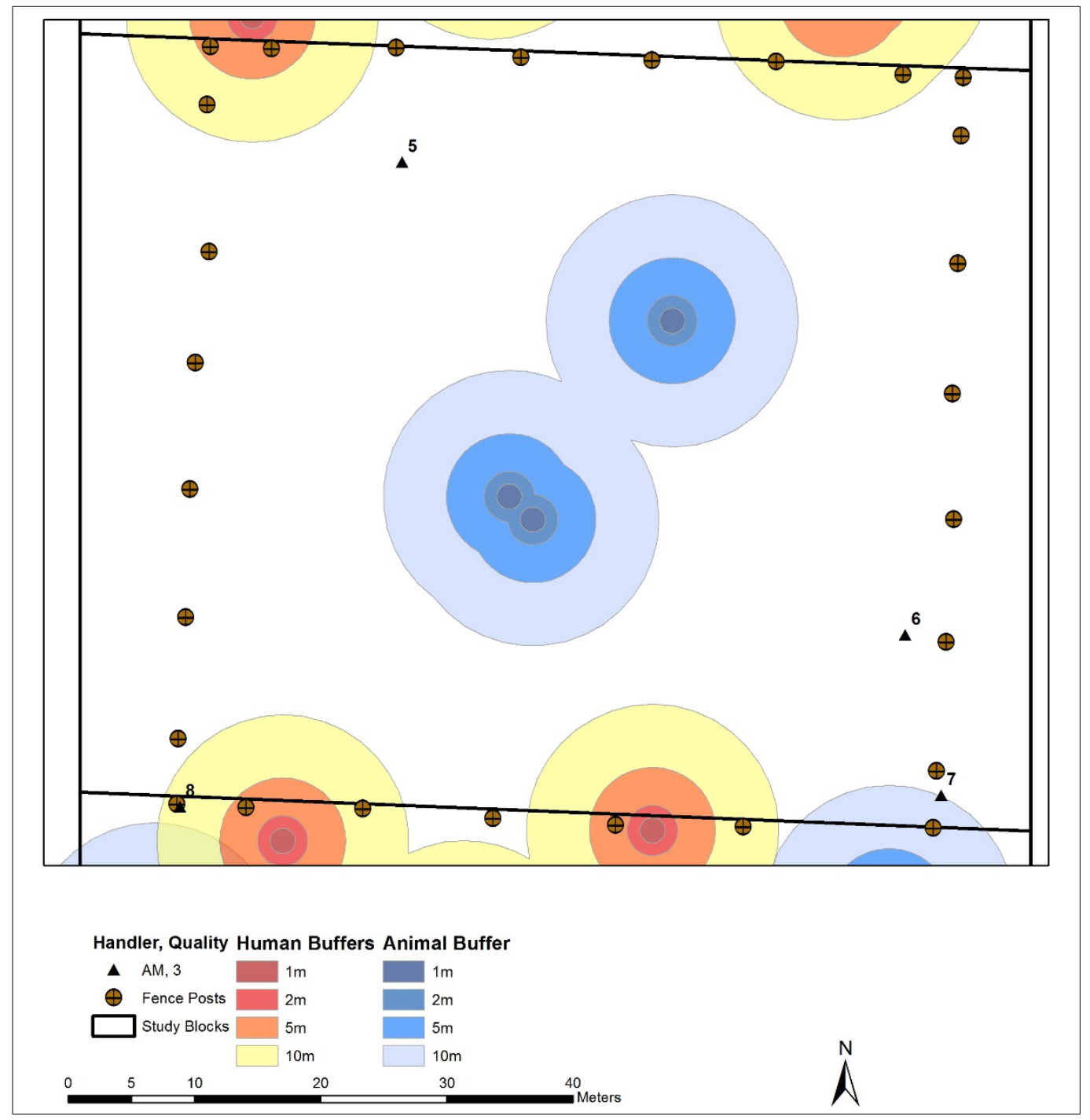


Figure 12. Results of Team BP dog survey of Control Area, Study Block B.

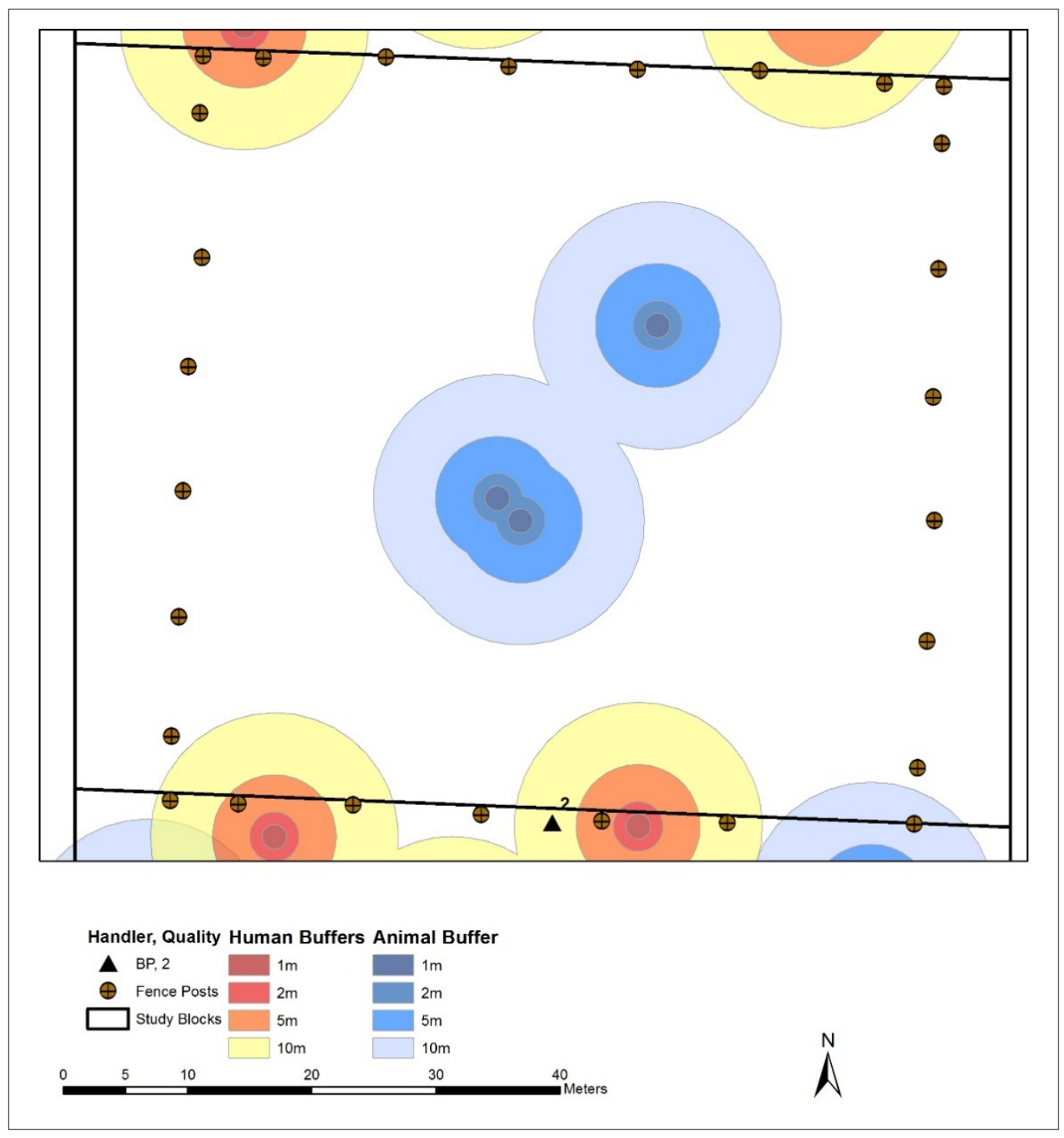


Figure 13. Results of Team JG dog survey of Control Area, Study Block B.

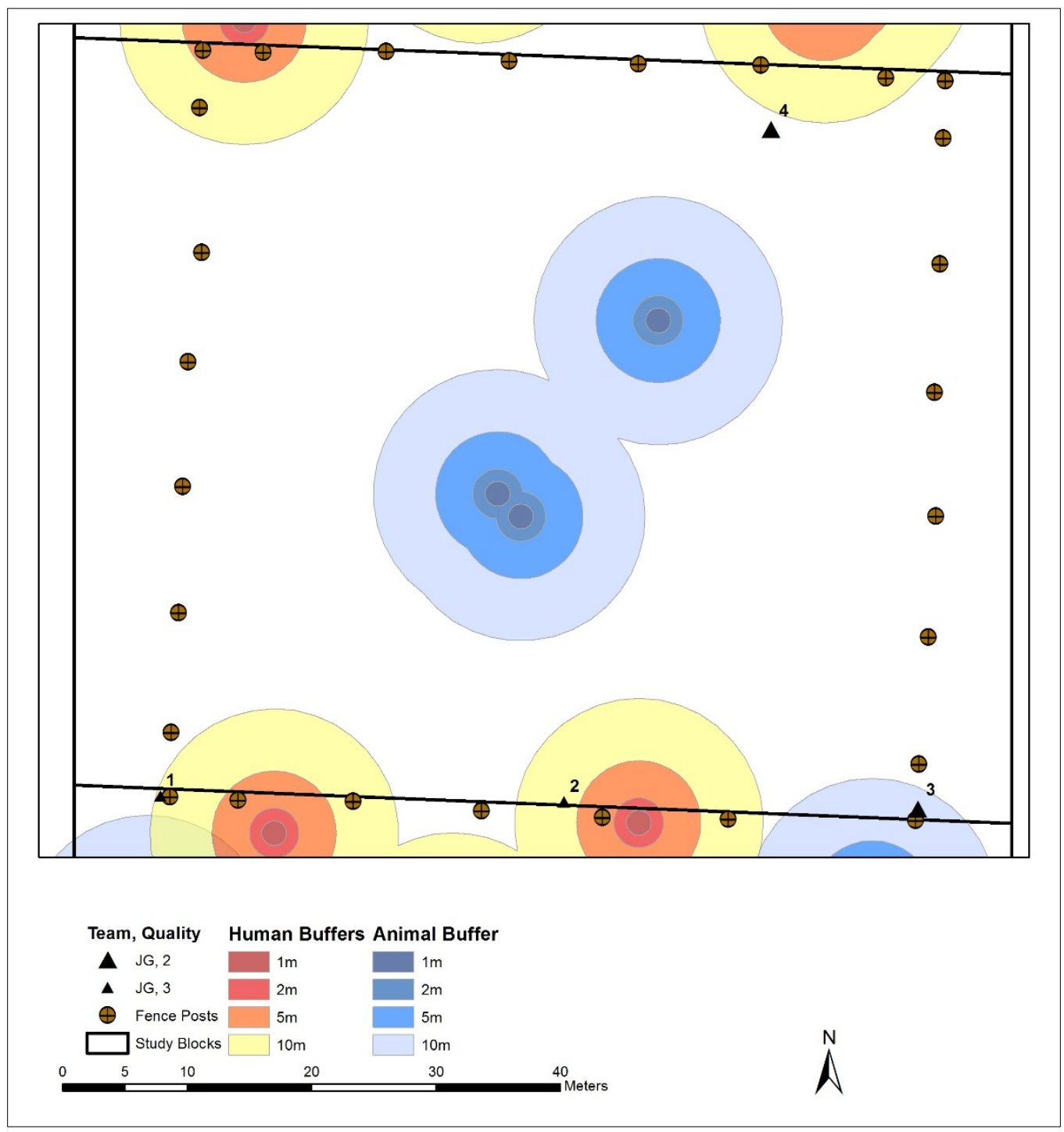


Figure 14. Results of Team LA dog survey of Control Area, Study Block B.

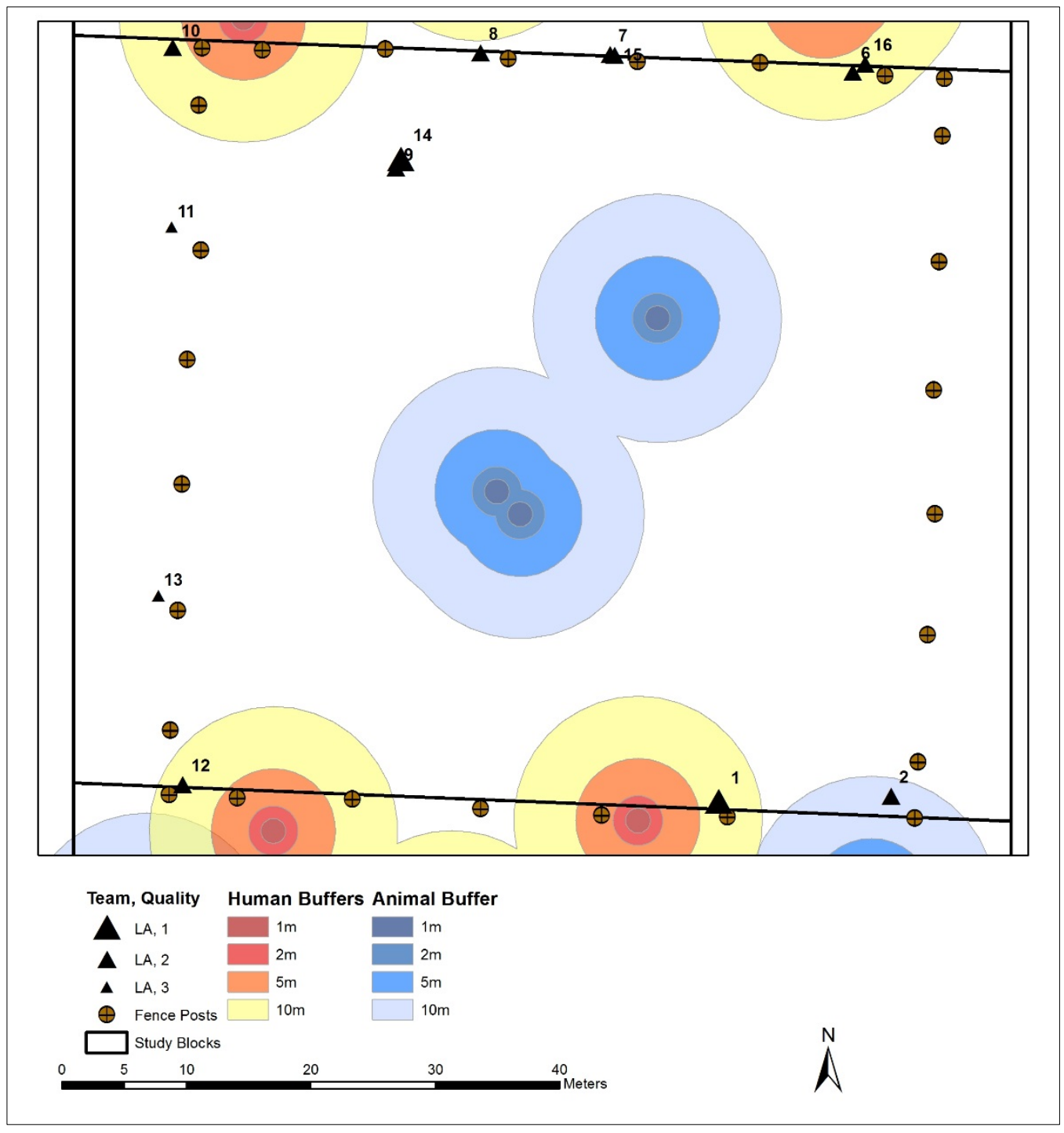

Table 5. Summary of dog surveys for Control Study, Block B.

\begin{tabular}{|l|c|c|c|c|}
\hline \multirow{2}{*}{ Results } & \multicolumn{3}{|c|}{ Team } \\
\cline { 2 - 5 } & AM & BP & JG & LA \\
\hline \# of alerts less than1 $m$ from human burial & & & & \\
\hline \# of alerts 1-2 $m$ from human burial & & & & \\
\hline \# of alerts 2-5 $m$ from human burial & & & & \\
\hline \# of alerts 5-10 $m$ from human burial & & & 2 & 3 \\
\hline \# of alerts less than 1 $m$ from animal burial & & & & \\
\hline \# of alerts 1-2 $m$ from animal burial & & & & \\
\hline
\end{tabular}




\begin{tabular}{|l|c|c|c|c|}
\hline \multirow{2}{*}{ Results } & \multicolumn{3}{|c|}{ Team } \\
\cline { 2 - 5 } & AM & BP & JG & LA \\
\hline \# of alerts 2-5 m from animal burial & & & & \\
\hline \# of alerts 5-10 m from animal burial & 1 & & 1 & \\
\hline \# of alerts not in any buffer zone & 2 & & 1 & 5 \\
\hline No alerts in this study area & & $X$ & & \\
\hline
\end{tabular}

\subsubsection{Study Block C results}

Figure 15. Results of Team AM dog survey of Control Area, Study Block C.

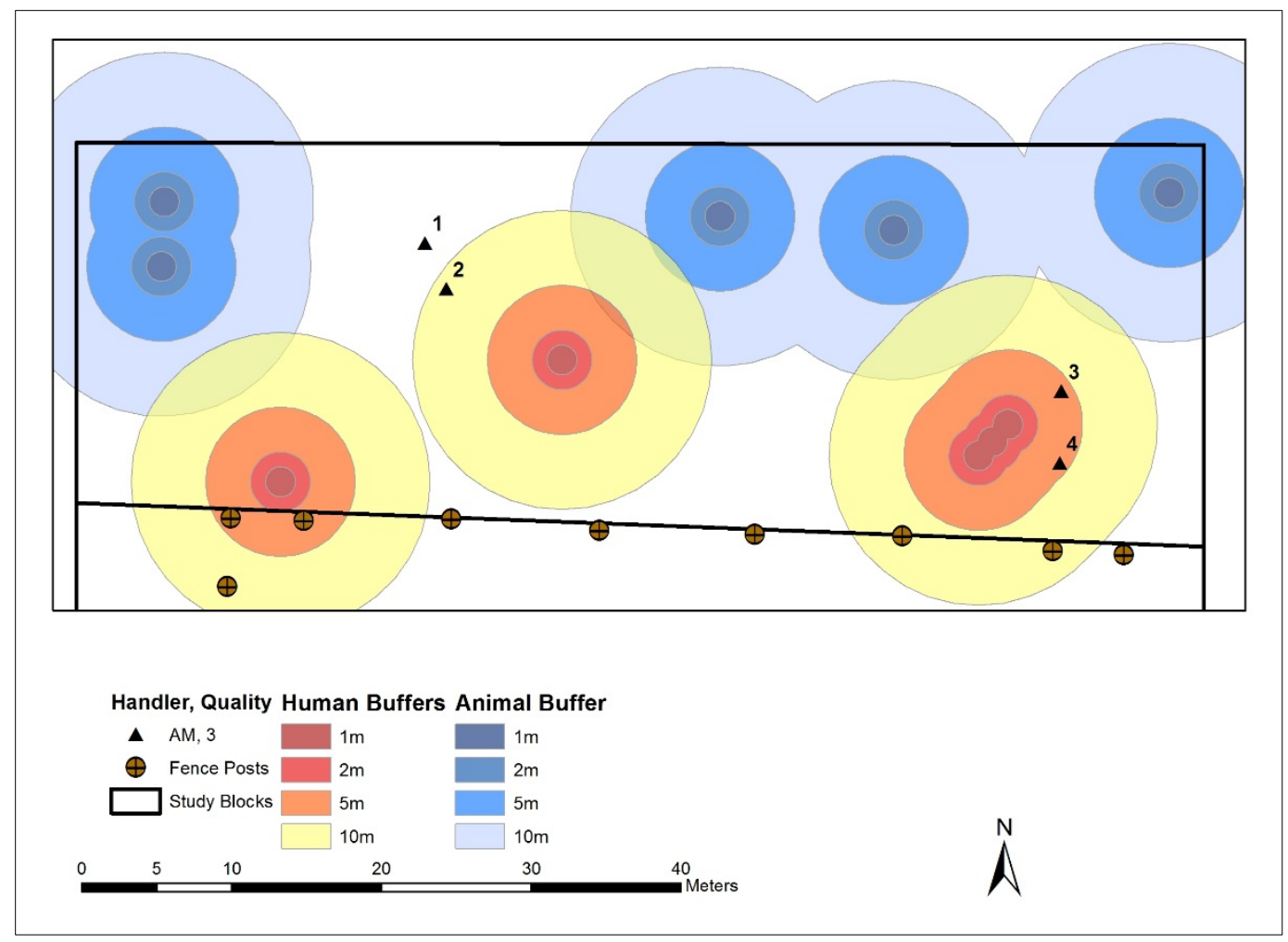


Figure 16. Results of Team JG dog survey of Control Area, Study Block C.

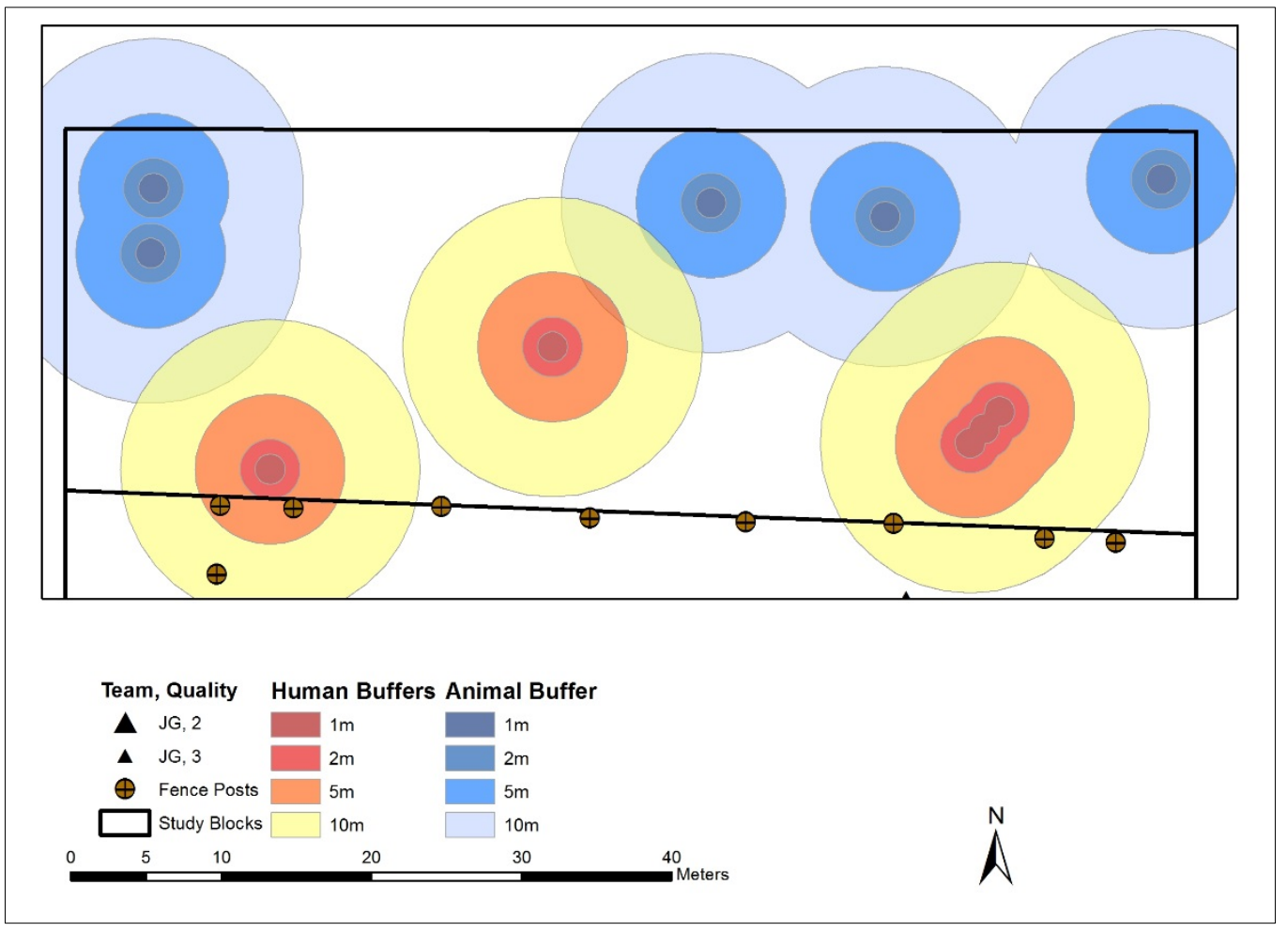

Figure 17. Results of Team LA dog survey of Control Area, Study Block C.

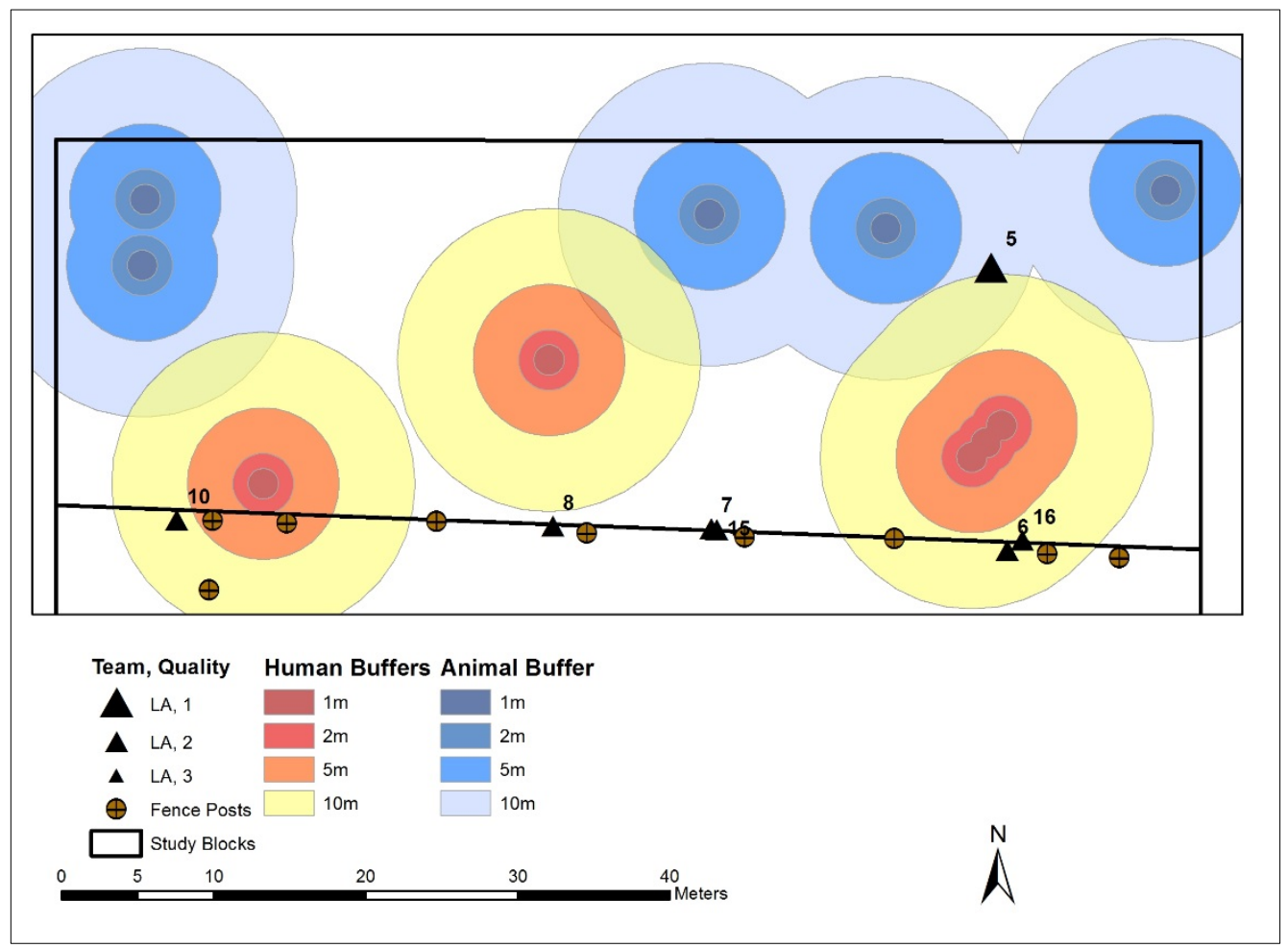


Table 6. Summary of dog surveys for Control Area, Study Block C.

\begin{tabular}{|c|c|c|c|c|}
\hline Team & AM & $\mathrm{BP}$ & $J G$ & LA \\
\hline \multicolumn{5}{|c|}{ \# of alerts less than $1 \mathrm{~m}$ from human burial } \\
\hline \multicolumn{5}{|l|}{ \# of alerts 1-2 m from human burial } \\
\hline \# of alerts $2-5 \mathrm{~m}$ from human burial & 2 & & & \\
\hline \# of alerts $5-10 \mathrm{~m}$ from human burial & 1 & & & \\
\hline \multicolumn{5}{|c|}{ \# of alerts less than $1 \mathrm{~m}$ from animal burial } \\
\hline \multicolumn{5}{|l|}{ \# of alerts 1-2 $\mathrm{m}$ from animal burial } \\
\hline \multicolumn{5}{|l|}{ \# of alerts $2-5 \mathrm{~m}$ from animal burial } \\
\hline \# of alerts 5-10 $\mathrm{m}$ from animal burial & & & & $1 *$ \\
\hline \# of alerts not in any buffer zone & 1 & & & 2 \\
\hline No alerts in this study area & & $x$ & $\begin{array}{c}\text { Did not } \\
\text { work this } \\
\text { area }\end{array}$ & \\
\hline
\end{tabular}

* One alert for team LA was located where a $10 \mathrm{~m}$ human and $10 \mathrm{~m}$ animal buffer zone overlapped. Since the alert location was closest to the animal burial site, it was counted as an animal alert.

\subsection{Summary and conclusions}

The findings in this experiment produced mixed results. It should be repeated that this kind of testing-burial of skeleton fragments after decomposition/defleshing has occurred-is not what the dogs are specifically trained for. Several patterns in the data, however, are readily observable.

The first is that no HHRD team alerted within $2 \mathrm{~m}$ of a burial site. This result could be explained by the fact the wind was blowing at $11.1 \mathrm{mph}$ by the end of testing, and occasional gusts were stronger still. It is possible that the prevailing wind caused the scent to disperse more quickly. Alerts were, however, occurring upwind as well as downwind of the burial site nearest to the alert, so the role of the wind in affecting alert location is not clearly defined.

There is also a clear pattern of alerts along the fence posts that surrounded Study Block B. Volatile organic compounds tend to travel along the paths of least resistance. It is extremely likely that the fence posts were acting as chimneys and funneling the scent to the surface. The majority of the fencepost alerts were occurring in proximity to burial sites, particularly along 
the fence line between Study Blocks A and B as well as the fence line between Study Blocks B and C.

In this experiment, depth and the amount of skeletal material did not seem to affect the quality of the dog alerts. Three of the four dog teams had alerts in the vicinity of Burials 8 and 10, despite the fact that Burial 10 is the second deepest of all human burials and it also had the smallest amount of bone (with four vertebra), when most other human burials had multiple scapula or ribs. Burial 11, which had four ribs at the secondshallowest depth, had no alerts associated with it at all.

Study Block B was intended to test the possibilities of false positives. There should have been no dog alerts within this area. However, only one team (Team BP) did not have any alerts in that area. The majority of the alerts were focused, however, along the fence posts when there were human burials on the other side of the fence. If we discard the alerts related to the fence posts, then Team JG had only one alert in Study Block B, and that alert was $11 \mathrm{~m}$ downwind of Burials 1-3 (the densest concentration of human bones on the site) located in Study Block C. Two dogs produced three alerts, including a Quality 1 alert, in the northwest corner of Study Block B. This area was a depression, at least $30 \mathrm{~cm}$ in depth, located immediately over a feature in the experimental archaeological site sitting under Study Block B. The turf in this area was cracked and disrupted by the soil's subsidence. The area is almost equidistant from Burial 6 (with five human ribs) to the northwest and the two pig carcasses to the southeast. Possible explanations for this alert are: (1) the disruption in the turf could have provided an easy conduit for the scent from either burial to escape, (2) the depression might have caused any scents blowing along the ground surface to pool and concentrate, or (3) the dogs or their handlers might have cued on the depression as a visual cue for ground disturbance activity. Subtle rectangular depressions are often visible at cemeteries and result from natural compaction of the soil or coffin collapse. Since the handlers had not been told in advance that excavations unrelated to this study had occurred more than 10 years previously, they might have assumed that any digging in the area had to have been related to this study. A second cluster of false positive alerts occurred in the southwest corner of Study Block A. Two dogs produced three false positives in this area, although this grouping was not as compact and distinct as the false positive cluster in Study Block B. Visual inspection of the site verified that there were no depressions, slight mounds, or turf disturbance in this area. These false positives, 
therefore, cannot be attributed to potential visual cues read by either the dogs or the handlers.

Another aspect of this control portion of the study was to determine if the dogs could differentiate between animal and human bones. The answer to this question is that they clearly can. In all three blocks, there were significantly more alerts associated with human burials than animal burials. In fact, there is a higher rate of alerts that are not within $10 \mathrm{~m}$ of any burial location than there are alerts within $10 \mathrm{~m}$ of an animal burial. The areas that should have produced the strongest scent associated with animal bones were the cluster of three deer burials in the southeast corner of Study Block A, the cluster of two coyote burials in the south-central portion of Study Block A, the three pig burials in Study Block B, and the loose cluster of two coyote burials in the northwest corner of Study Block C. There were no dog alerts associated with any of these areas. The pig burials had the potential to be very problematic for the dogs, since those burials were the only cases of in-situ decomposition. Additionally, as domesticated animals, their diet would have been corn- and/or soy-based, resulting in a ratio of bodily compounds more similar to humans (who also have a diet rich in corn and soy products) than to wild deer or coyote. Despite this similarity, there were no dog alerts in the vicinity of the pig burials.

The conclusions from this portion of the study are:

- The dogs appear to be able to distinguish human skeletal remains. Every location with human bones had at least one dog alert within $10 \mathrm{~m}$ of the burial location. Only two locations with animal bones had alerts, and one of those locations was where human and animal buffer zones overlapped. The areas of the highest concentrations of animal bones had no alerts at all.

- The dogs were able to detect human remains at various depths from near surface to $100 \mathrm{~cm}$ below surface.

- The highest concentrations of false-positive alerts (either within animal bone $10 \mathrm{~m}$ buffer zones or outside any buffer zone) were associated with ground disturbances such as fence posts or ground depressions. 


\section{Clements Cemetery Surveys}

Clements Cemetery is a moderately sized, private cemetery in Champaign County, Illinois. The earliest legible tombstones date to 1810-1820. Evidence from the tombstones indicate that one Revolutionary War veteran and multiple Civil War veterans are buried in this cemetery. Burials appear to have occurred once every few years throughout the last half of the 19th century and much of the 2oth century. The rate of burials seemed to slow in the 1980 os and 1990s. Personal communication with Mr. Cecil McCormick (2012 and 2013), the currently appointed trustee of the Clements Cemetery Association, indicated that during those two decades, the cemetery became overgrown and many of the stones suffered damage. Maintenance of the site resumed in the late 1990 and continues to this day. Much effort had been put toward repairing or replacing damaged stones, and there are at least a dozen examples of new marble stones placed immediately next to the stubs of earlier headstones broken off at the ground. Two new graves have been added to the cemetery in the past year.

The names on stones indicate there are several family clusters within the cemetery. One family cluster is still surrounded by a $3 \mathrm{ft}$ tall wrought-iron fence. A second cluster has the remnants of a concrete and brick border or fence foundation. The southeastern quarter of the cemetery is the older portion and, in addition to the family clusters, there are multiple open spaces where there is the strong possibility of unmarked graves being present. Unmarked graves might occur as a result of the original markers being made of wood that decayed and was not replaced. Another possibility is that stone markers might have been pulled up or broken at ground level, and their foundations have become buried over time.

This portion of the study was intended to test the effectiveness of HHRD dogs in locating unmarked graves within a grouping of known graves.

\subsection{GPR survey}

When the Clements GPR data were processed and analyzed, it became apparent that soil moisture was a limiting factor. Numerous hyperbolas are visible in the GPR profiles, but in most cases, these hyperbolas are characterized by low amplitudes and modest dimensions. The hyperbolas shown 
in Figure 18-Figure 23 represent some of the most prominent examples. These hyperbolas are reasonably prominent only because the visual contrast in these figures has been increased by using a very high display gain (hence the strong contrast that also characterizes other portions of the profiles). Of course, the maximum depth of penetration is located at or near the lower extent of the profile, well below the lower-most extent of nearly all of the hyperbolas.

Figure 18. Selected GPR hyperbolas detected in the southwest survey area, Clements Cemetery (Grid 52; $x=0.51 ; y=4.00$ ).

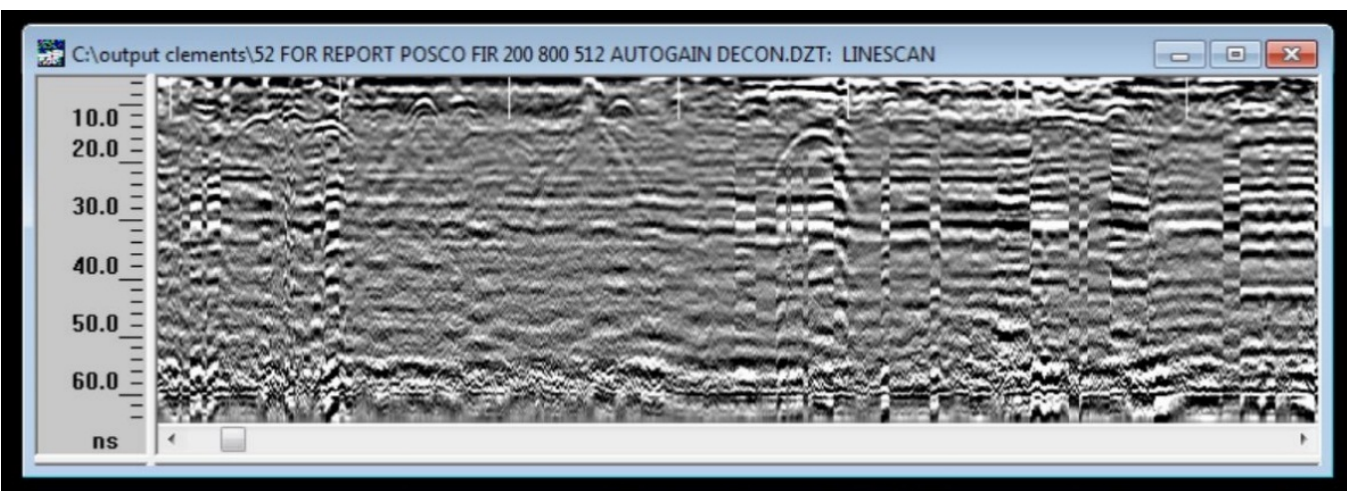

Figure 19. Selected GPR hyperbolas detected in the northeast survey area, Clements Cemetery (Grid 51; $x=12.00 ; y=4.02$ ).

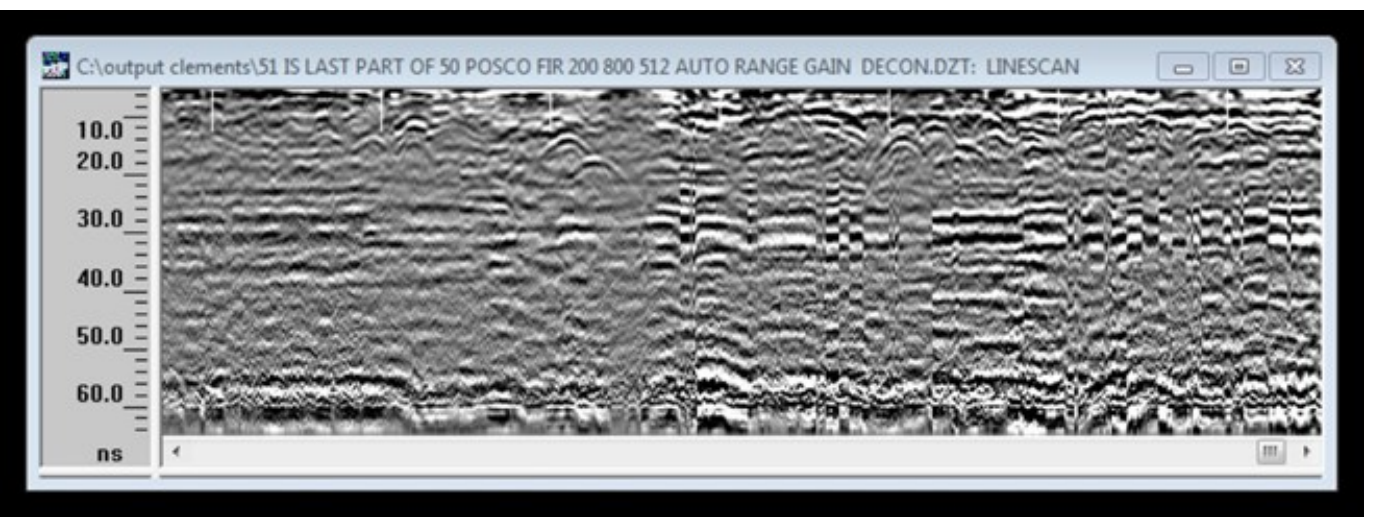


Figure 20. Selected GPR hyperbolas detected in the northeast survey area, Clements Cemetery (Grid 51; $x=6.78 ; y=9.58$ ).

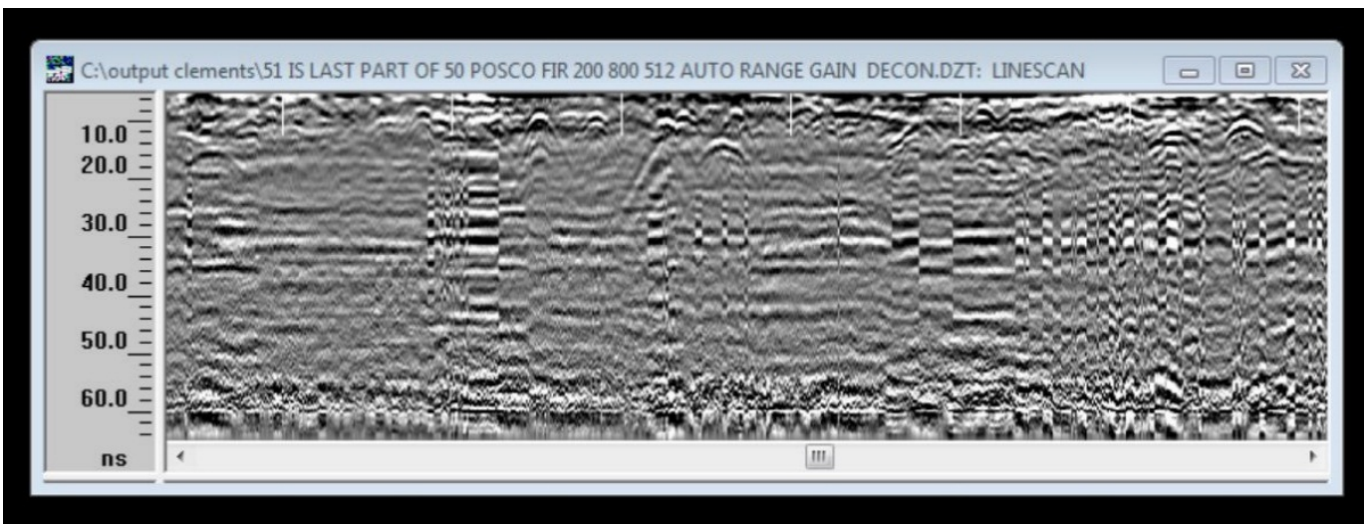

Figure 21. Selected GPR hyperbolas detected in the northeast survey area, Clements Cemetery (Grid 50; $x=7.47 ; y=12.02$ ).

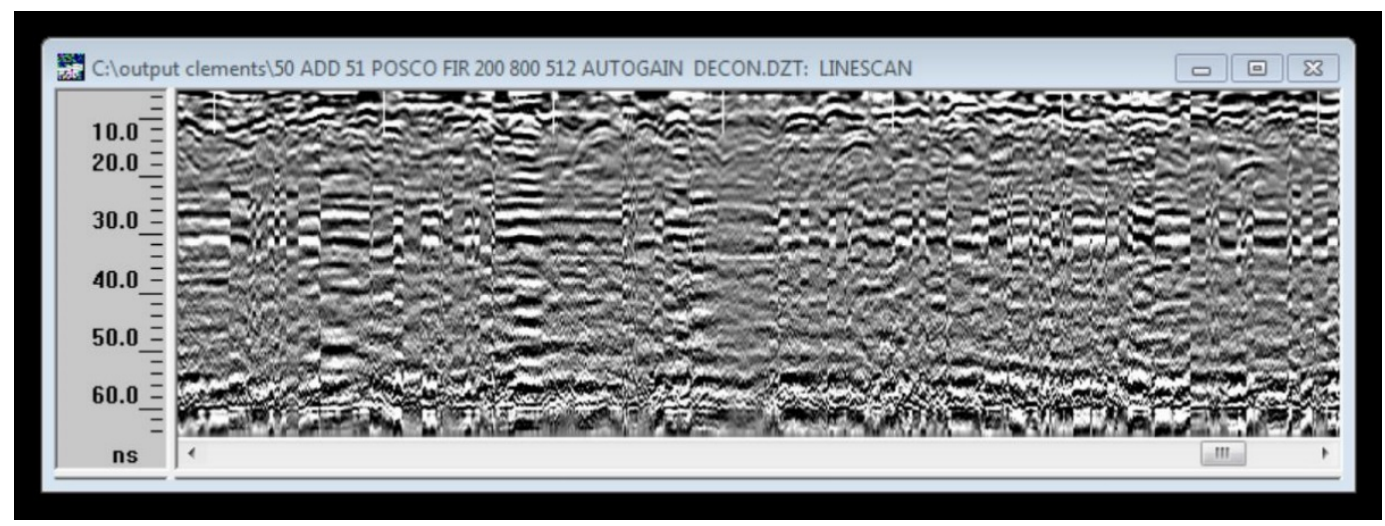

Figure 22. Selected GPR hyperbolas detected in the southeast survey area, Clements Cemetery (Grid 49; $x=8.72 ; y=1.44)$.

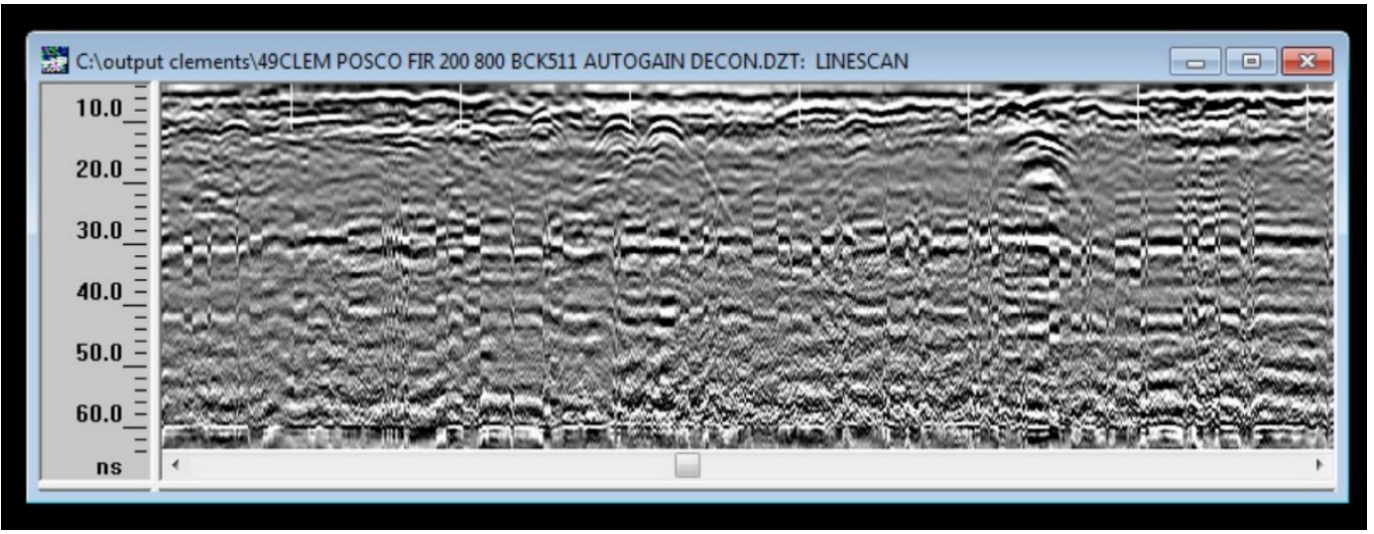


Figure 23. Selected GPR hyperbolas detected in the southeast survey area, Clements Cemetery (Grid 49; $x=9.74 ; y=4.86$ ).

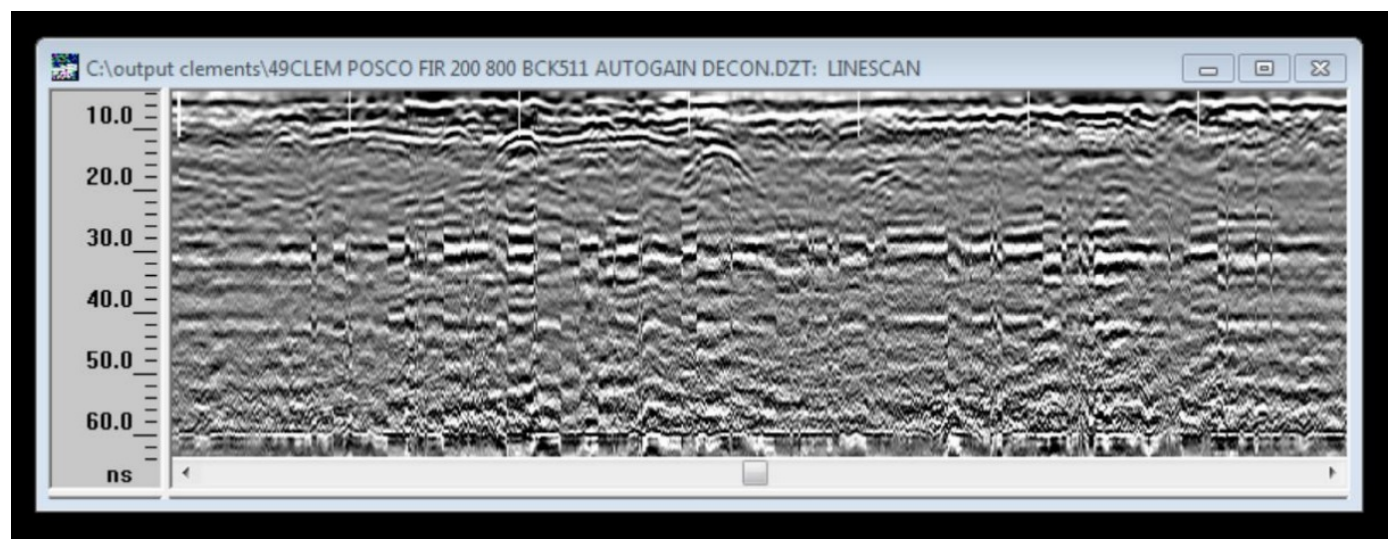

Importantly, the apexes of most of the hyperbolas are located near the top of the GPR profiles, suggesting that their sources are located at very shallow depths. The position of the hyperbolas in the GPR profiles seems inconsistent with their being associated with caskets that are presumably located approximately $1.5^{-2} \mathrm{~m}$ below the surface. However, Conyers (2012,134-137) illustrates a number of hyperbolas associated with caskets whose apexes are plotted at approximately $.6 \mathrm{~m}$ below surface (but none apparently as near the surface as those at Clements Cemetery). It is possible that our hyperbolas are reflections associated with the corners of upper portions of grave shafts. The caskets and lower portions of the shafts may not be manifest in the data because soil moisture has attenuated the signal. We assumed soil moisture and resultant poor radar penetration caused the hyperbolas detected at Clements Cemetery to be small (in horizontal dimensions) and weak (low amplitude). However, Conyers also notes that reflections from graves not located directly under the antenna often exhibit low amplitudes $(2012,137)$.

Authors of this report also considered two alternative sources for the hyperbolas at Clements Cemetery. First, there are naturally occurring rocks and, in a few cases, displaced grave marker stones located immediately below the humus layer. In addition, several large trees are located in the two eastern survey areas (Figure 24 and Figure 25), and their roots (as well as the roots of trees that are no longer standing) may explain some of the hyperbolas in those areas. However, no trees are present in the two western survey areas, suggesting that roots are an unlikely explanation for the hyperbolas located there. 
Figure 24. GPR survey at Clements Cemetery, looking west. Note that inscriptions are on the east side of some markers.

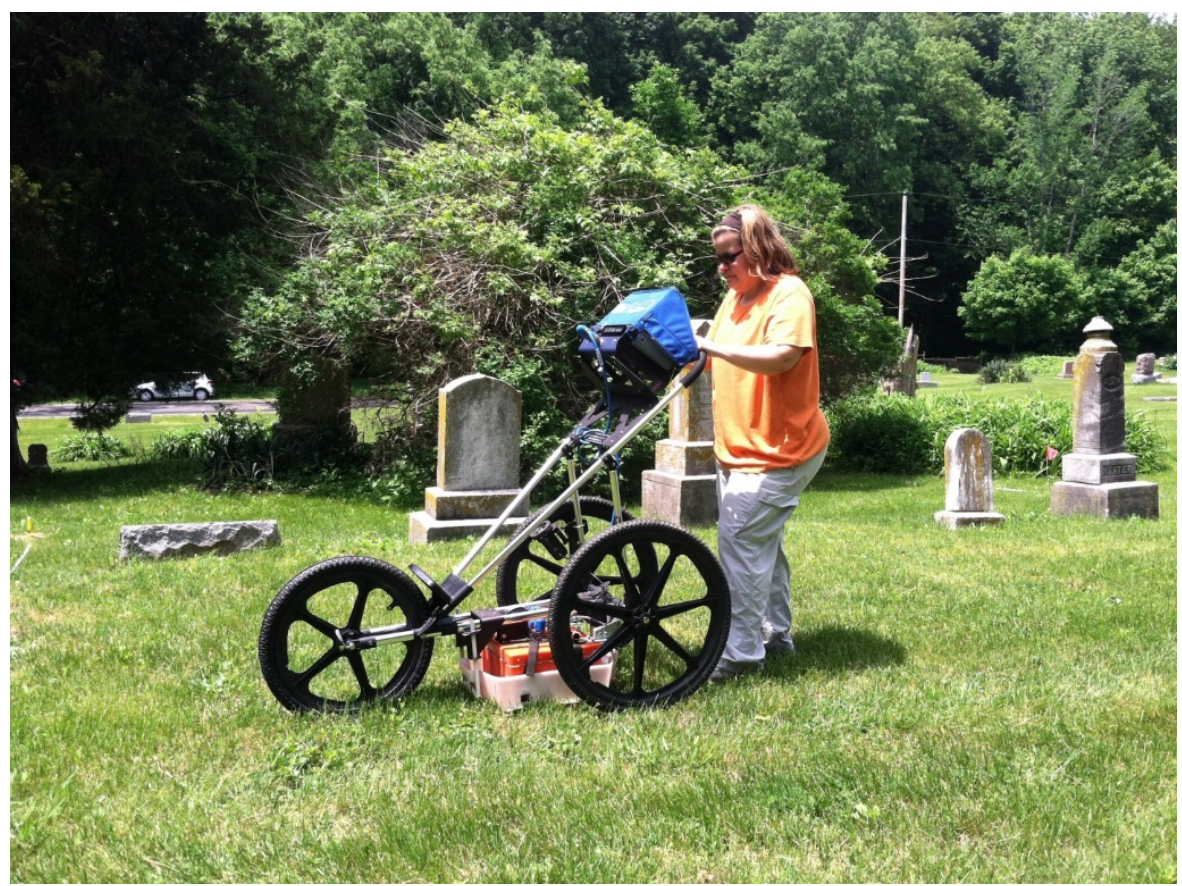

Figure 25. GPR survey at Clements Cemetery, looking east. Note that inscriptions are on the west side of many markers.

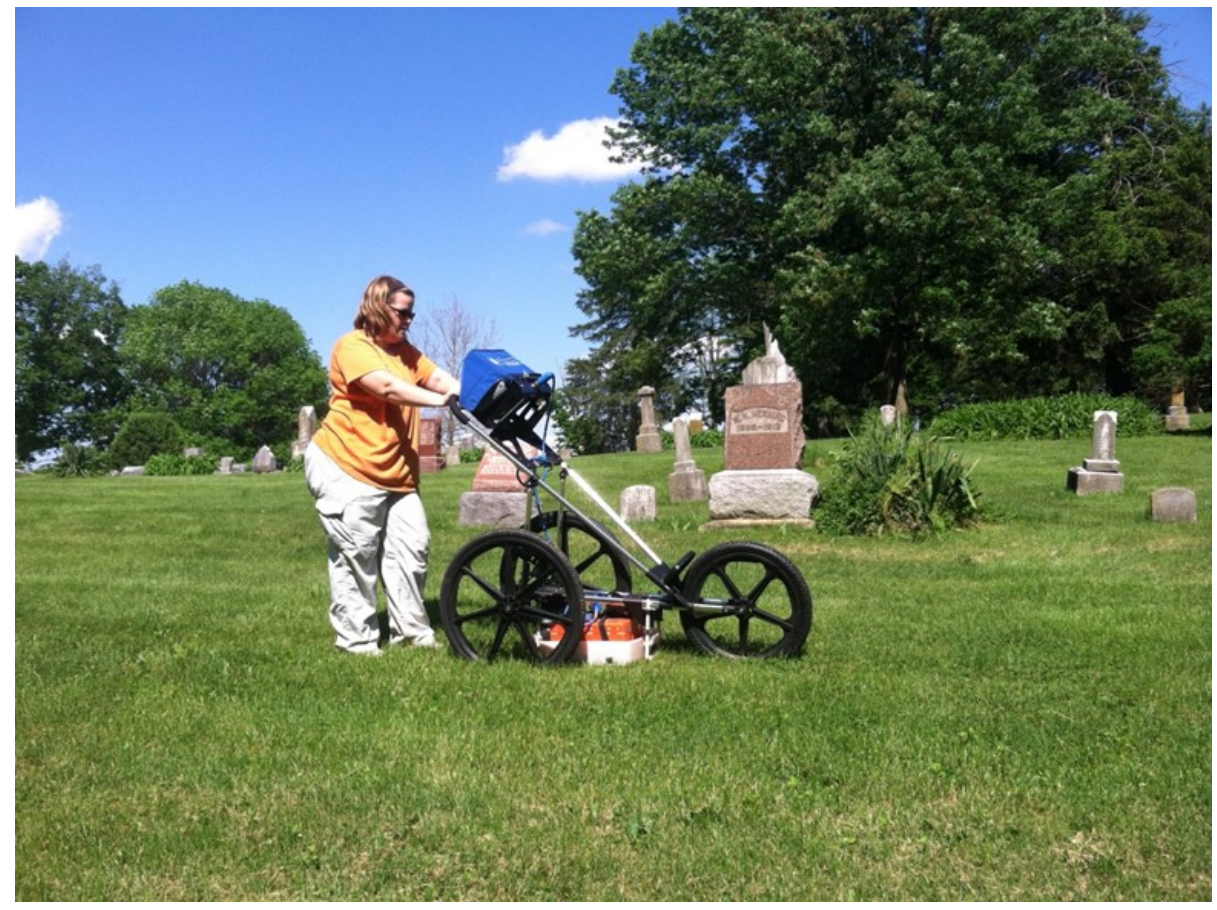

Amplitude slices at various depths were produced for each survey area (Figure 26). These slices were found to exhibit strong linear patterns that parallel the data collection transects. The linear patterns are interpreted as 
resulting from soil moisture; we assume that soil moisture caused much of the transmitted energy to be absorbed at shallow depth. The higher amplitude values (indicated by the red and yellow colors in Figure 26) presumably occurred directly beneath the antenna, whereas the lower amplitude (blue color) values occurred between transects and in localized areas of slightly greater soil moisture.

Figure 26. Amplitude slices of west survey area, Clements Cemetery. North-south linear patterns are clearly visible.

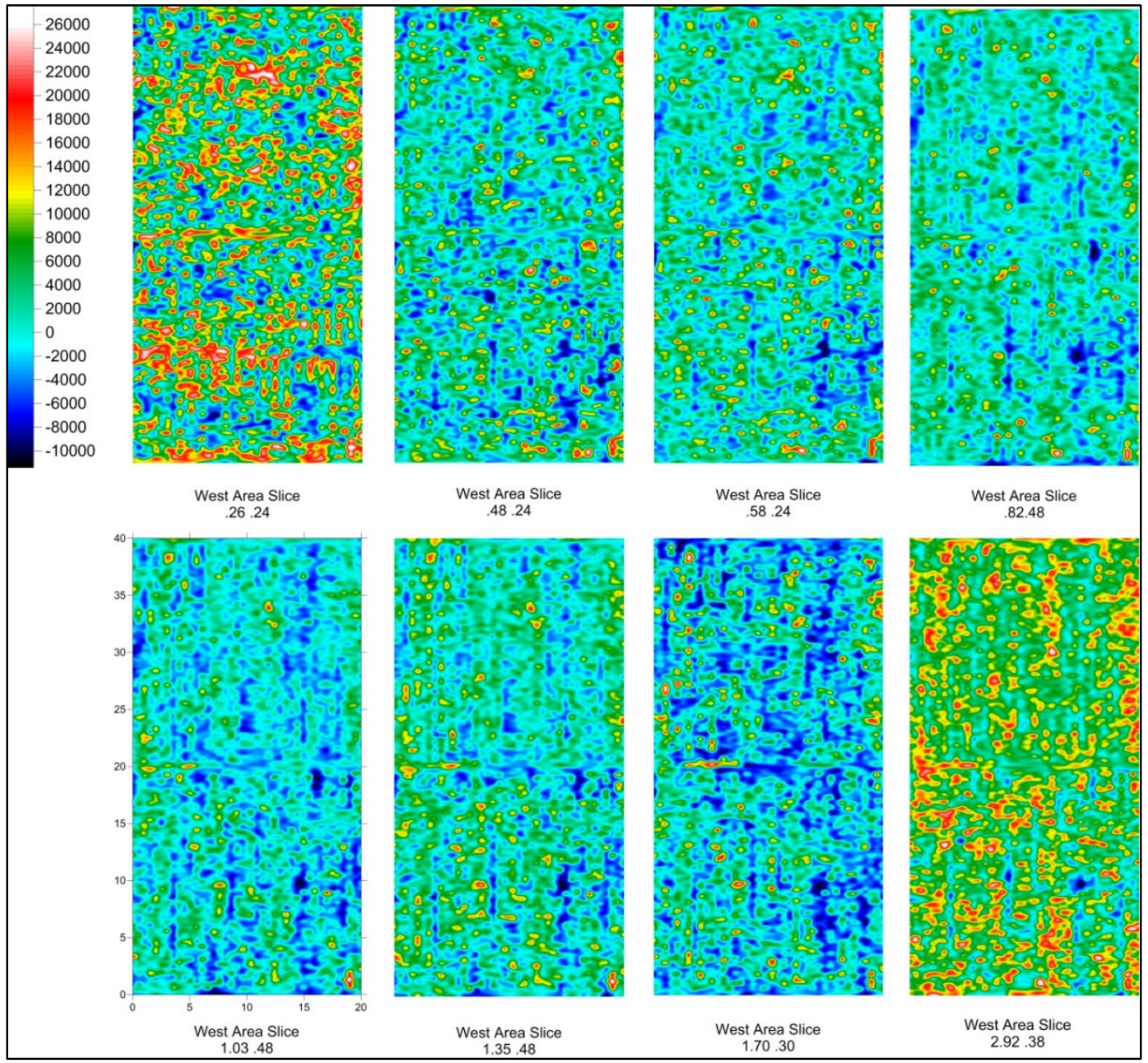

The linear patterns and absence of discrete high- or low-amplitude areas in the slices (that would be suggestive of individual graves) caused us to focus on the GPR profiles for each transect rather than the slices. Initially, the $x y$ coordinates of virtually all of the hyperbola apexes detected in the profiles were recorded, regardless of small size. A total of 519 hyperbolas were recorded, ranging from 61 in the northwest grid to 162 in the southwest grid. The northeast and southeast grids included 146 and 150 hyper- 
bolas, respectively. After further analysis, it was decided to consider only the larger hyperbolas, defined as those whose lowermost extent spanned a horizontal distance of at least (approximately) $1 \mathrm{~m}$. We assumed that if any of the hyperbolas are associated with caskets, the larger ones would be the best candidates. This size criterion reduced the total number of hyperbolas for all four grids to 165 (36 in the northeast, 47 in the southeast, 29 in the northwest, and 53 in the southwest). These larger hyperbolas are plotted as red circles in Figure 27-Figure 29.

Figure 27. Locations of GPR hyperbolas possibly associated with graves and observed grave marker stones, Clements Cemetery.

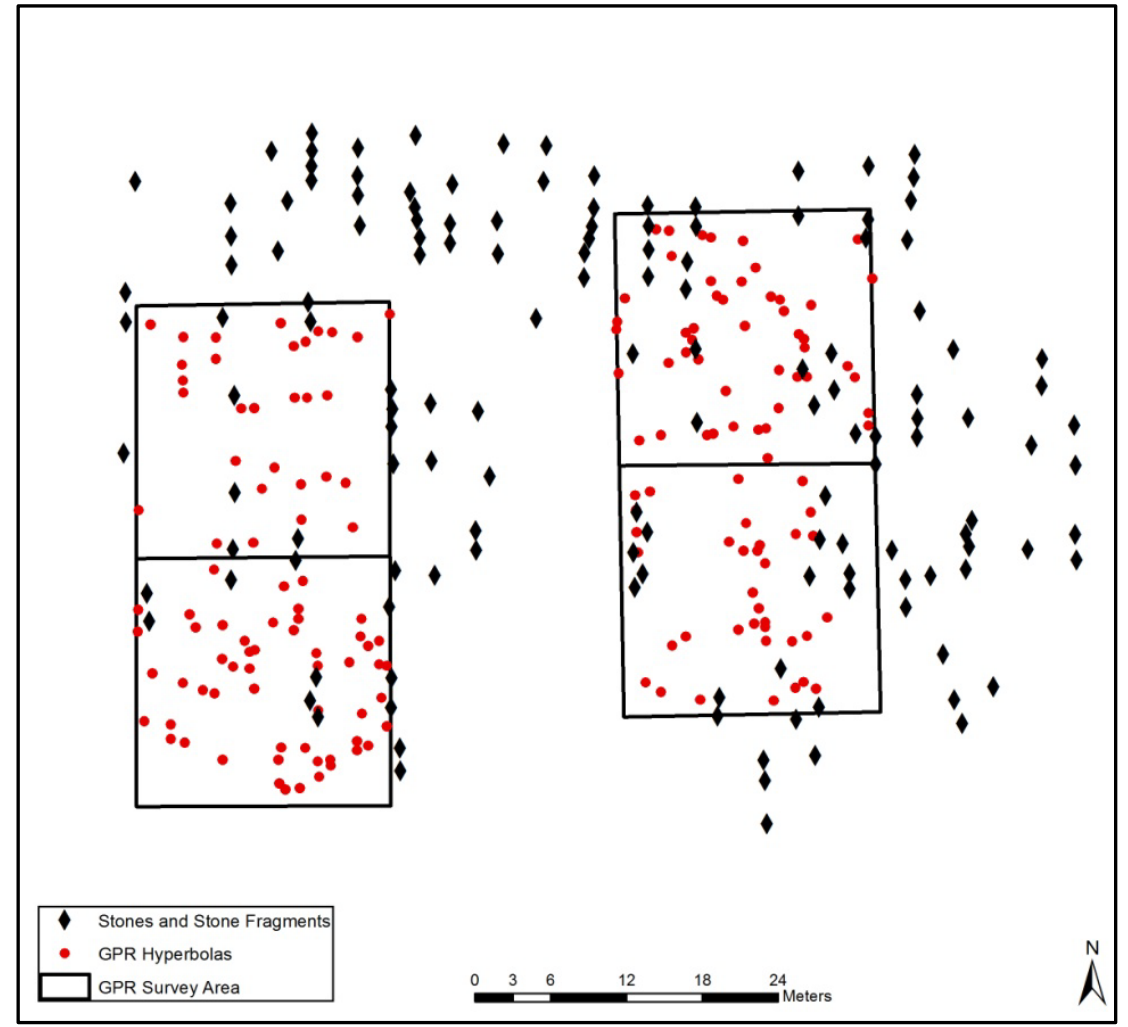


Figure 28. Alignments of observed grave marker stones and GPR hyperbolas possibly associated with graves, Clements Cemetery.

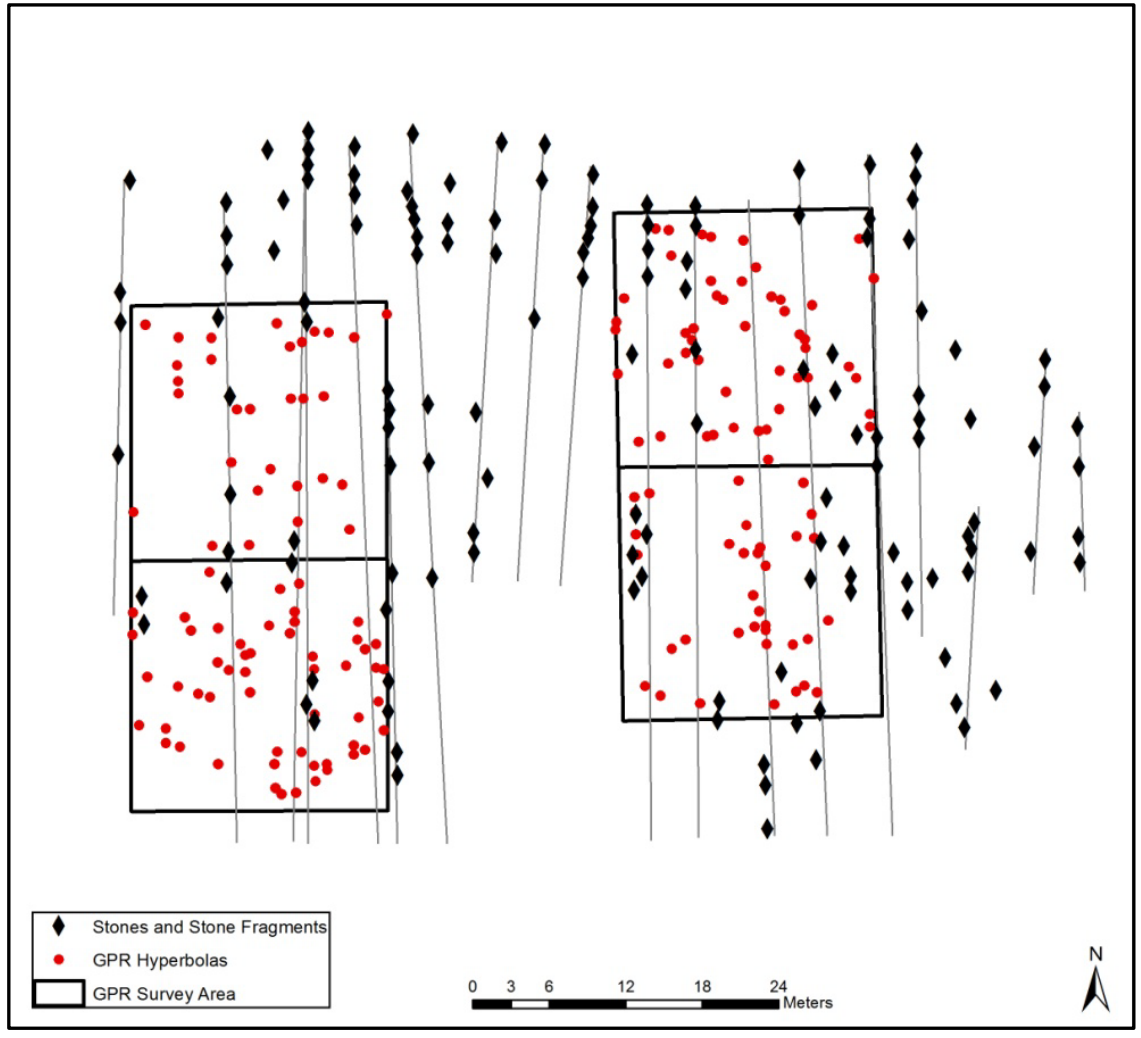

Figure 29. Cases where hyperbolas occur within $1 \mathrm{~m}$ of a marker stone (shown as green circles), Clements Cemetery.

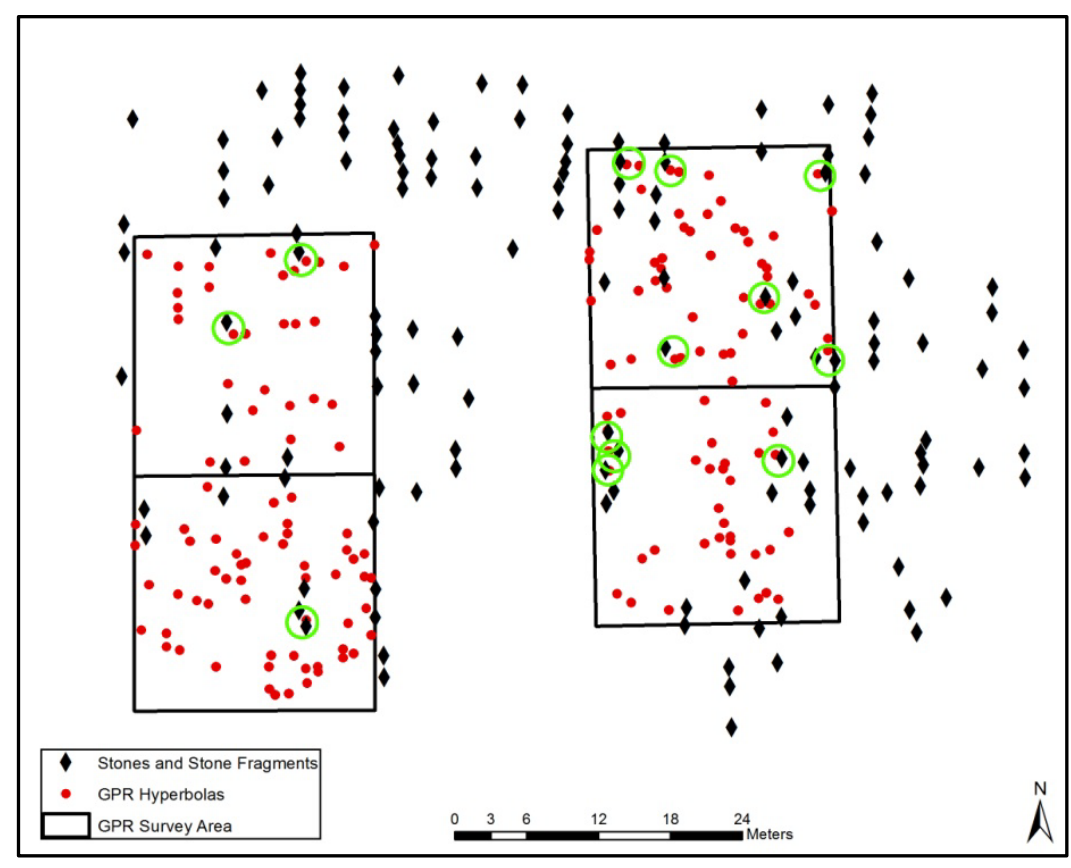


For this study, an important question is whether these hyperbolas relate to historic graves. As noted, their tendency to be located very high in the profiles would seem to argue against this association, but they could conceivably be associated with portions (most likely corners) of the upper portions of grave shafts. Several other lines of evidence were considered to further assess if the hyperbolas are associated with graves. Inspection of several aerial photographs of Clements Cemetery available on Google Earth indicated that most of the existing grave markers are arranged in north-south rows. Visible grave outlines and the information inscribed on the grave markers indicates that most of the actual graves are located west of the in-situ markers, but inscriptions are located on the east side of some markers (Figure 24 and Figure 25). Additionally, some of the marker stones (Figure 27-Figure 29) whose locations were recorded within the survey areas are small and may represent footstones rather than headstones. These observations raise the possibility that some graves could be located east of their associated marker.

One obviously expects the hyperbolas to be arranged in north-south lines because they were all identified in the north-south-oriented data collection transects. Because the parallel transects are closely spaced (at $50 \mathrm{~cm}$ intervals), a random distribution of hyperbolas could, at least to some degree, obfuscate the underlying north-south linear pattern. If the hyperbolas are associated with graves, many of them may be aligned with the marked graves. Figure 28 shows the distribution of hyperbolas relative to those alignments (gray lines). Each of the gray lines was drawn to connect as many of the marker stones as possible. Some of the lines are based on a small number of widely separated marker stones. A little more than onehalf of the alignments of marker stones exhibit a roughly consistent northsouth orientation while a smaller number (particularly those located between the survey areas) are oriented a little more northeast-southwest.

Closely spaced hyperbolas could be associated with different parts of a relatively large object (e.g., grave, rock). Also, any portion of a grave or other object could be the actual source for the hyperbola. To allow for this, hyperbolas are counted as being near a grave (and therefore associated with an alignment of marked graves) if they are located within $1 \mathrm{~m}$ of the red line. Using these criteria, about $50 \%(n=88)$ of the 165 hyperbolas are located near the alignments of marked graves. While we have not conducted any statistical tests, this reasonably high number seems to suggest that the 
hyperbolas tend to be associated with the apparent alignments of marked graves.

A second way to evaluate the likelihood that the hyperbolas are associated with historic graves is to assess their locations relative to individual marker stones. If the hyperbolas are associated with graves, some of them should be located near a marker. However, one might not expect too many such cases of proximity. If the hyperbolas are in fact associated with graves, most of the markers have clearly been removed. Here, we again use a proximity criterion of $1 \mathrm{~m}$. Inspection of Figure 29 reveals that 14 hyperbolas are located within $1 \mathrm{~m}$ of one of the 38 marker stones located within the survey area (these cases are indicated by green circles). This finding includes two cases where pairs of contiguous hyperbolas are located near the same stone. In most of the 14 cases, the hyperbola is located northeast, southwest, southeast, or southwest of a marker. These locations relative to stones might seem less likely than the expected situation where a grave is located east or west of a stone. These locations could conceivably represent situations where two graves (e.g., husband and wife) share a single marker stone (and only one grave is manifest by a hyperbola). Overall, $36.8 \%$ of the stones are located within $1 \mathrm{~m}$ of a hyperbola. Again, we have not tested this pattern statistically (as we are not aware of a suitable test), but this seems like a reasonably high occurrence rate, given the relatively small number of stones inside the survey areas.

\subsubsection{Summary and conclusions}

Soil moisture limited the success of our GPR survey of Clements Cemetery. The amplitude slices yielded unreliable results, and we relied on information from the GPR profiles (which was standard practice before the development and wide use of amplitude slicing). We plotted the location of the hyperbolas with maximum widths of at least $1 \mathrm{~m}$. The hyperbolas appear to be associated with apparent alignments of existing marker stones, suggesting that these hyperbolas are associated with graves. Similarly, the occurrence of hyperbolas in close proximity (within $1 \mathrm{~m}$ ) of marker stones may also support the interpretation that the hyperbolas are associated with graves. Nevertheless, we are far from certain of this interpretation. A conservative interpretation of all of the available evidence leads us to view the results of the Clements Cemetery GPR survey as inconclusive. As such, they do not provide a reliable basis for evaluating the performance of the HHRD dogs. Results of the Fort Gordon surveys were more reliable and do 
provide a reasonable (if not certain) basis for assessing the dog's ability to detect graves (see Chapter 6).

\subsection{HHRD dog survey}

The ICF team survey took place at Clements Cemetery on 12 November 2013. Early on that morning, the temperature dropped significantly, so the temperature was well below freezing and snow was falling. Survey work was delayed to 13:00 in the hope that the windchill would rise above freezing and the snow would melt. While conditions improved, there was still snow on the ground in portions of the site during testing. The handlers indicated that this was the first time any of the dogs had ever been asked to work in snow, and the first time that some of the dogs had ever seen snow.

The survey began at 13:13 and continued until 15:39. Air temperatures started at $35.2^{\circ} \mathrm{F}$ and fell to $31.5^{\circ} \mathrm{F}$. Ground temperatures ranged from $53.5^{\circ} \mathrm{F}$ to $31.1^{0} \mathrm{~F}$ throughout the afternoon. Humidity was at $47.1 \%-54.6 \%$, and the winds were $3.7-4.3 \mathrm{mph}$ from $40-42$ degrees azimuth. The ICF team coordinator determined the ground visibility at $80 \%-100 \%$.

The survey area was divided into four blocks, and the HHRD dog survey limits were larger than the GPR survey limits to insure complete HHRD dog coverage of all GPR areas (Figure 30). Blocks A and D formed the western survey area, and Blocks B and C formed the eastern survey area. 
Figure 30. Clements Cemetery showing GPR (black outline) and HHRD dog (red outline) survey blocks.

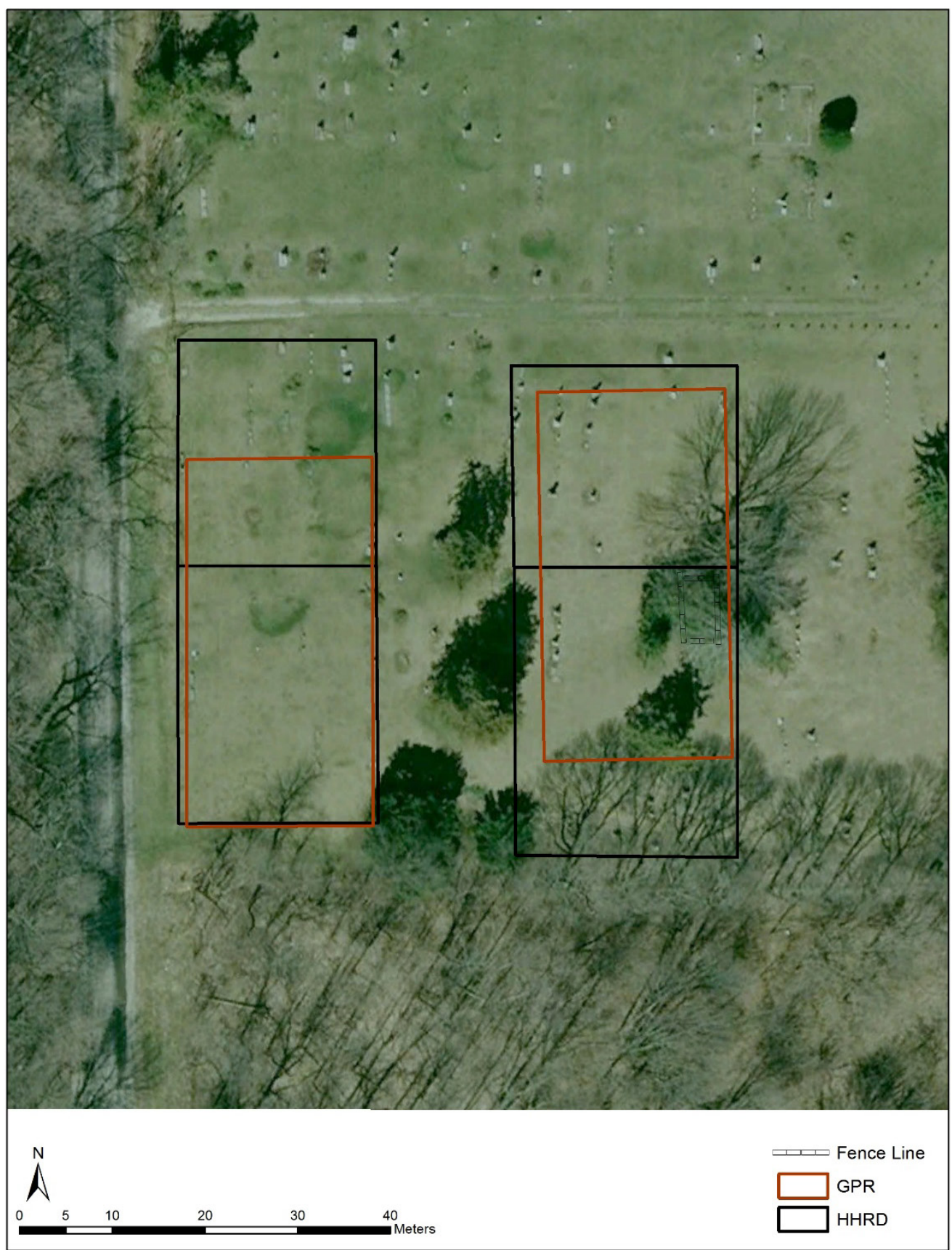

Buffers of $1 \mathrm{~m}$ and $2 \mathrm{~m}$ were generated around each GPR hyperbola anomaly. The buffers were added to approximate the size of grave shafts around the anomaly features. HHRD team results were plotted on top of these layers. Alert quality designations by the HHRD dogs were collected but not utilized in the analysis. The reason the quality of alerts was not included is because each dog produced a large number of alerts, but each dog's alerts 
were consistently at the same level. For example, all of team BP's alerts were Quality 2 alerts, and all of team AM alerts were Quality 3 alerts. Quality, therefore, was not seen as a useful analysis tool in this instance. The results of the HHRD dog surveys are presented in Figure 31-Figure 36.

Figure 31. Results of Team AM dog survey for Clements Cemetery, Blocks A and D.

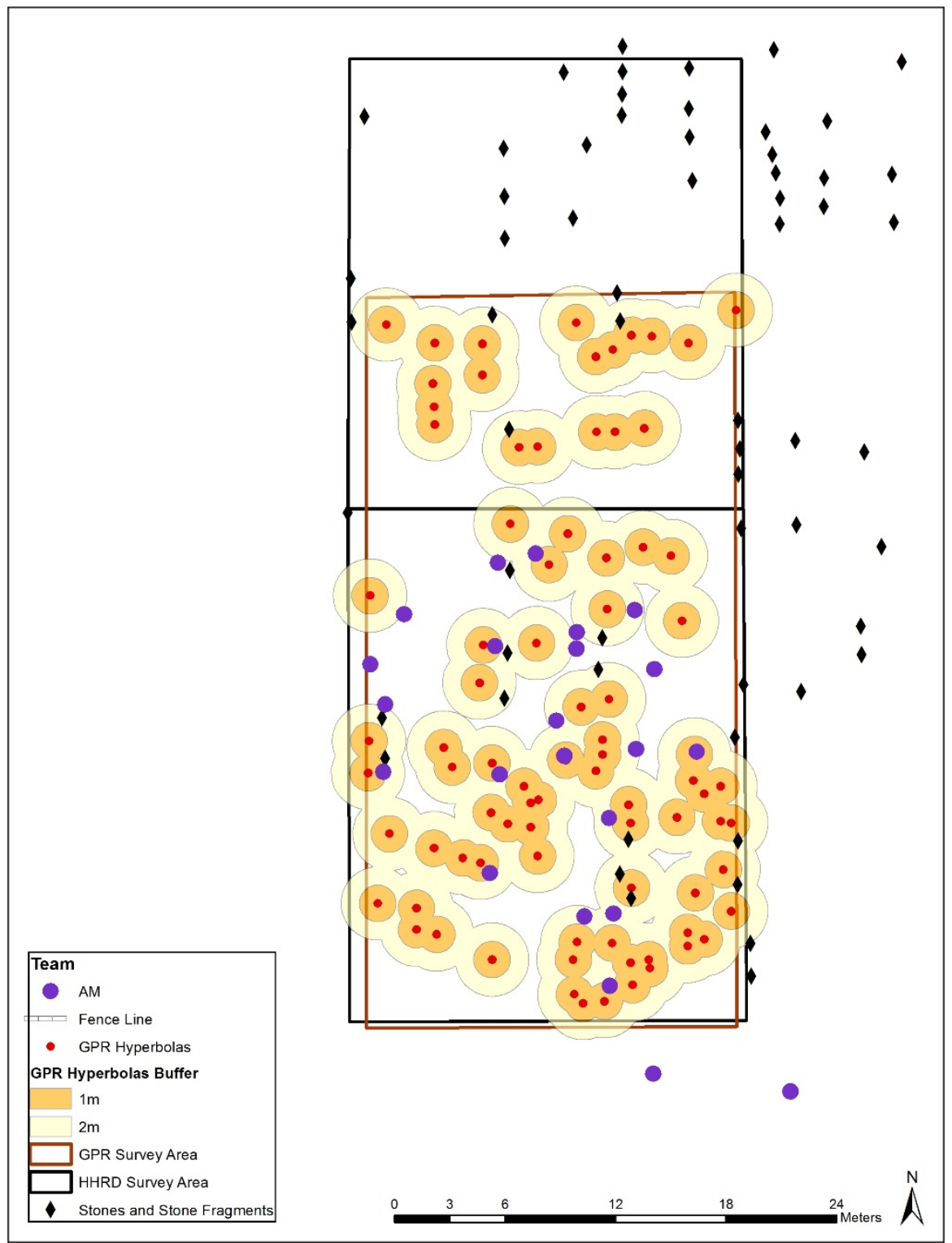


Figure 32. Results of Team JG dog survey for Clements Cemetery, Blocks A and D.

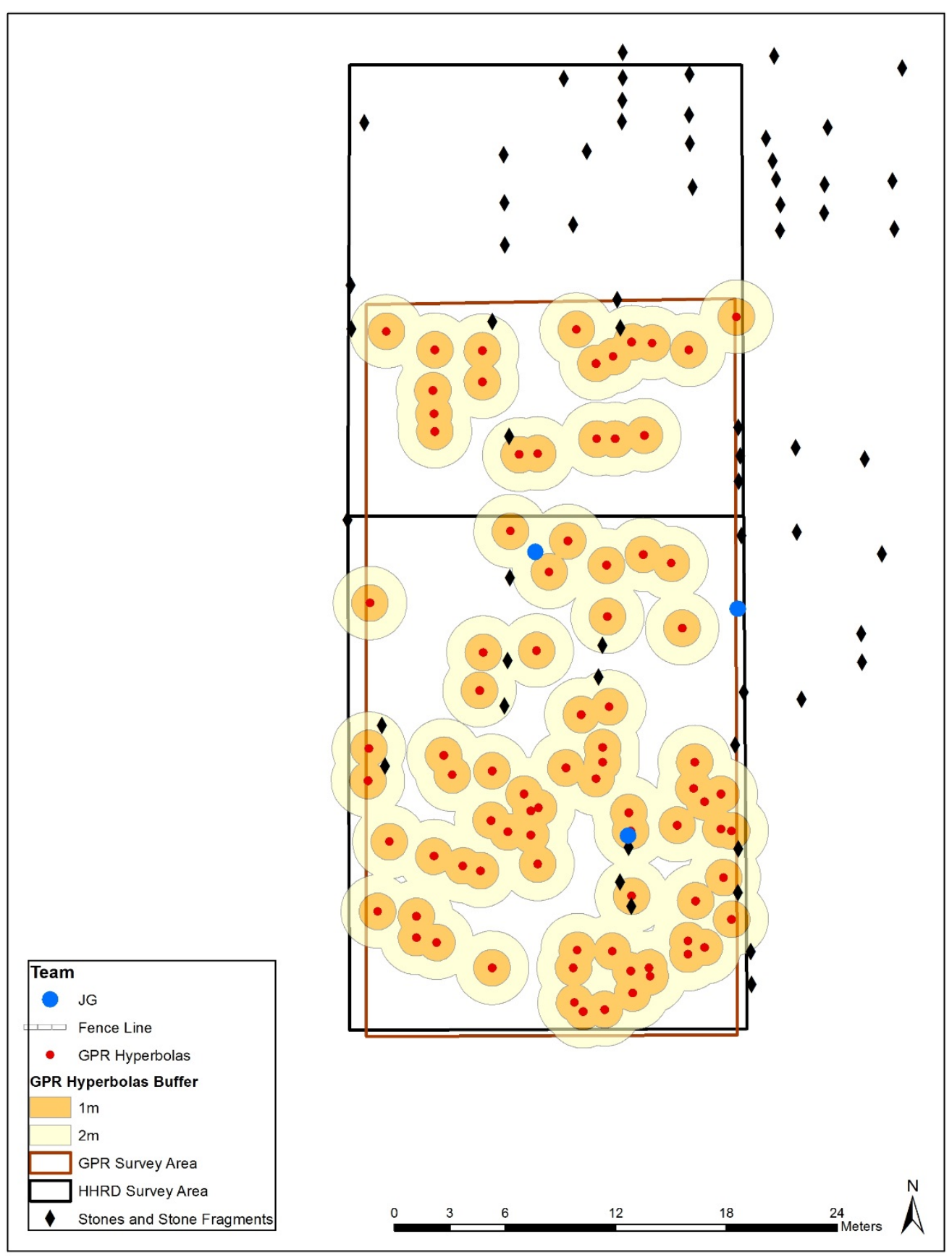


Figure 33. Results of Team LA dog survey for Clements Cemetery, Blocks A and D.

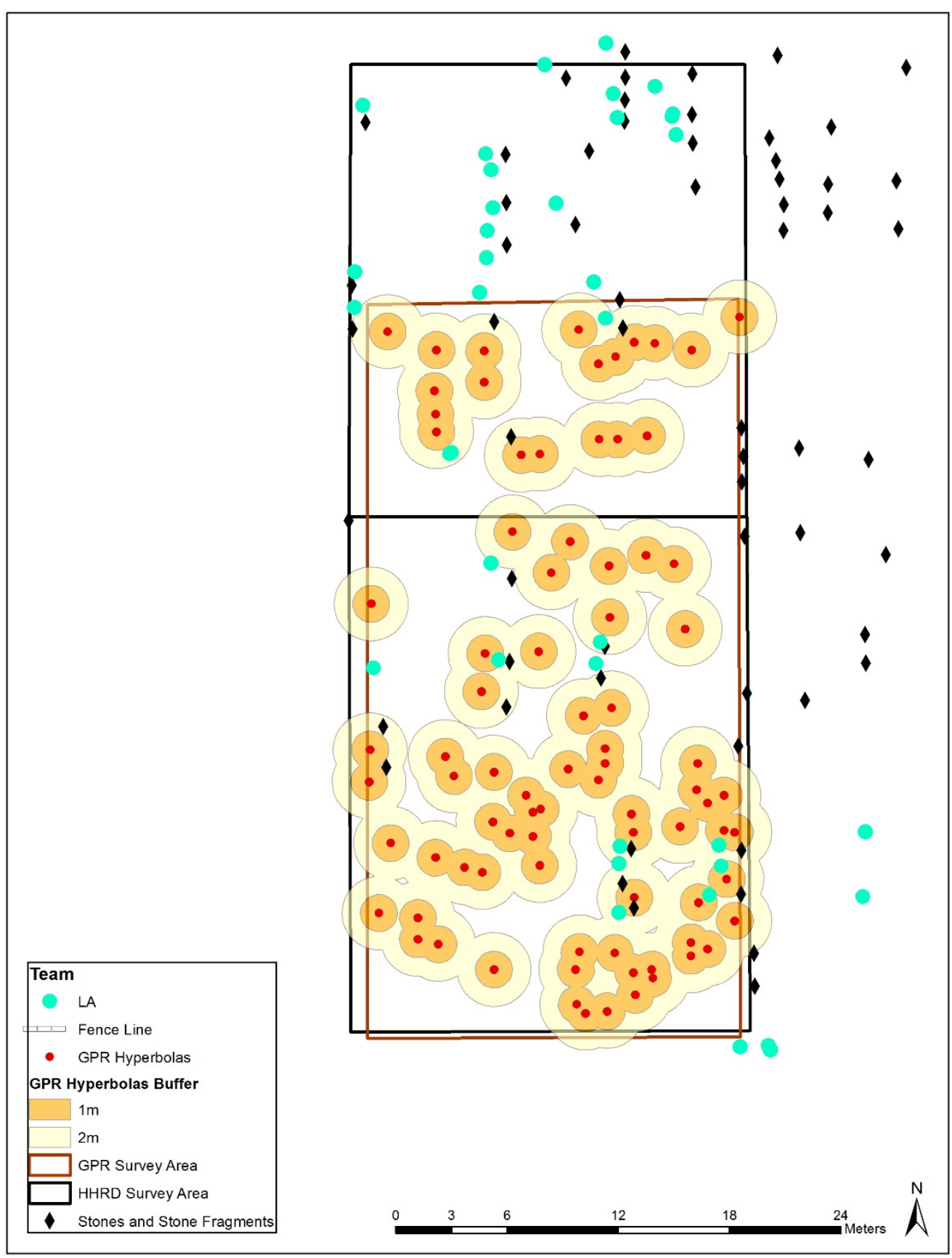


Figure 34. Results of Team AM dog survey for Clements Cemetery, Blocks B and C.

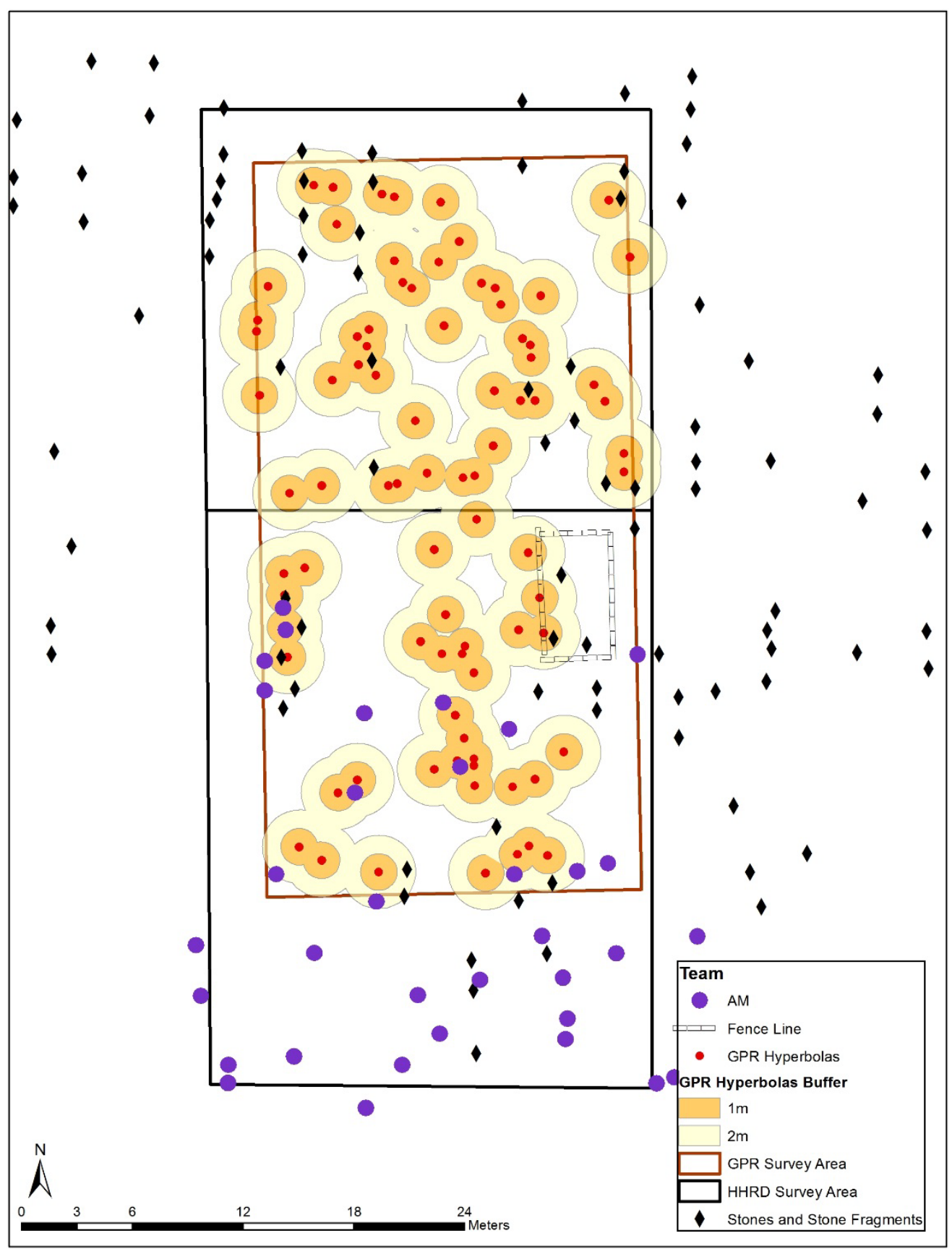


Figure 35. Results of Team BP dog survey for Clements Cemetery, Blocks B and C.

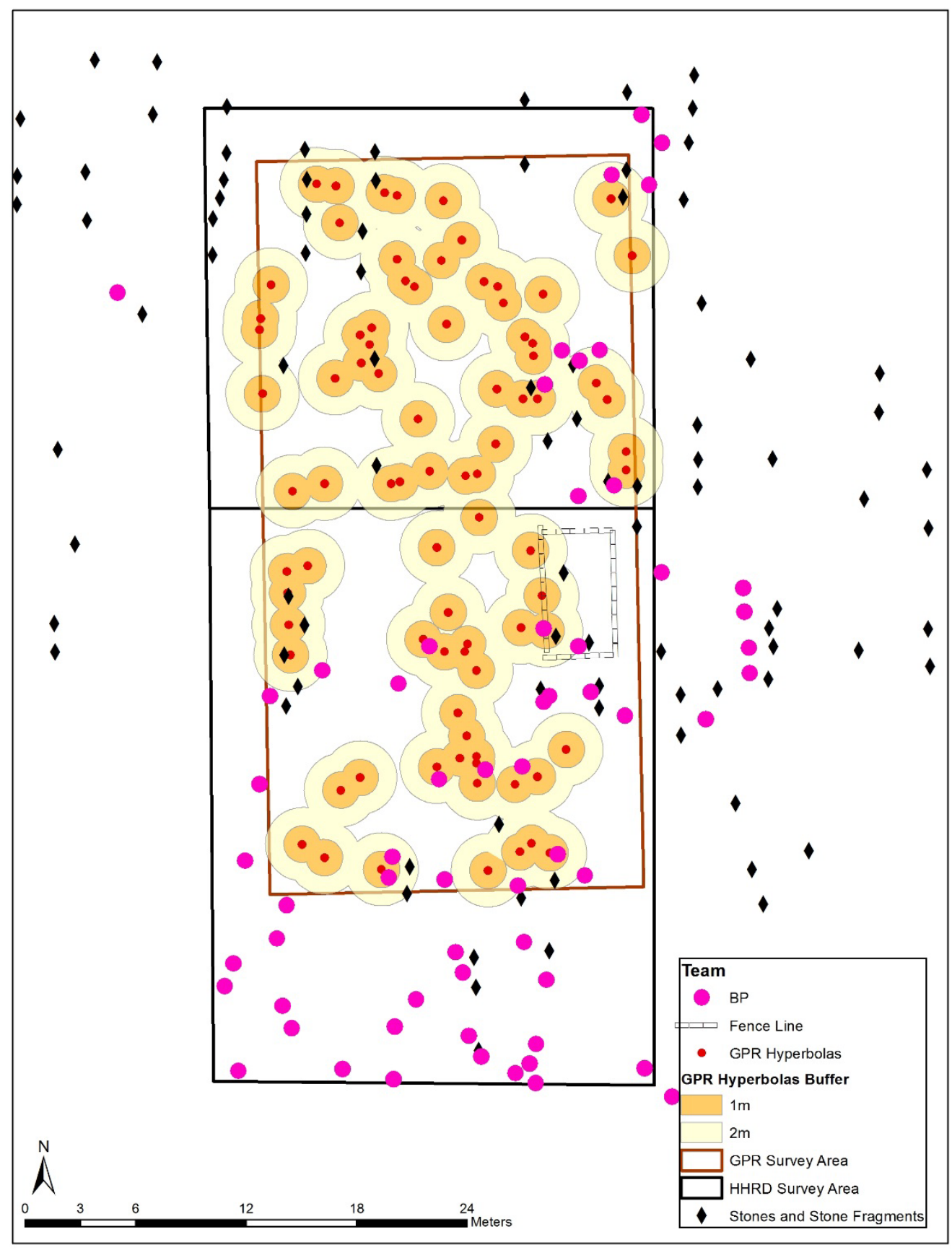


Figure 36. Results of Team JG dog survey for Clements Cemetery, Blocks B and C.

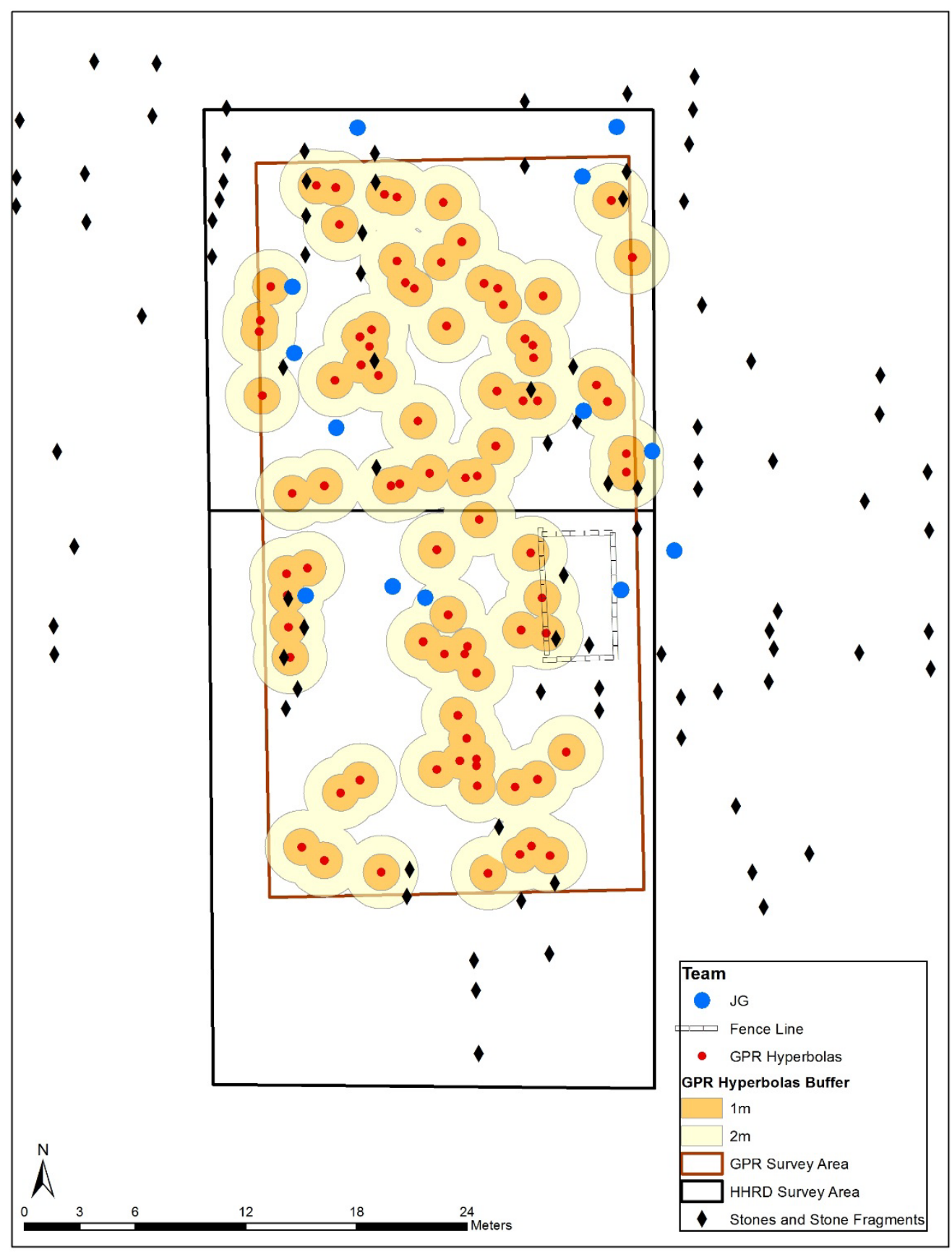




\subsubsection{Summary and conclusions}

The first item the data shows is that not every team worked in all four blocks. The second item is that a large number of dog alerts corresponded directly to headstones. This is most obvious in the Team LA's alerts in the Blocks A and D (Figure 33). The ICF handlers stated that there were so many graves in this cemetery, it was producing a general aura of human decomposition; the dogs were being overwhelmed and were unable to pick out specific alert locations. One handler explained it as being in the middle of a cloud and trying to pick out which parts were wetter. Combined with the snow on the ground (which was a complete novelty for a couple of the dogs), and the dogs became distracted and did not want to work. The handler for team JG stated that his dog was not sniffing, she was just alerting on the site of grave stones. The handlers tried to rest their dogs and then refocus their efforts, but this attempt met with varying degrees of success. As a result, by the end of the day not all dogs had completed each of the search blocks.

This event highlights an area of cemetery searches where HHRD dogs may not be the best method to use. The handlers stated that the pervasive scent would have been a problem even without the snow. This demonstrates that HHRD dogs are not well suited to find individual graves within a group of graves. It also highlights that the ability to work field dog teams may be as dependent on environmental conditions as some geophysical techniques (note that part of the issue with the GPR survey was the water content of the soil). Finally, this effort demonstrated that the dogs are intelligent enough to associate the scent of decomposition with the presence of a headstone. When they were unable to produce alerts on scent alone, some of them were utilizing visual cues to alert on and receive their reward. The handlers, however, were able to determine after a period of time what some of these dogs were doing and modified their interpretation of the dog alerts accordingly. 


\section{Fort Gordon Cemeteries Surveys}

\subsection{Background}

Five cemeteries $(9,20,26,31$, and 34) that predate the 1940 establishment of Fort Gordon, Georgia, were surveyed with HHRD dogs as part of this effort. The same five cemeteries were previously surveyed with GPR and four of the five (excluding Cemetery 20) were previously surveyed with magnetic gradiometer by this report's authors in 2010. A complete and detailed description of the geophysical survey methods, analysis, and results can be found in the report of that work (Hargrave 2011); a summary was given in Chapter 3 of this report. The results of the 2010 geophysical surveys are summarized here (by cemetery) to compare and contrast geophysical results to HHRD dog results.

Geophysical survey anomalies with the potential to be graves were marked with 1 x $2 \mathrm{~m}$ rectangles (average historic Christian burial grave shaft size). These shapes correspond to the center point plus $1 \mathrm{~m}$ radius buffer used at the Control Site and Clements Cemetery Site surveys (as described in Chapters 4 and 5). The $1 \mathrm{~m}$ radius buffer on Fort Gordon cemetery maps corresponds to the $2 \mathrm{~m}$ radius buffer zones at the Control Site and Clements Cemetery sites. Finally, the $4 \mathrm{~m}$ buffer at Fort Gordon cemeteries corresponds to the $5 \mathrm{~m}$ buffer used at the previous survey sites. Due to the proximity of the geophysical survey anomalies, use of the $10 \mathrm{~m}$ buffer created buffer overlaps that were so large as to be unsuitable for analysis, and the $10 \mathrm{~m}$ buffer was discarded for the analysis. The same HHRD dog alert quality criteria utilized in the control site and Clements Cemetery were utilized at all Fort Gordon cemeteries.

\subsection{Cemetery 9}

Cemetery 9 is bordered on the southeast by an unnamed one-lane dirt road and on the other three sides by a dirt lane that appears to be used as a turnaround location for the dirt road. Three sides of the cemetery are surrounded by a wooden post and barbed wire fence, and the area is designated by signage (Figure 37). The soil at this site consisted of loose, fine sand that was, within the fence line of the cemetery, anchored by grass that appears to be regularly mowed. 
Both GPR and magnetic data were collected from this site. Strong anomalies in both sets of data indicate the possibility of at least six graves located in the northern corner of Survey Area A (Figure 38). The anomalies occur in parallel lines orientated on a northeast-southwest axis. This somewhat conforms to historic Christian burial practice of orientating the lengths of the graves on an east-west axis. The orientation bolsters the argument that this site is a cemetery from the historic period. Based on geophysical survey, this cemetery was evaluated as having a high likelihood of containing actual graves (Hargrave 2011).

Interestingly, the potential graves are not located in the center of the fenced area now designated as the cemetery boundary. The potential graves are located in the north eastern corner of area, with one grave extending under the fence line into the dirt track that circles the cemetery. It is very likely that the fence line for the cemetery was historically larger and included the dirt track that is now used as a turnaround site. It was for this potential that Cemetery 9 was considered primary to this study. If the dog handlers were influencing the interpretation of the dog alerts based on what they thought should be there, one would expect to see multiple alerts in the center of the fenced-off area and not in the dirt track outside the fence.

The geophysical survey conducted in 2010 only covered the area within the fence and a portion of the dirt track that surrounds it (designated here as Area A). After some discussion, author Baxter and the ICF coordinator decided to add a second survey area (designated here as Area B) to the north of the cemetery area to see if the dogs would indicate that burials might be located beyond the dirt track in the wooded area that surrounds the cemetery on three sides. As there is no geophysical data for Area B from the 2010 work, the alerts in Area B are reported here as a matter of interest but are not included in the summary table (Table 7). Dog alerts by team are reported in Figure 39-Figure 42. 
Figure 37. View to north of Cemetery 9 at Fort Gordon.

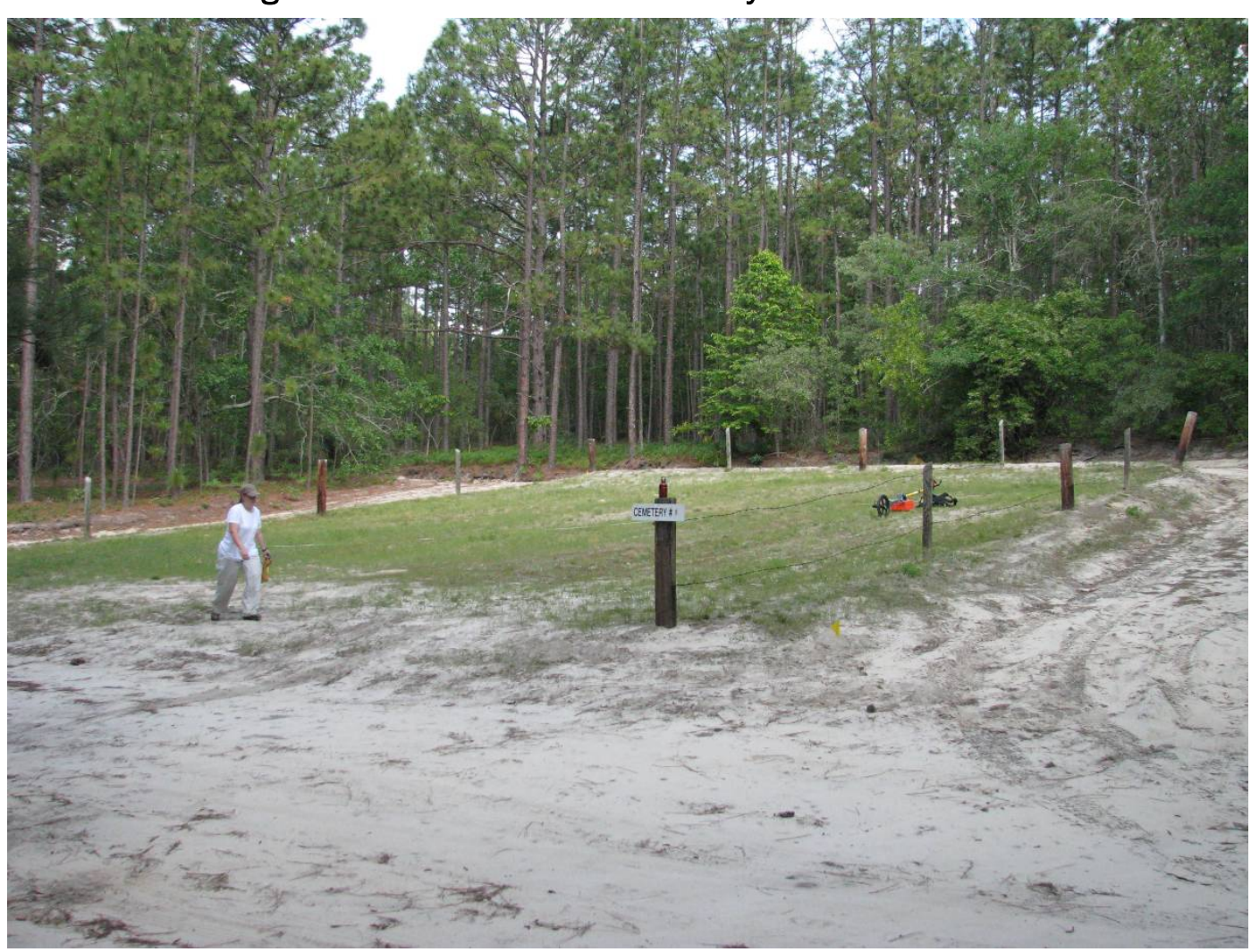


Figure 38. Overlay of magnetic data onto GPR data, showing two rows of possible graves. Coordinates are in meters. (Hargrave 2011, Figure 3-7).

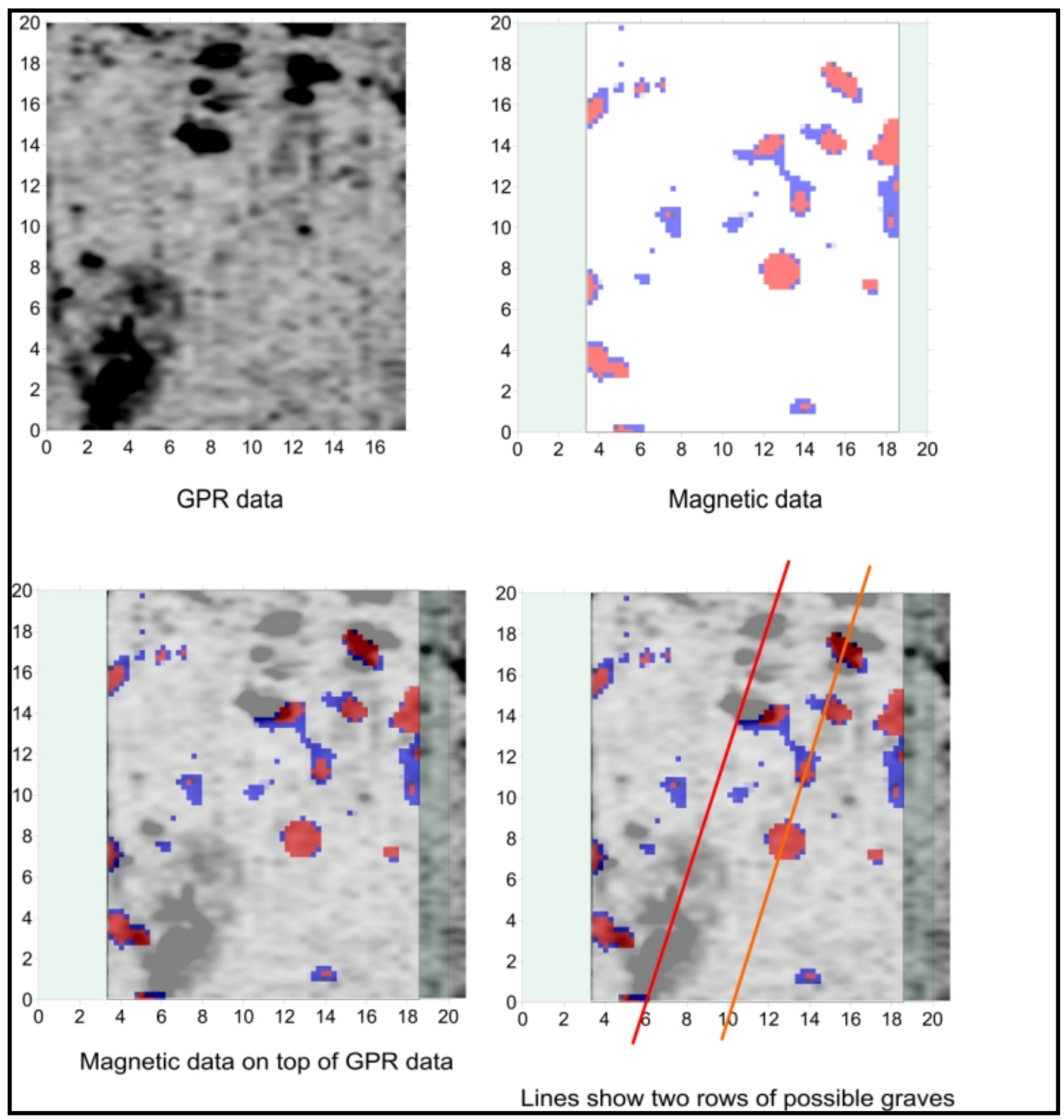


Figure 39. Results of Team AM dog survey of Cemetery 9 at Fort Gordon.

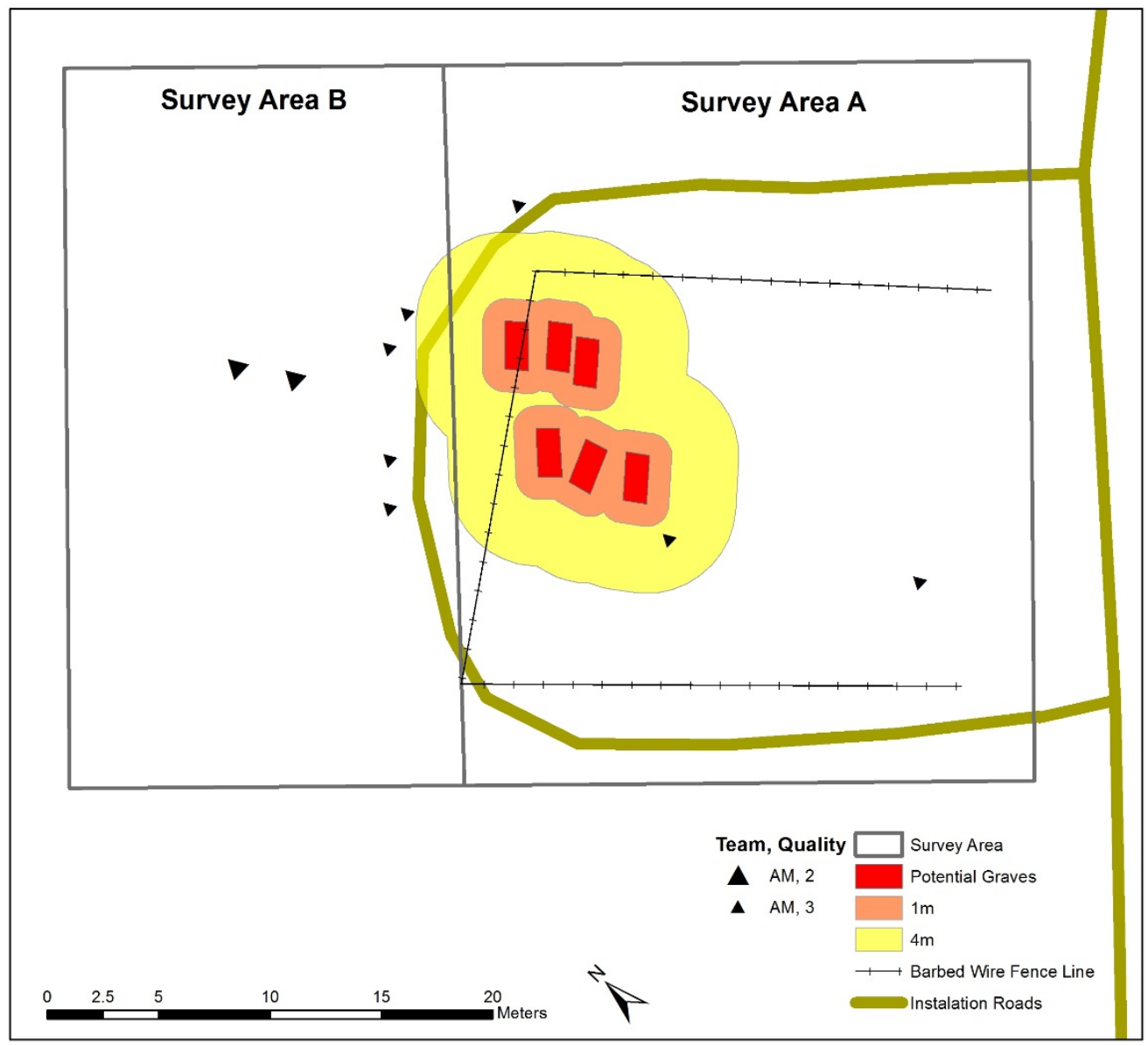


Figure 40. Results of Team BP dog survey of Cemetery 9, Fort Gordon.

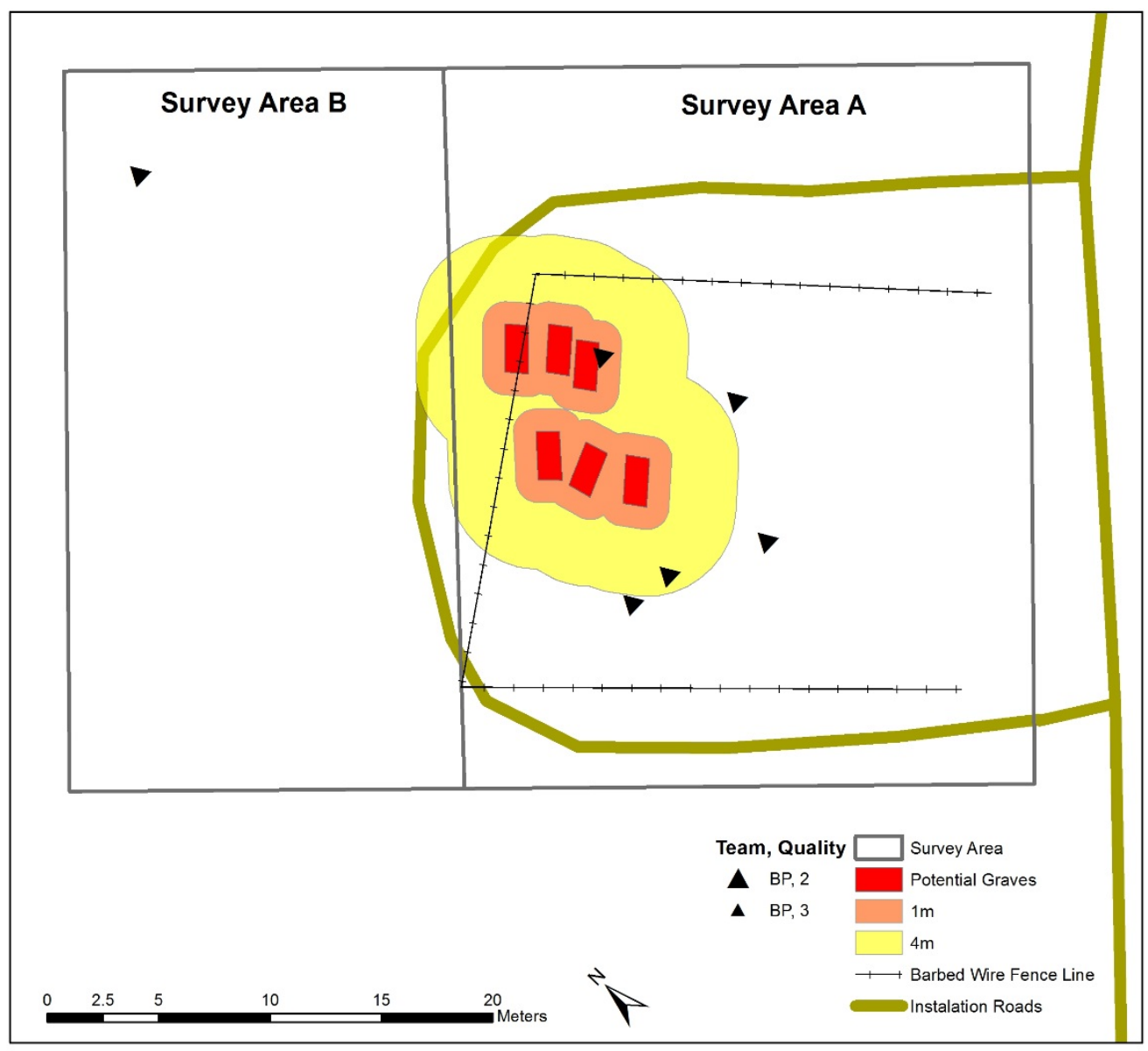


Figure 41. Results of Team JG dog survey of Cemetery 9, Fort Gordon.

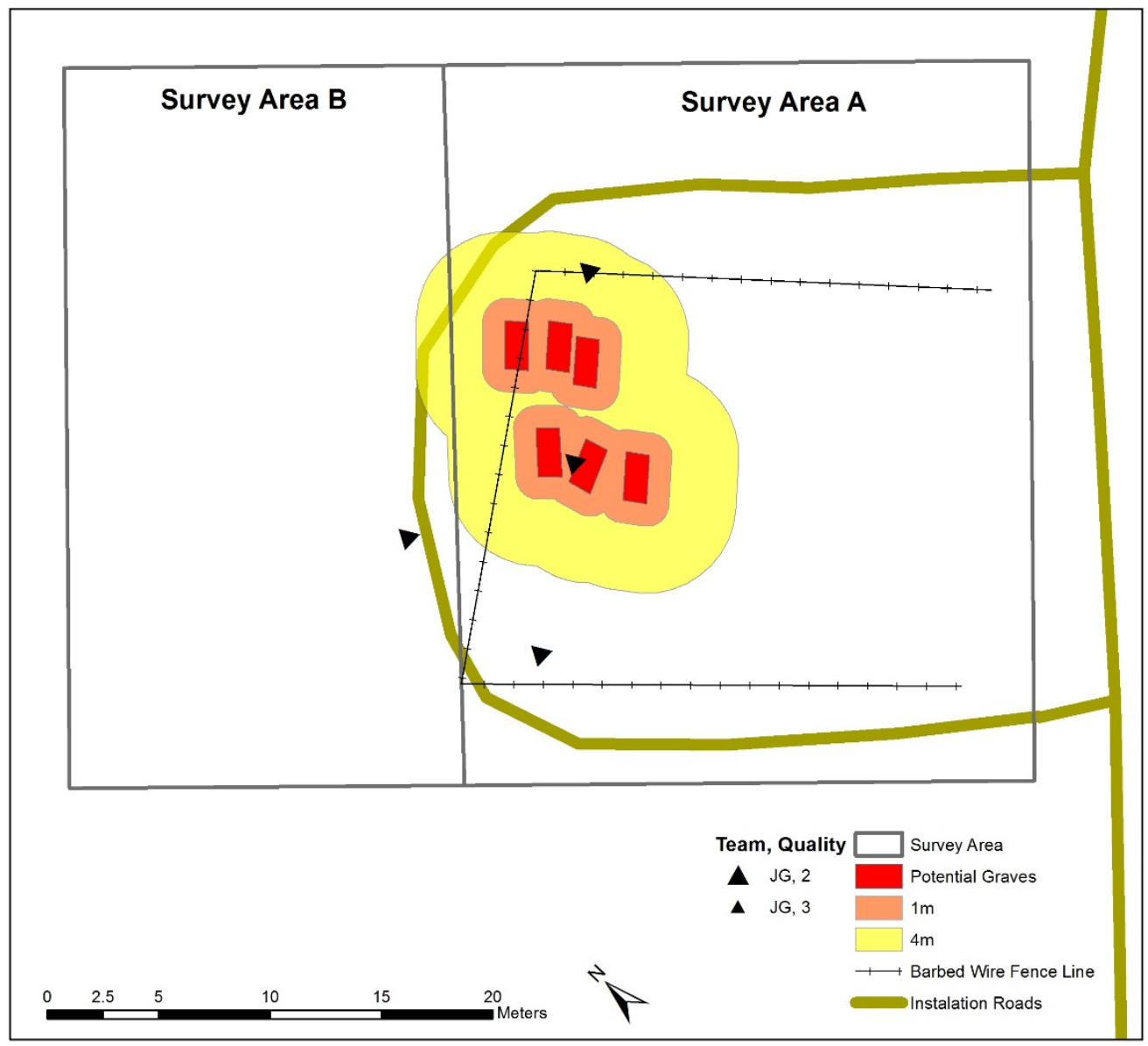


Figure 42. Results of Team LA dog survey of Cemetery 9, Fort Gordon.

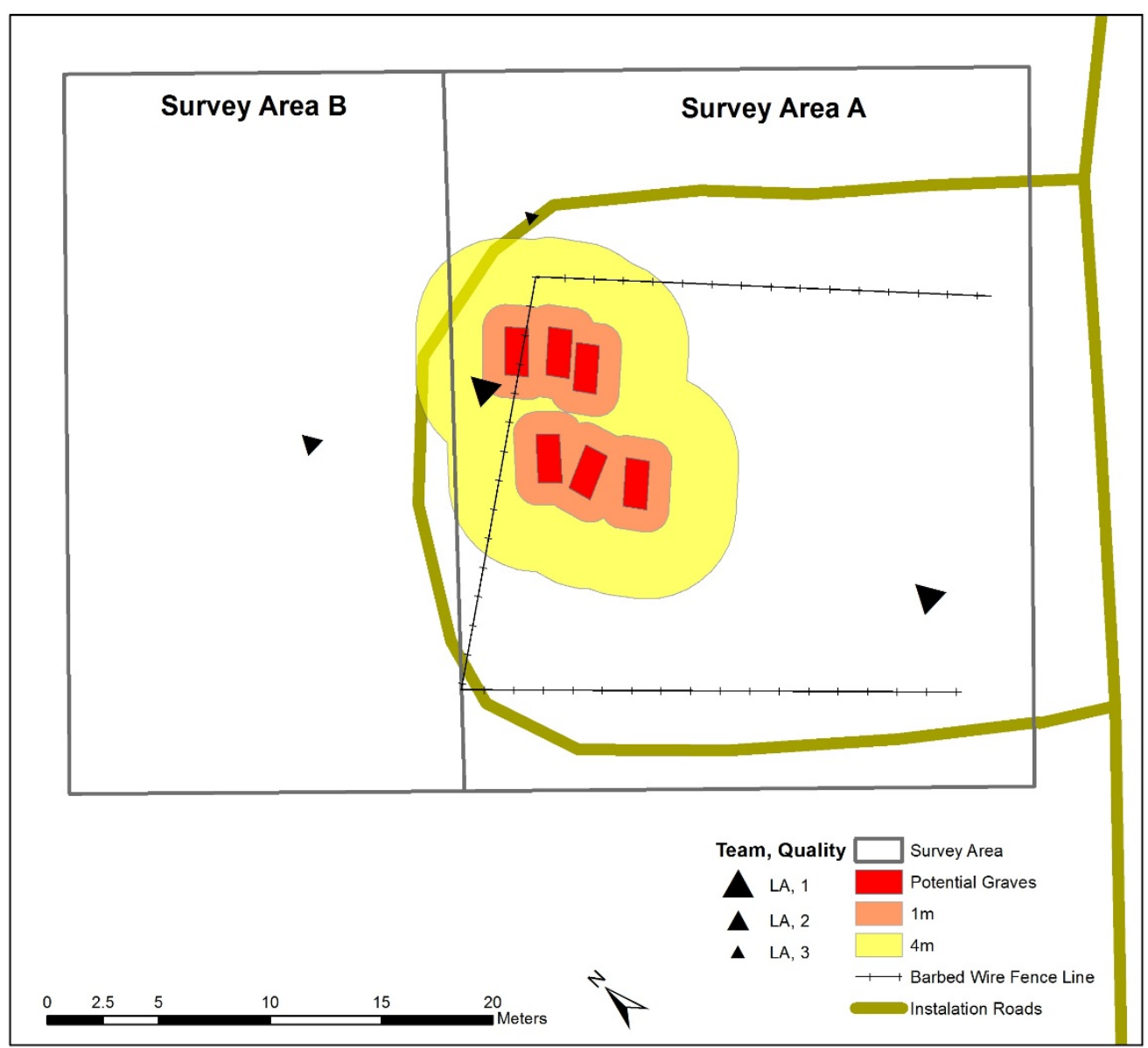

Table 7. Summary of HHRD dog surveys, Cemetery 9, Fort Gordon.

\begin{tabular}{|l|l|l|l|l|}
\hline $\begin{array}{l}\text { Dog } \\
\text { Team }\end{array}$ & $\begin{array}{l}\text { Alerts over } \\
\text { Possible Graves }\end{array}$ & $\begin{array}{l}\text { Alerts within 1 m } \\
\text { of Possible Graves }\end{array}$ & $\begin{array}{l}\text { Alerts within 1-4 m } \\
\text { of Possible Graves }\end{array}$ & $\begin{array}{l}\text { Alerts more than } \\
\text { 4 m from Possible } \\
\text { Graves }\end{array}$ \\
\hline AM & & & 1 & 2 \\
\hline BP & 1 & & 1 & 3 \\
\hline JG & 1 & & 1 & 1 \\
\hline LA & & 1 & & 2 \\
\hline
\end{tabular}

The results of this survey were extremely positive. Three of the four teams alerted in Survey Area A at locations that were either on or outside the fence line on the eastern corner of the site. All but one of the alerts within the fence line (western alert by team JG [Figure 41]) are either in close proximity to the possible grave locations or occur in the roughly north- 
south orientation of the parallel grave lines identified by Dr. Hargrave and shown in Figure 38. Only team BP had the majority of alerts in the center portion of the fenced area, where one would expect the graves to be located based on visual cues. The same team, however, also had one of the closest alerts to a suspected grave. The fact that multiple teams alerted in Area $\mathrm{B}$, in roughly the same line as the possible graves identified through geophysical survey, would suggest that an additional geophysical survey needs to be conducted to determine the full extent of this cemetery.

\subsection{Cemetery 20}

Cemetery 20 was located in a wooded area approximately $10 \mathrm{~m}$ from a multilane paved road. GPR was the only geophysical technique deployed at this site (Hargrave 2011). Significant undergrowth in the project area would have prevented accurate magnetic data collection. No grave markers were observed. Some architectural debris was observed, but it appeared to be the result of a dumping event and not in-situ debris.

There were 15 anomalies identified, based on their size and shape (Figure 43). These anomalies were assessed as less likely to be real graves than some anomalies seen at other cemeteries, due to a continuous range of variability between these 15 selected anomalies and other anomalies that were identified as not grave-like. Additionally, there were a series of perpendicular anomalies observed on slices more than $1 \mathrm{~m}$ below surface. Perpendicular patterns typically do not correspond to small cemetery layouts (Hargrave 2011).

HHRD dog survey results are depicted in Figure 44- Figure 47 and summarized in Table 8 . The results of this survey were more ambiguous than at other survey sites. One team had only one alert, and that was more than $4 \mathrm{~m}$ away from the possible grave anomalies. A second team had 2 alerts closer than $4 \mathrm{~m}$ to an anomaly, and two that were more than $4 \mathrm{~m}$ distant. In total, $64.3 \%$ of all alerts were located farther than $4 \mathrm{~m}$ from any geophysical anomaly. There were no Quality 1 alerts recorded at this cemetery, and there did not appear to be a clear pattern to the alerts between teams. However, there was one alert directly over an anomaly and four more alerts within the $1 \mathrm{~m}$ buffer zone. These alerts comprise $35 \%$ of the total alerts for the site. 
Figure 43. Possible graves based on all GPR slices, Cemetery 20, Fort Gordon (Hargrave 2011, Figure 3-11).

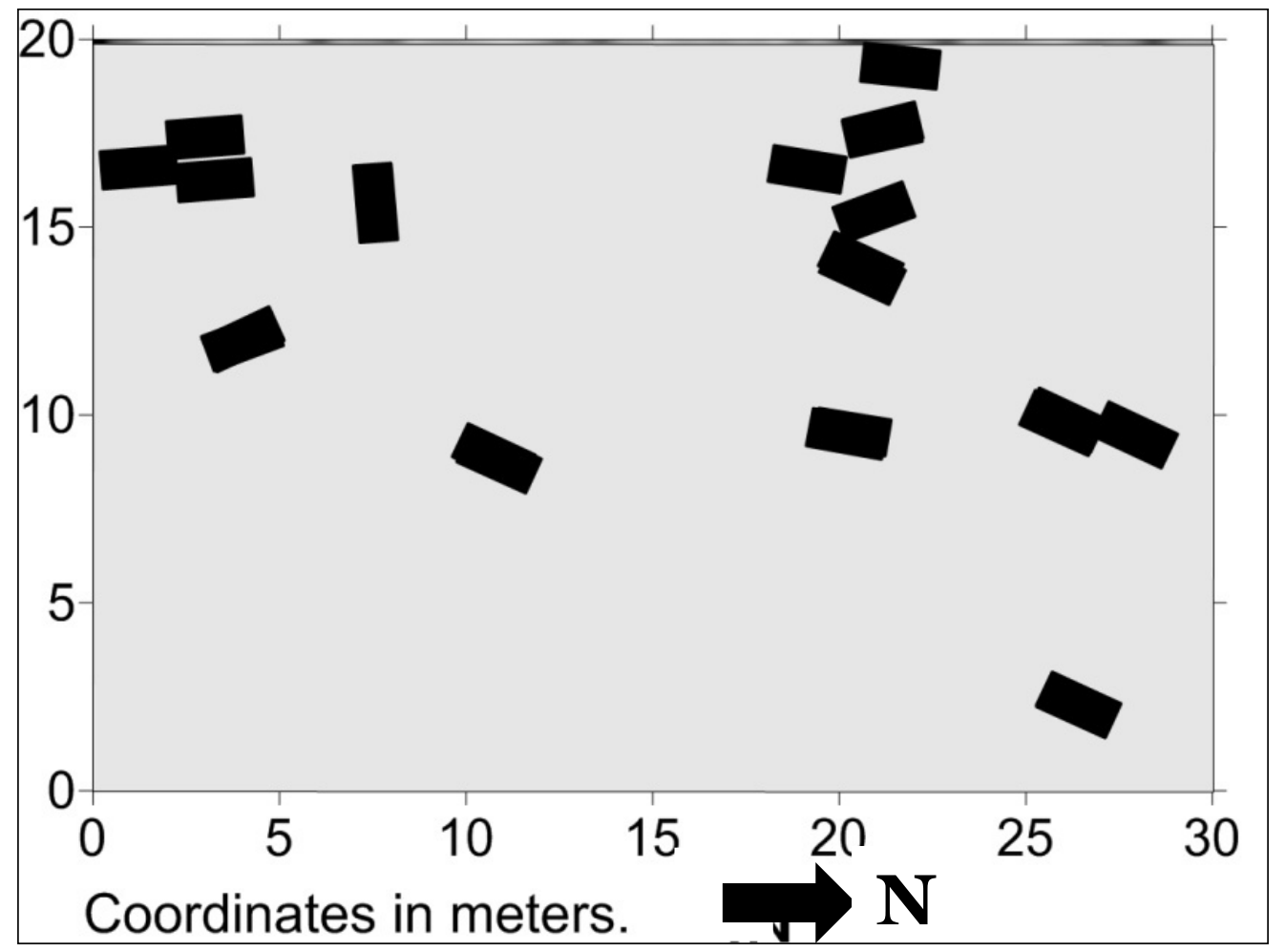


Figure 44. Results of Team AM dog survey, Cemetery 20, Fort Gordon.

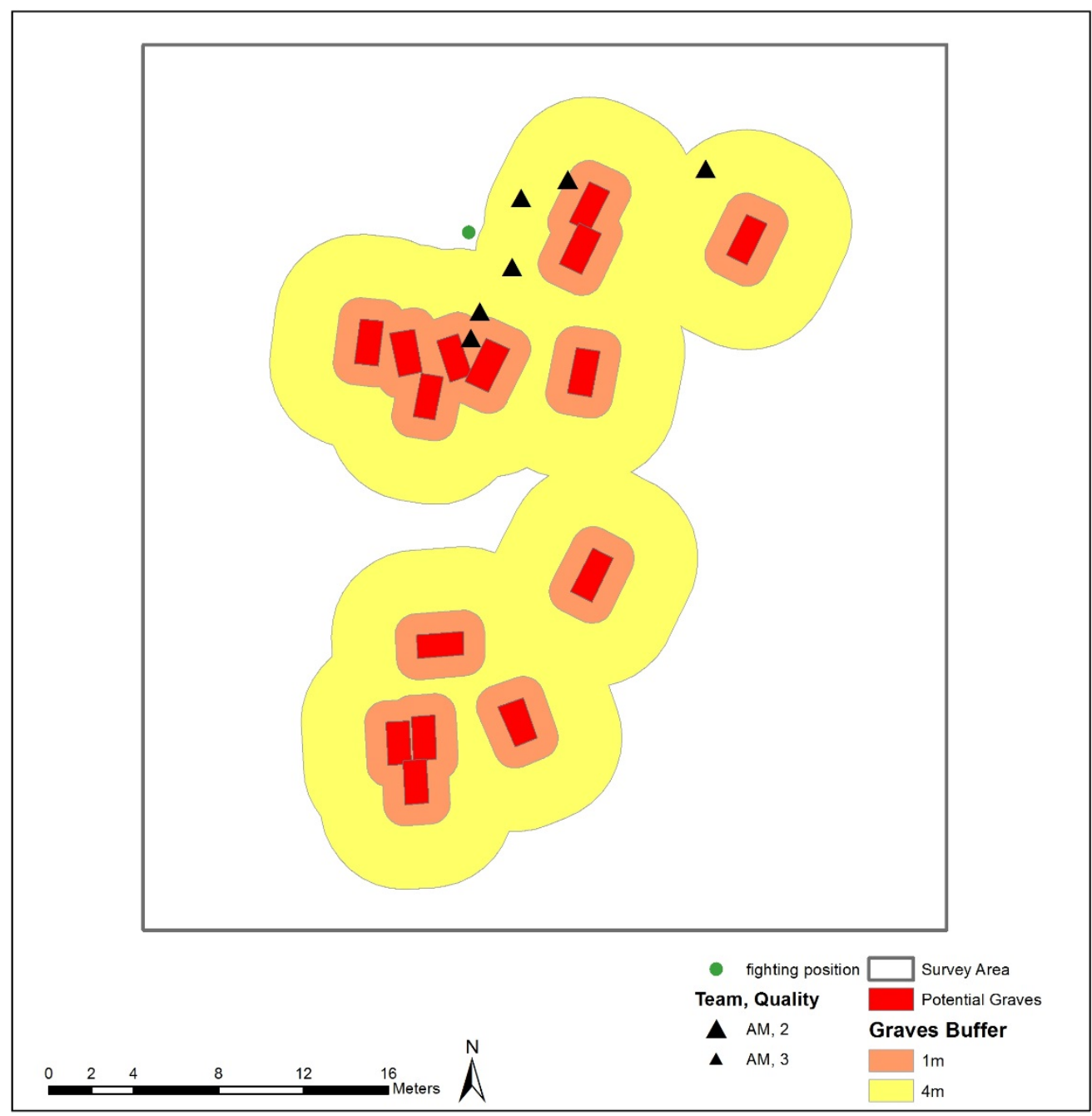


Figure 45. Results of Team BP, Cemetery 20, Fort Gordon.

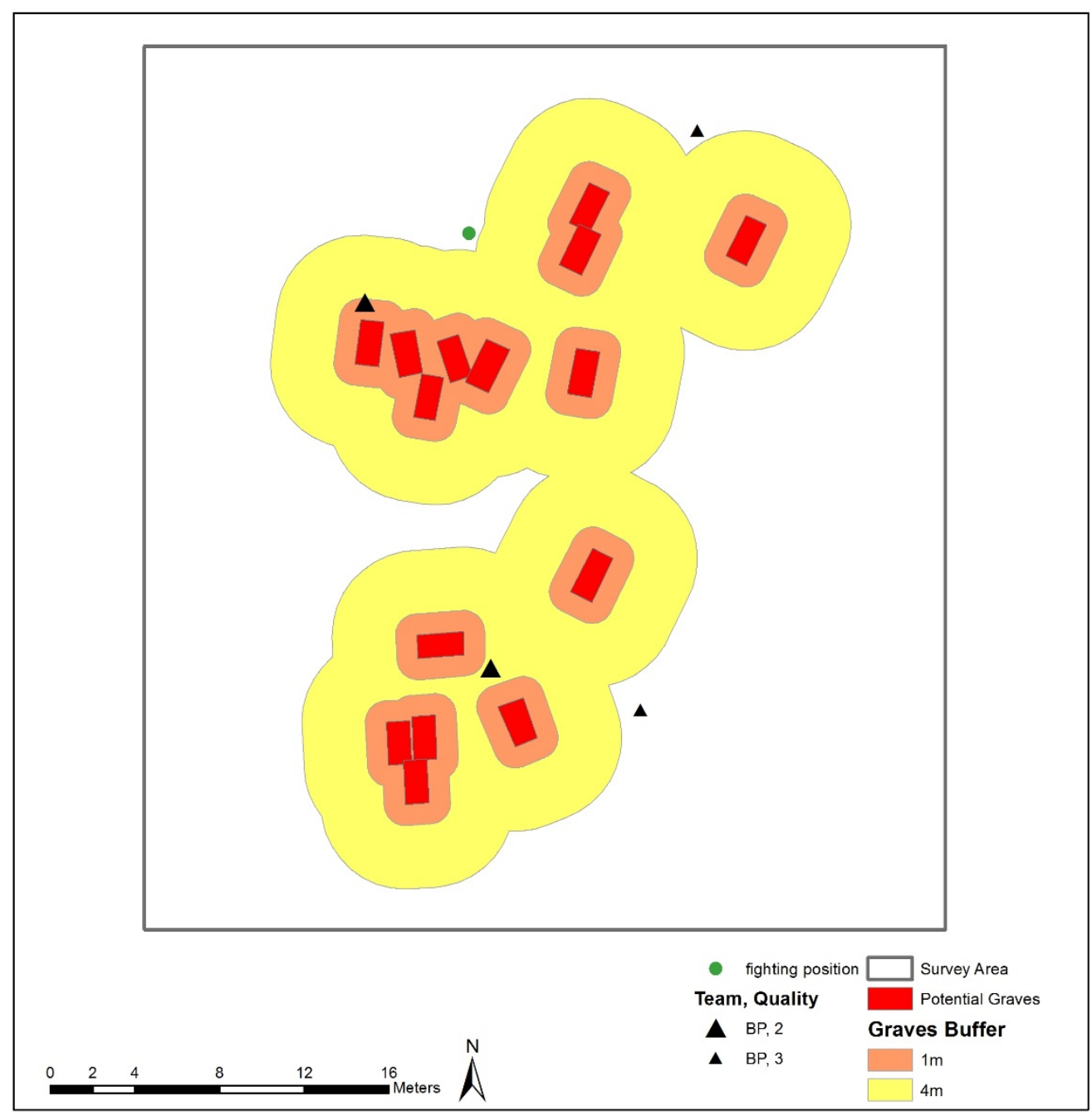


Figure 46. Results of Team JG, Cemetery 20, Fort Gordon.

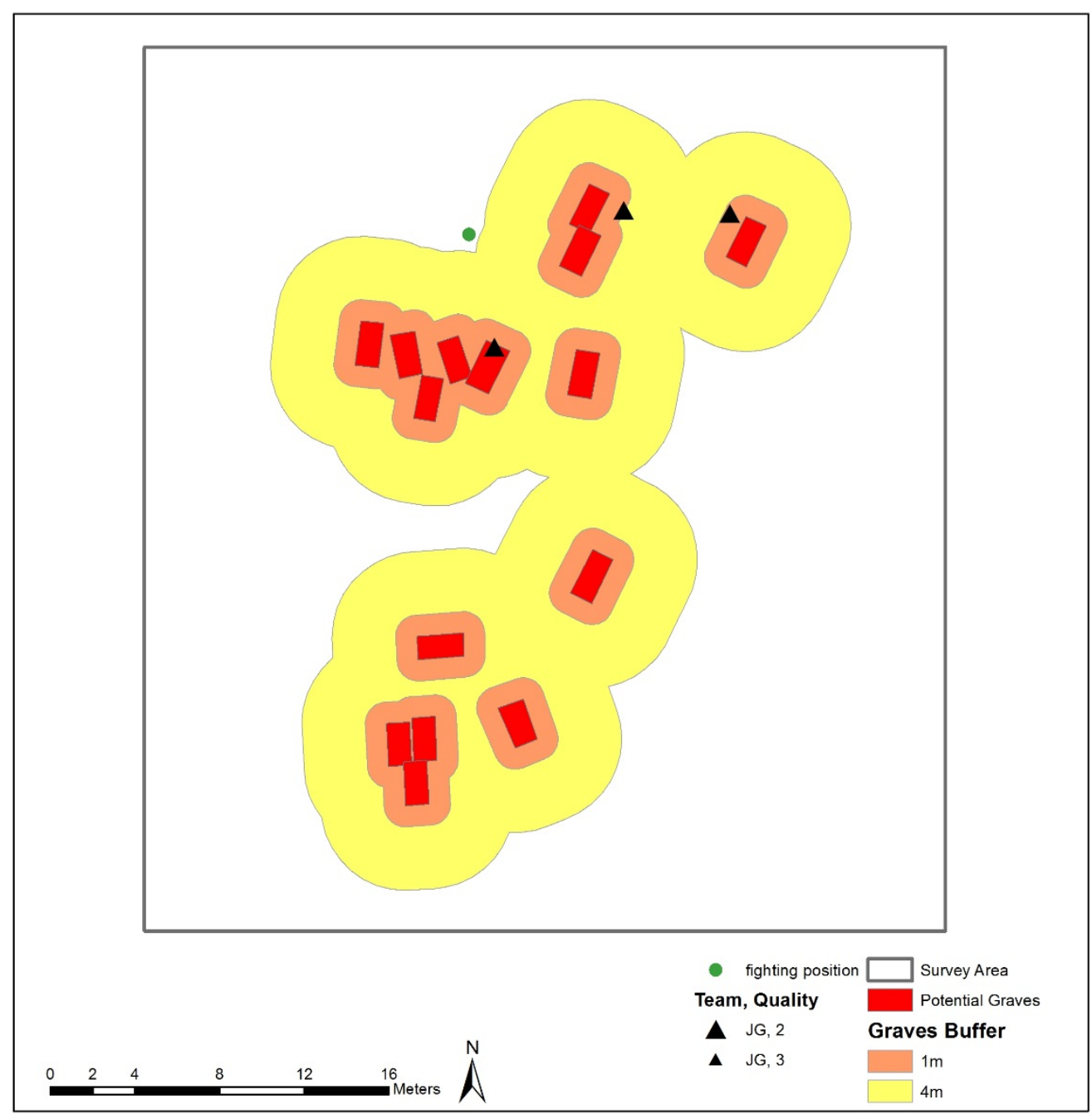


Figure 47. Results of Team LA, Cemetery 20, Fort Gordon.

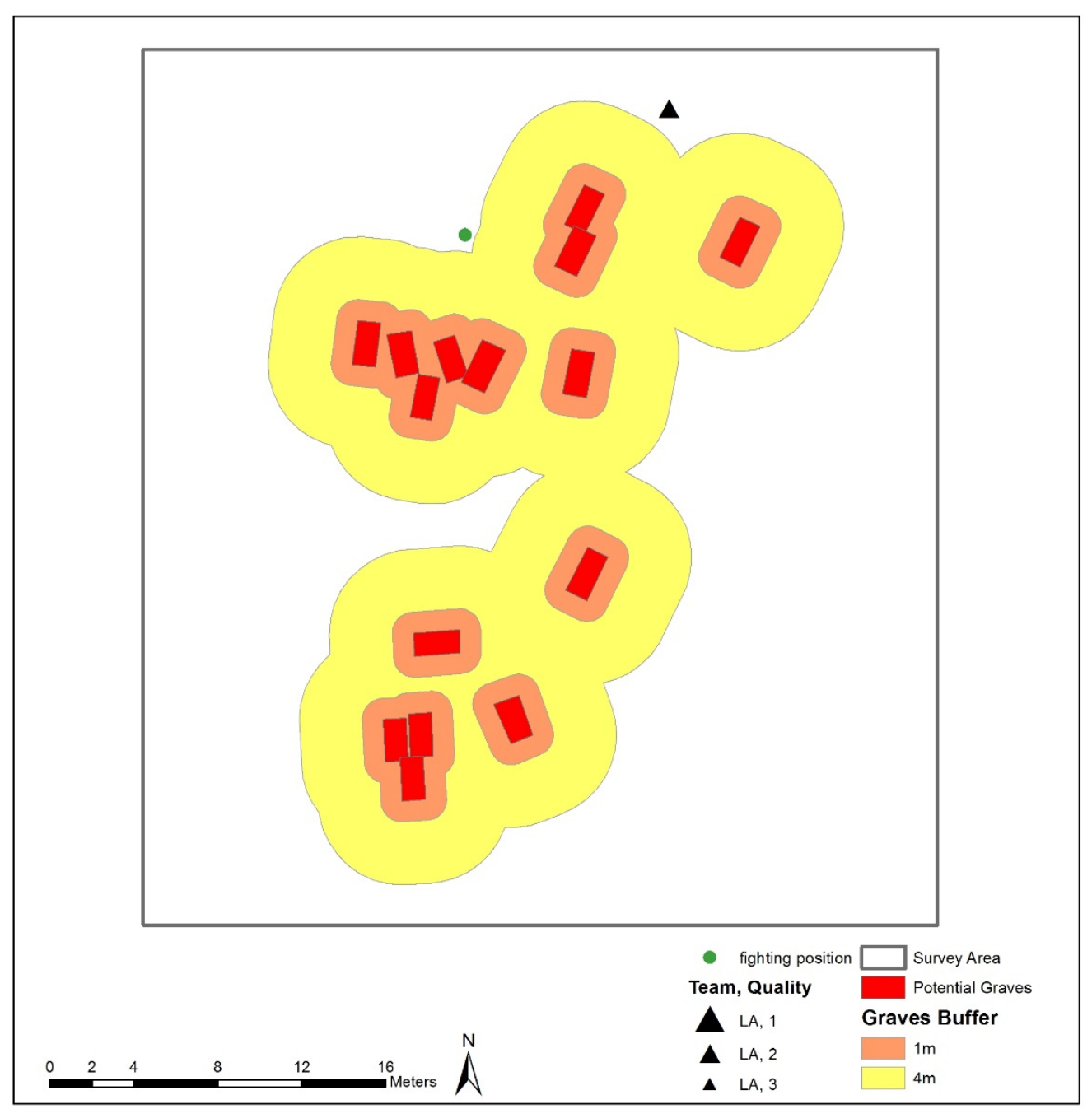

Table 8. Summary of HHRD dog surveys, Cemetery 20, Fort Gordon.

\begin{tabular}{|l|l|l|l|l|}
\hline $\begin{array}{l}\text { Dog } \\
\text { Team }\end{array}$ & $\begin{array}{l}\text { Alerts over } \\
\text { Possible Graves }\end{array}$ & $\begin{array}{l}\text { Alerts within 1 m } \\
\text { of Possible Graves }\end{array}$ & $\begin{array}{l}\text { Alerts within 1-4 m } \\
\text { of Possible Graves }\end{array}$ & $\begin{array}{l}\text { Alerts more than } \\
4 \text { m from Possible } \\
\text { Graves }\end{array}$ \\
\hline AM & & 2 & 4 & \\
\hline BP & & 1 & 1 & 2 \\
\hline JG & 1 & 1 & 1 & 1 \\
\hline LA & & & & 1 \\
\hline
\end{tabular}




\subsection{Cemetery 26}

Cemetery 26 is located .05 $\mathrm{km}$ from the nearest major road and is accessible only on a fire-break road. Several thin slabs of limestone were present that could be interpreted as grave markers. Two stones were lying on the ground surface, but one stone that had been broken off at ground level had once been orientated vertically (Figure 48). All of these stones, however, were less than $10 \mathrm{~cm}$ thick (much thinner than one would expect for a tombstone), and there was no evidence of smoothing or inscriptions on the surface of the slabs. The stones were located immediately adjacent to a small berm and uneven ground surface that might have been the result of heavy equipment use.

Figure 48. View to northwest of possible grave stones, Cemetery 26, Fort Gordon.

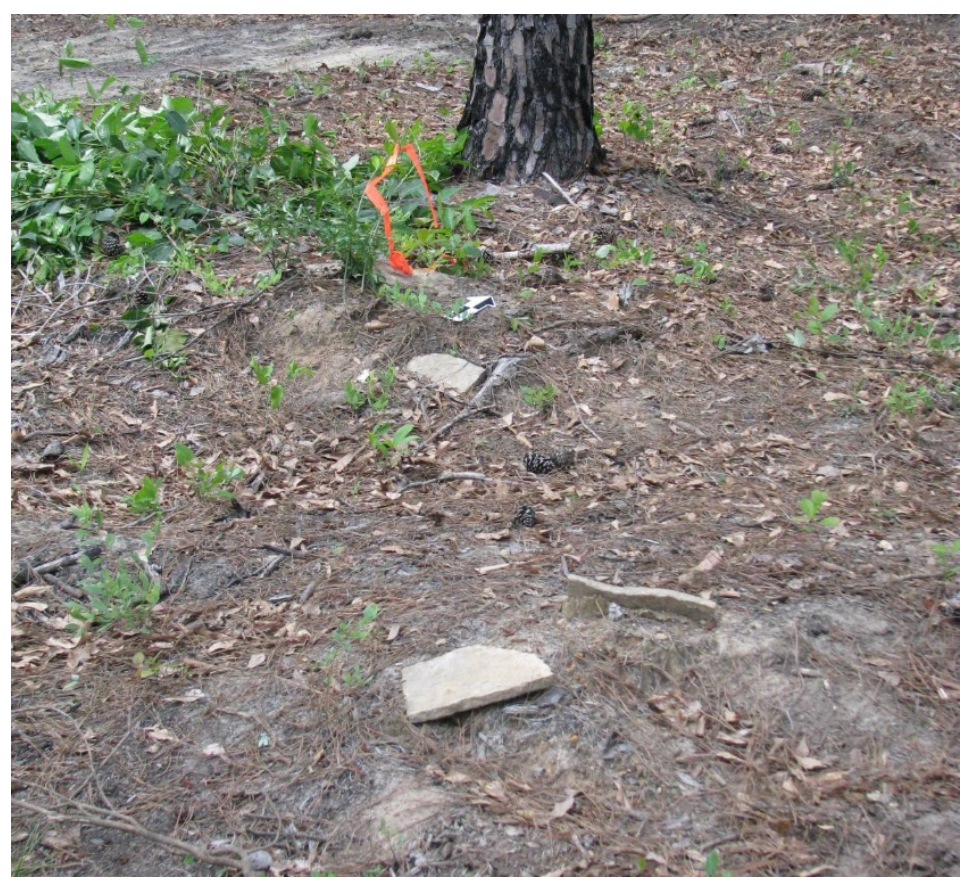

A series of linear anomalies radiating from a point near the center of the survey area (Figure 49) were observed in the GPR data. Due to their length, these anomalies were interpreted as the result of vehicle activity. The GPR anomaly near the stones is sitting over one of those linear features and therefore, is suspect as a grave. A series of magnetic dipoles (both positive and negative components in close proximity) of various sizes occurred throughout the survey area. This pattern is typical of a scattering of small metal objects that indicate transitory use that is more typical of a bivouac, training, or logging area instead of a habitation site. Two weaker monopoles and one dipolar magnetic anomaly are aligned on the 
eastern side of the survey area. Also in this area, GPR results show a cluster of grave-like anomalies and a lone grave-like anomaly that are not associated with the linear features. While the GPR and magnetic anomalies do not correspond to each other, the presence of multiple unexplained anomalies in a single portion of the site raises the possibility that these features may be graves, despite the improbability of so many graves being placed in such a tight cluster. All things considered, it was determined to be a moderate likelihood that the anomalies on the east side of this cemetery site represent historic graves. 
Figure 49. Possible graves at Cemetery 26, Fort Gordon, based on all GPR slices (top), all magnetic data (center), and overlay of magnetic anomalies on possible graves (bottom) (Hargrave 2011, Figure 3-15).

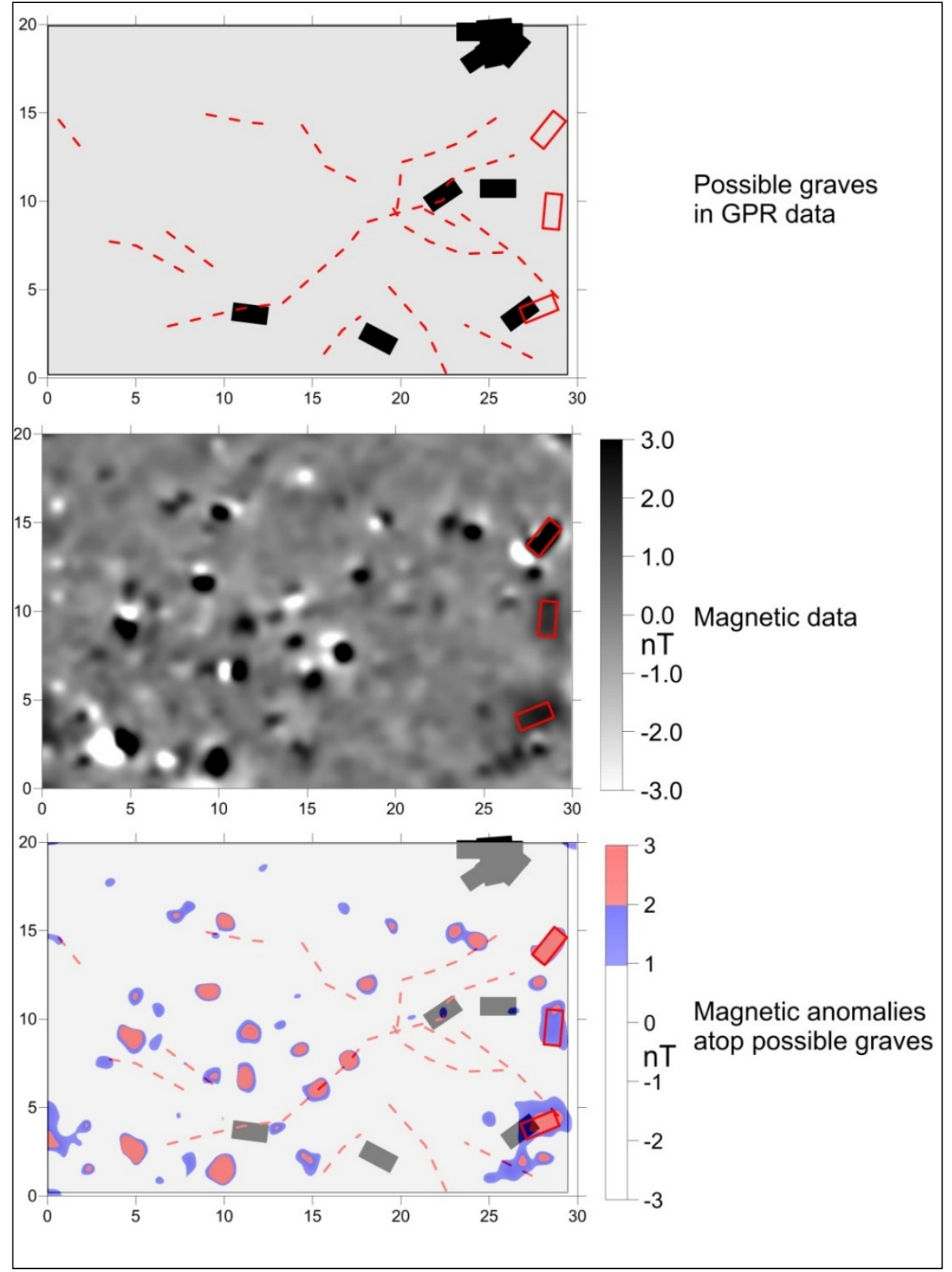

All four dog teams surveyed this cemetery, but only two teams registered alerts. These alerts are shown in Figure 50 and Figure 51 and summarized in Table 9. Both alerts were Quality 2 and within $1 \mathrm{~m}$ of a geophysical anomaly. Only the alert by team JG, however, was in proximity to one of the anomalies determined by Hargrave as more likely to be an historic grave; the other alert (Team LA) was located on an anomaly that was associated with the linear features determined as likely to be the result of vehicular activity. 
Figure 50. Results of Team JG dog survey, Cemetery 26, Fort Gordon.

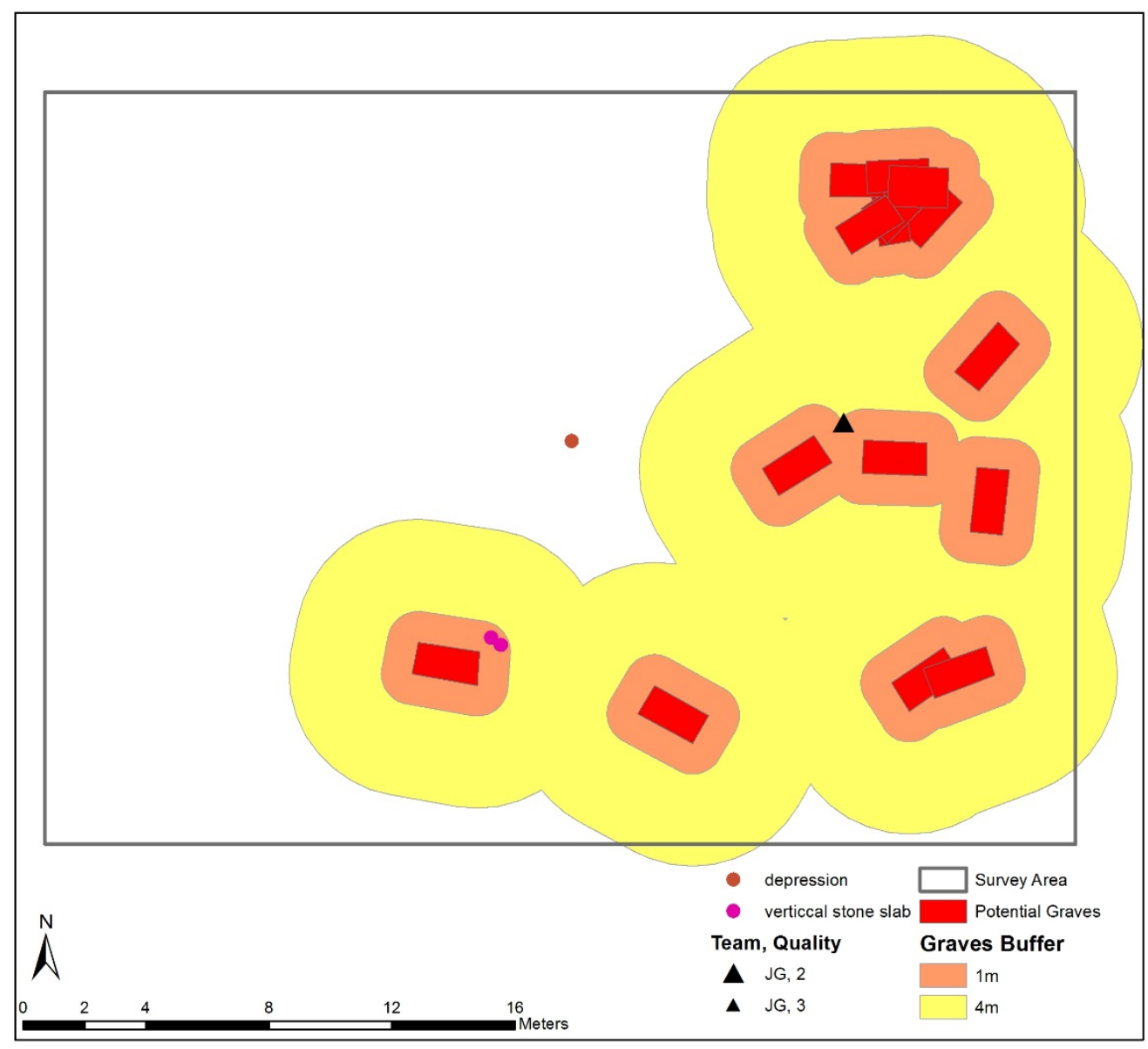


Figure 51. Results of Team LA dog survey, Cemetery 26, Fort Gordon.

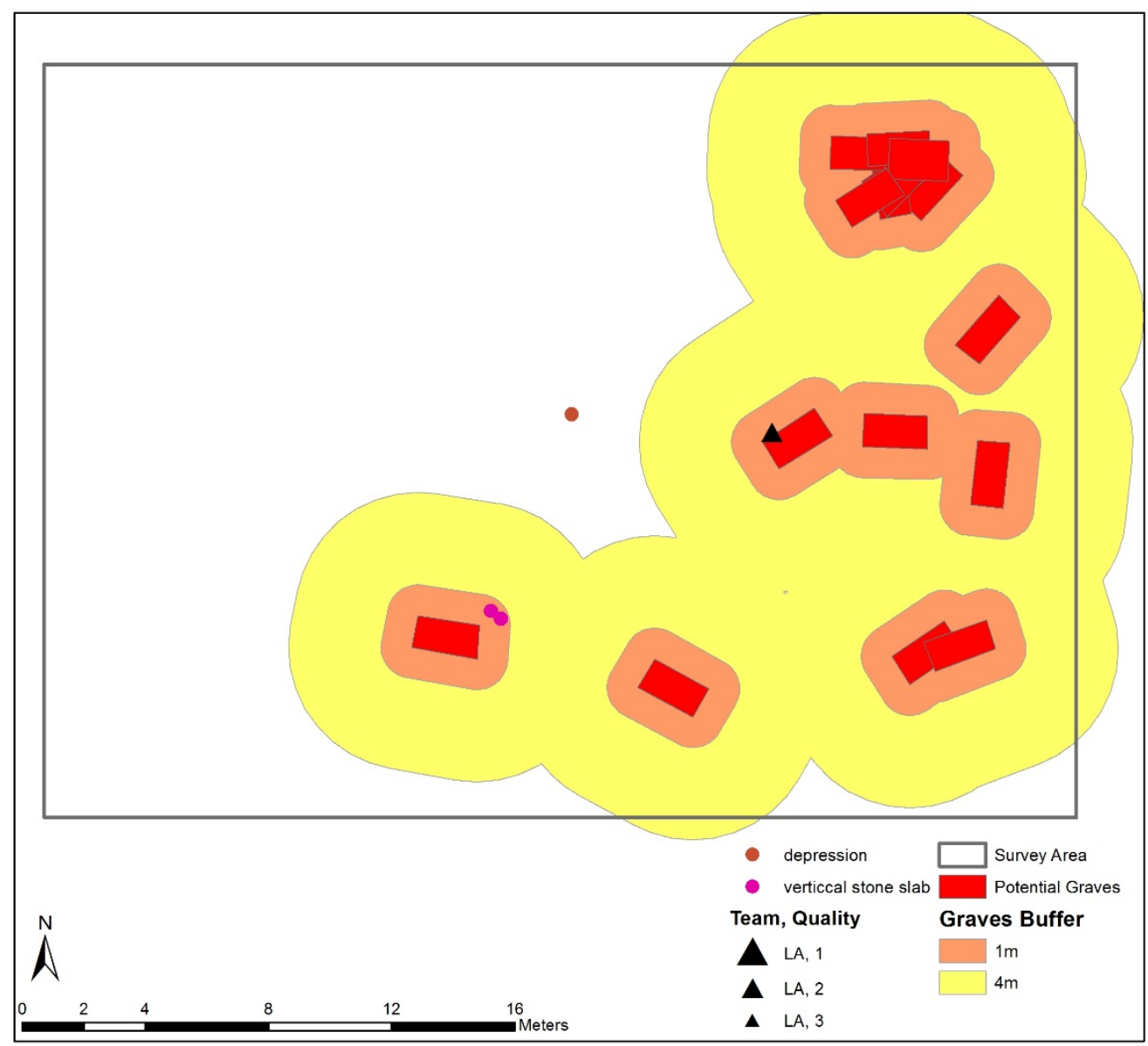

Table 9. Summary of HHRD dog survey, Cemetery 26, Fort Gordon.

\begin{tabular}{|c|c|c|c|c|}
\hline Dog Team & $\begin{array}{c}\text { Alerts over } \\
\text { Possible Graves }\end{array}$ & $\begin{array}{c}\text { Alerts within 1 m } \\
\text { of Possible Graves }\end{array}$ & $\begin{array}{c}\text { Alerts within 1-4 m } \\
\text { of Possible Graves }\end{array}$ & $\begin{array}{c}\text { Alerts more than } \\
4 \mathrm{~m} \text { from Possible } \\
\text { Graves }\end{array}$ \\
\hline AM & & & & \\
\hline BP & & 1 & & \\
\hline JG & & 1 & & \\
\hline LA & & & & \\
\hline
\end{tabular}




\subsection{Cemetery 31}

Cemetery 31 is located near an abandoned landing strip. The center of the area had a scatter of bricks at the surface that did not appear aligned or arranged. Visits to other cemeteries in the region (not part of this study) demonstrated that occasionally bricks were used to outline graves (see Chapter 3, Figure 2). A lone cedar tree was also present at the site. Fort Gordon CRM staff indicated that in this region, cedar trees were often planted in cemeteries. A small raised area or berm was located near the center of the site, but the age of this feature was indeterminate, and it might have been the result of heavy equipment use on the site after the original abandonment.

Approximately 18 GPR anomalies are identified as possible graves, with the majority orientated near northwest to southeast. Several of the anomalies overlap, so only 12 distinct areas occur in this survey area. The magnetic data is characterized by a number of large, strong, dipolar anomalies that are consistent in size and shape, indicating they may have a similar source or cause. A number of the magnetic anomalies roughly correspond in location and orientation to GPR anomalies described as grave-like (Figure 52). It is possible (but unlikely given the socioeconomic setting of the historic region) that the strong magnetic reading within graves could represent metal-lined coffins or vault lines from vaults made of metal or reinforced with rebar. An alternate possibility is that a grave outlined by fired bricks could also produce the geophysical signatures seen at Cemetery 31 . This possibility may also explain the scattering of loose brick on the surface. All of the evidence indicates that it is highly likely that historic graves are present at Cemetery 31.

HHRD dog surveys resulted in 29 total alerts including five Quality 1 hits, as shown in Figure 53-Figure 56 and summarized in Table 10. Three of the four dogs had alerts within $1 \mathrm{~m}$ of the central anomalies that had correlation between magnetic and GPR data. Of all the alerts, $62 \%$ were located within $4 \mathrm{~m}$ of grave-like anomalies. The tight clustering of alerts around the central portions of the site correlates well with the geophysical data. The presence, however, of multiple strong alerts by multiple dogs some meters away from the buffer zones would raise the suggestion that the limits of the geophysical survey could be expanded to determine if the cemetery is larger than is currently assumed. 
Figure 52. Possible graves in Cemetery 31 at Fort Gordon. Strong magnetic anomalies (red and blue) atop possible graves, based on all GPR slices. There is some correlation of magnetic and GPR indications of graves. All coordinates given in meters, and north is at top of figure. (Hargrave 2011, Figure 3-22).

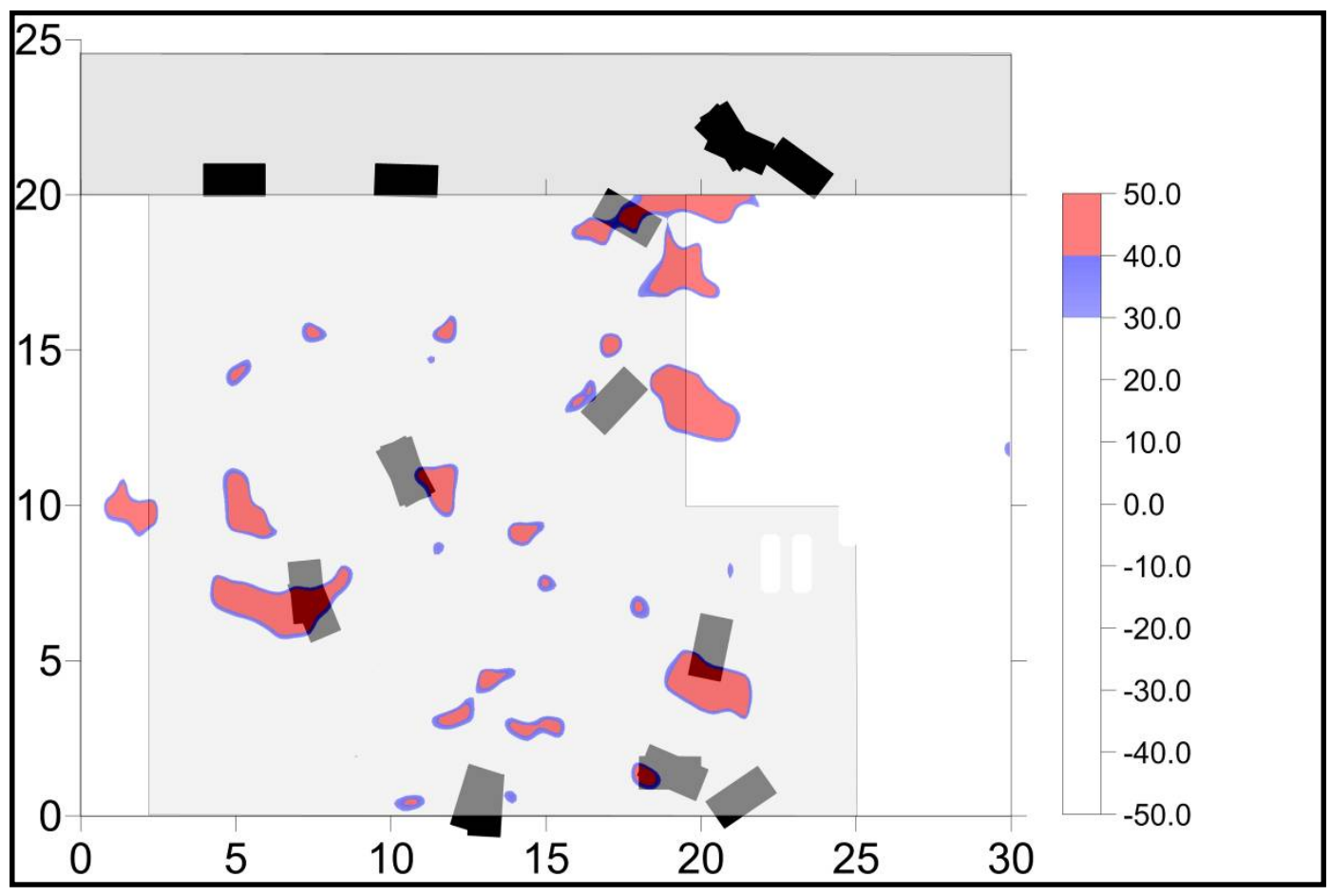


Figure 53. Results of Team AM dog survey, Cemetery 31, Fort Gordon.

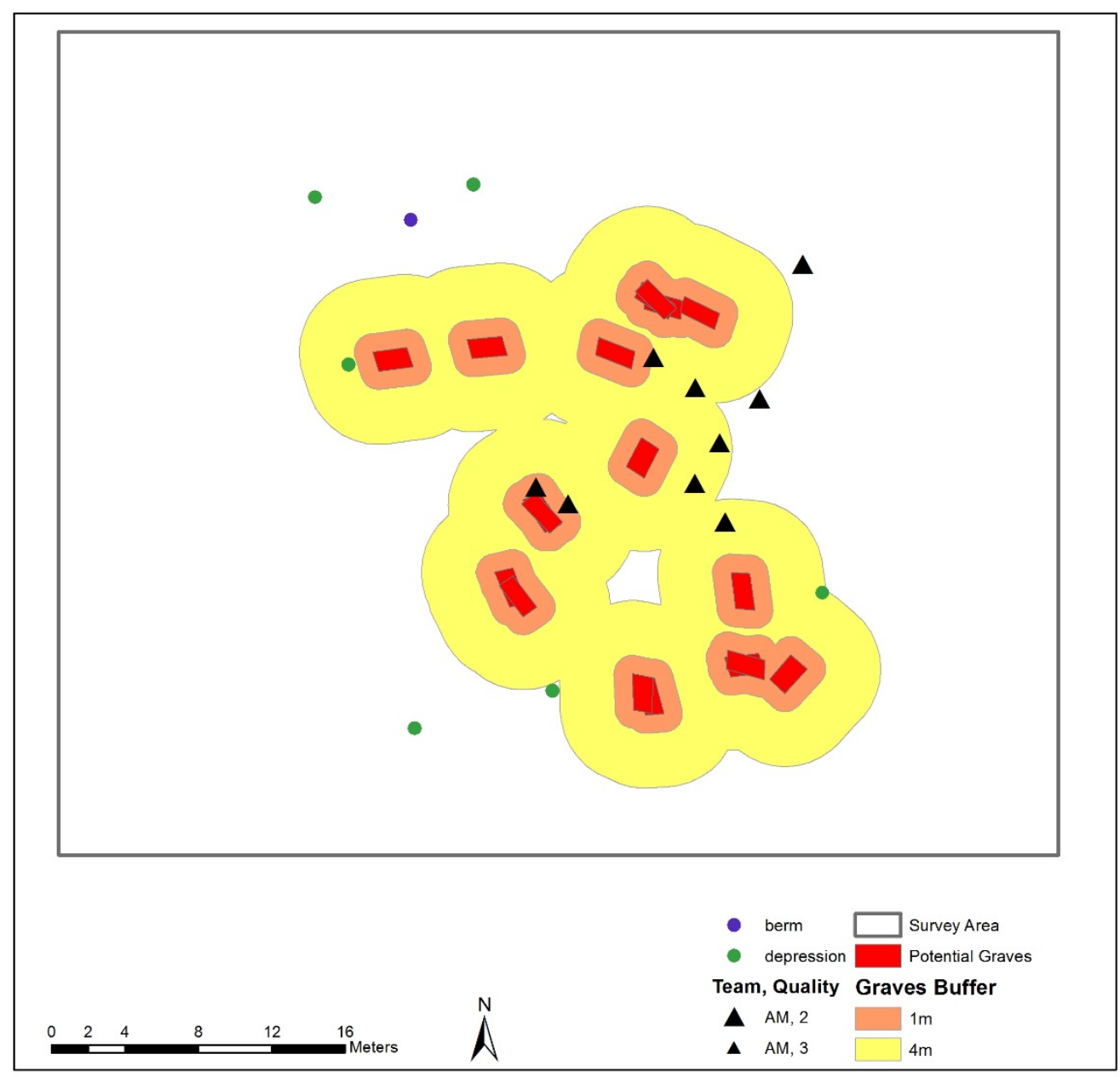


Figure 54. Results of Team BP, Cemetery 31, Fort Gordon.

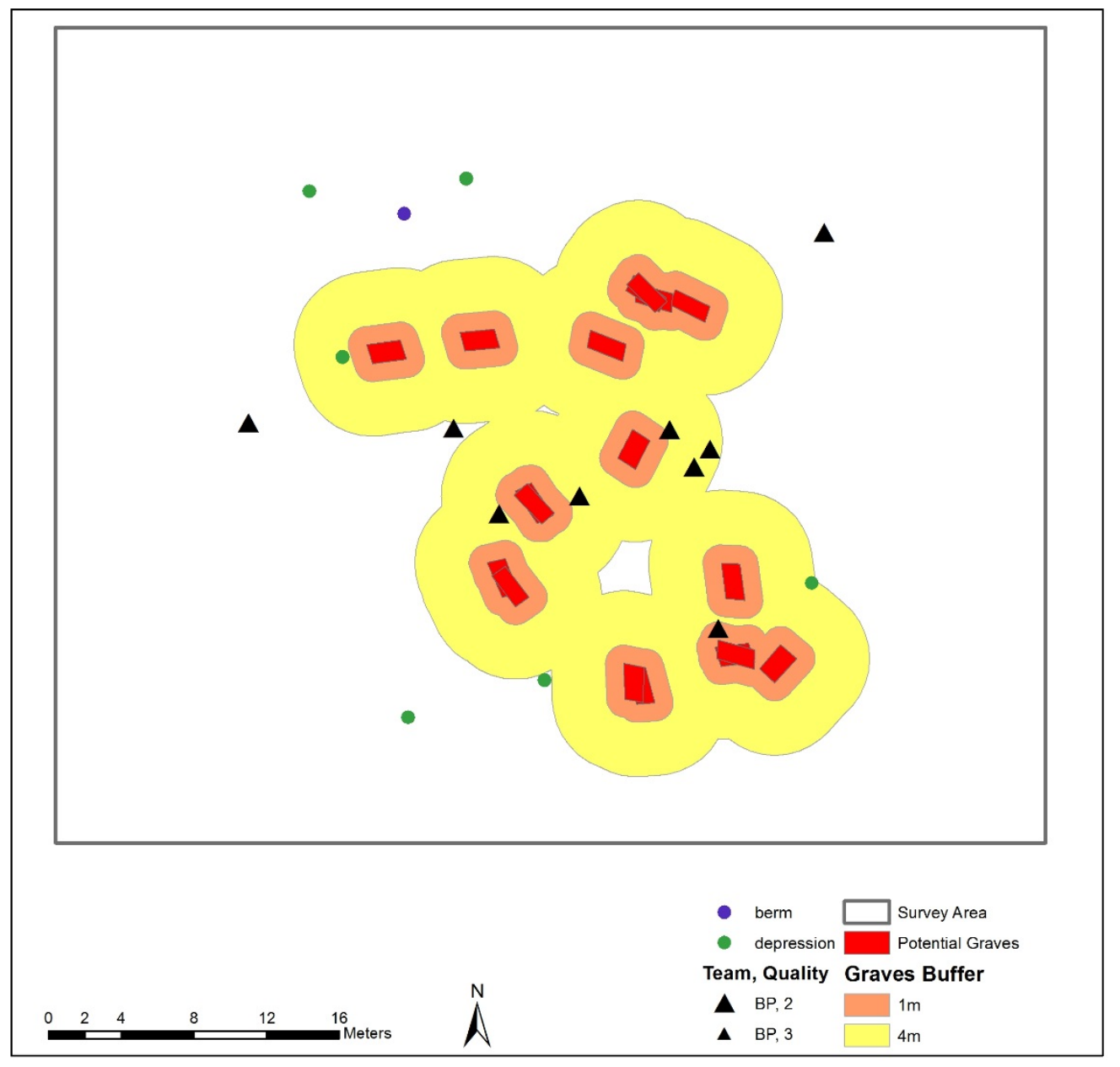


Figure 55. Results of Team JG, Cemetery 31, Fort Gordon.

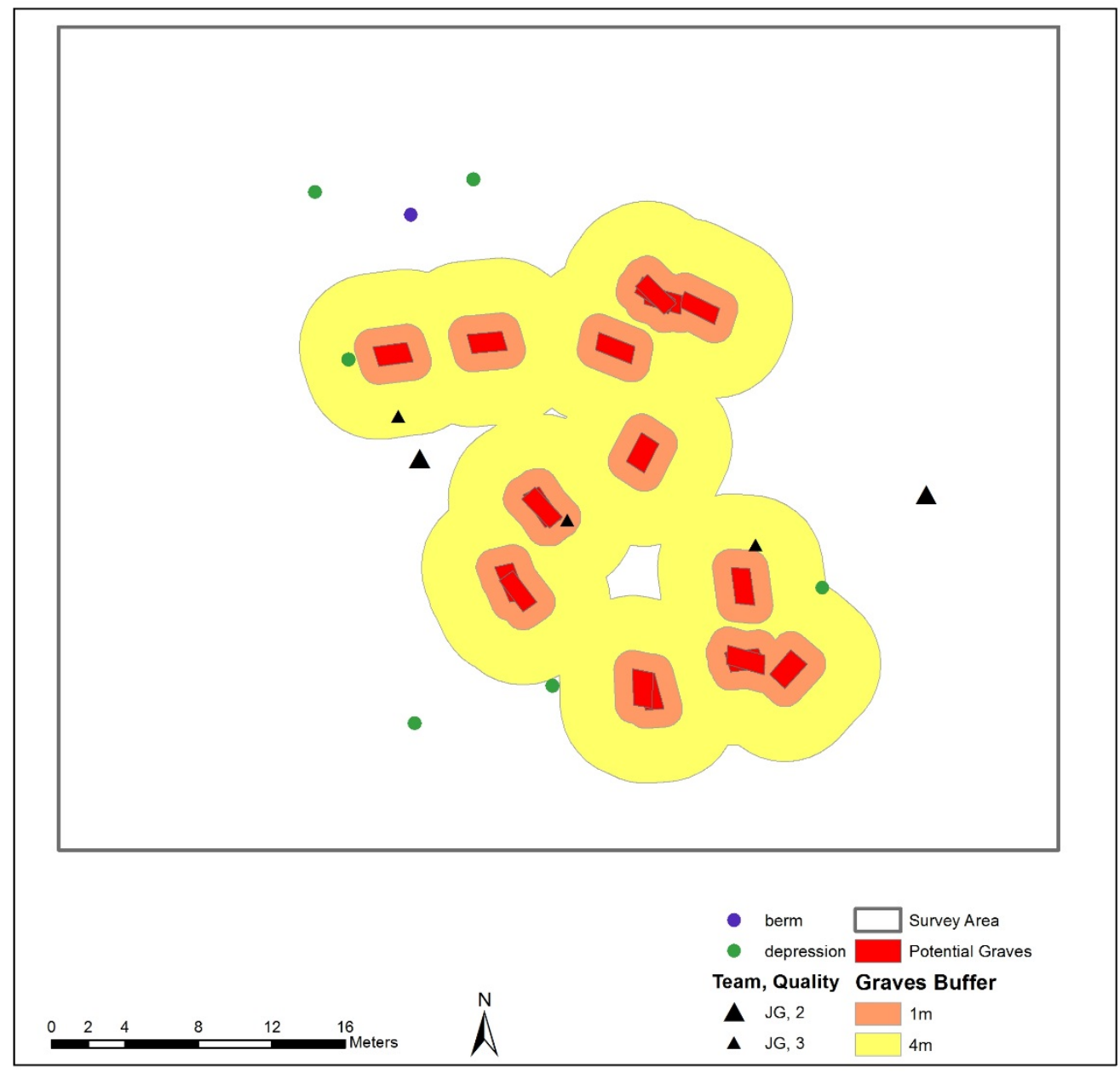


Figure 56. Results of Team LA, Cemetery 31, Fort Gordon.

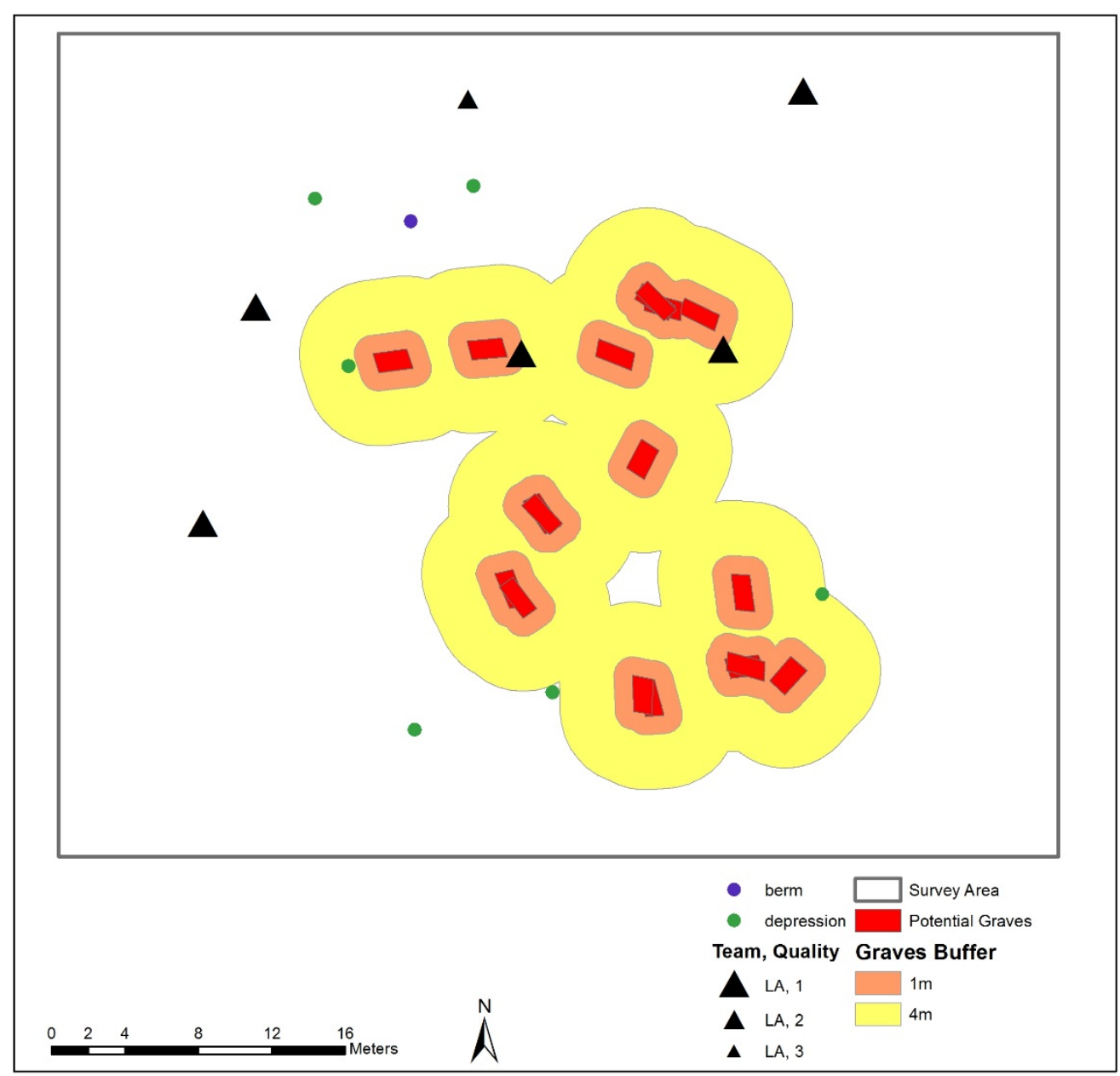

Table 10. Summary of HHRD dog survey, Cemetery 31, Fort Gordon.

\begin{tabular}{|c|c|c|c|c|}
\hline Dog Team & $\begin{array}{c}\text { Alerts over } \\
\text { Possible Graves }\end{array}$ & $\begin{array}{c}\text { Alerts within } 1 \mathrm{~m} \\
\text { of Possible Graves }\end{array}$ & $\begin{array}{c}\text { Alerts within 1-4 m } \\
\text { of Possible Graves }\end{array}$ & $\begin{array}{c}\text { Alerts more than } \\
4 \text { m from Possible } \\
\text { Graves }\end{array}$ \\
\hline AM & & 3 & 4 & 2 \\
\hline BP & & 1 & 5 & 3 \\
\hline JG & & 1 & 2 & 2 \\
\hline LA & & 1 & 1 & 4 \\
\hline
\end{tabular}




\subsection{Cemetery 34}

Cemetery 34 is located near Cemetery 31, approximately $0.3 \mathrm{~km}$ west of a major, multilane dirt road. Two depressions and an earthen berm studded with pieces of concrete, brick, and stone are situated on the northern portion of the survey area. It is possible that this feature represents a retaining or enclosure wall around a cemetery. Two cedar trees were located $30 \mathrm{~m}$ north of the survey area.

Approximately 30 GPR anomalies were identified as possible historic graves. Many of the possible graves are in clusters, but there appears to be an apparent northwest-southeast alignment of 7 or 8 anomalies along the north-central portion of the site. There are several large magnetic anomalies, but these anomalies do not appear to be associated with GPR anomalies (Figure 57) as we saw at Cemetery 31. The GPR anomalies also are not as spatially discrete as the anomalies seen in Cemeteries 9 and 31. At Cemetery 34, there is more of a continuous range of variation in anomaly dimensions. As a result, it is moderately likely that the anomalies seen as Cemetery 34 are historic graves.

HHRD dog survey results are shown in Figure 58- Figure 61 and summarized in Table 11. This site produced 41 total alerts. It is interesting to note that only Team BP alerted in the area of the cluster of anomalies highlighted in Hargrave 2011 as the anomalies most likely to be graves. Three of the four dogs' alert patterns were focused on a cluster of anomalies west of the center of the survey area. The GPR data, however, does show that these anomalies are fairly consistent to the deepest data slice at $2.29 \mathrm{~m}$ below the surface. Two of these anomalies are orientated north-south, with only one orientated east-west. Is this a case of a subsurface feature creating a conduit where the scent is being brought to the soil surface where it is more easily detected by the dog teams? Or, is this a case of the archaeologists privileging the cultural norms of east-west grave orientation too much? 
Figure 57. Possible graves at Cemetery 34, Fort Gordon. All magnetic data (top) and magnetic anomalies atop all possible graves (below).

(Hargrave 2011, Figure 3-29).

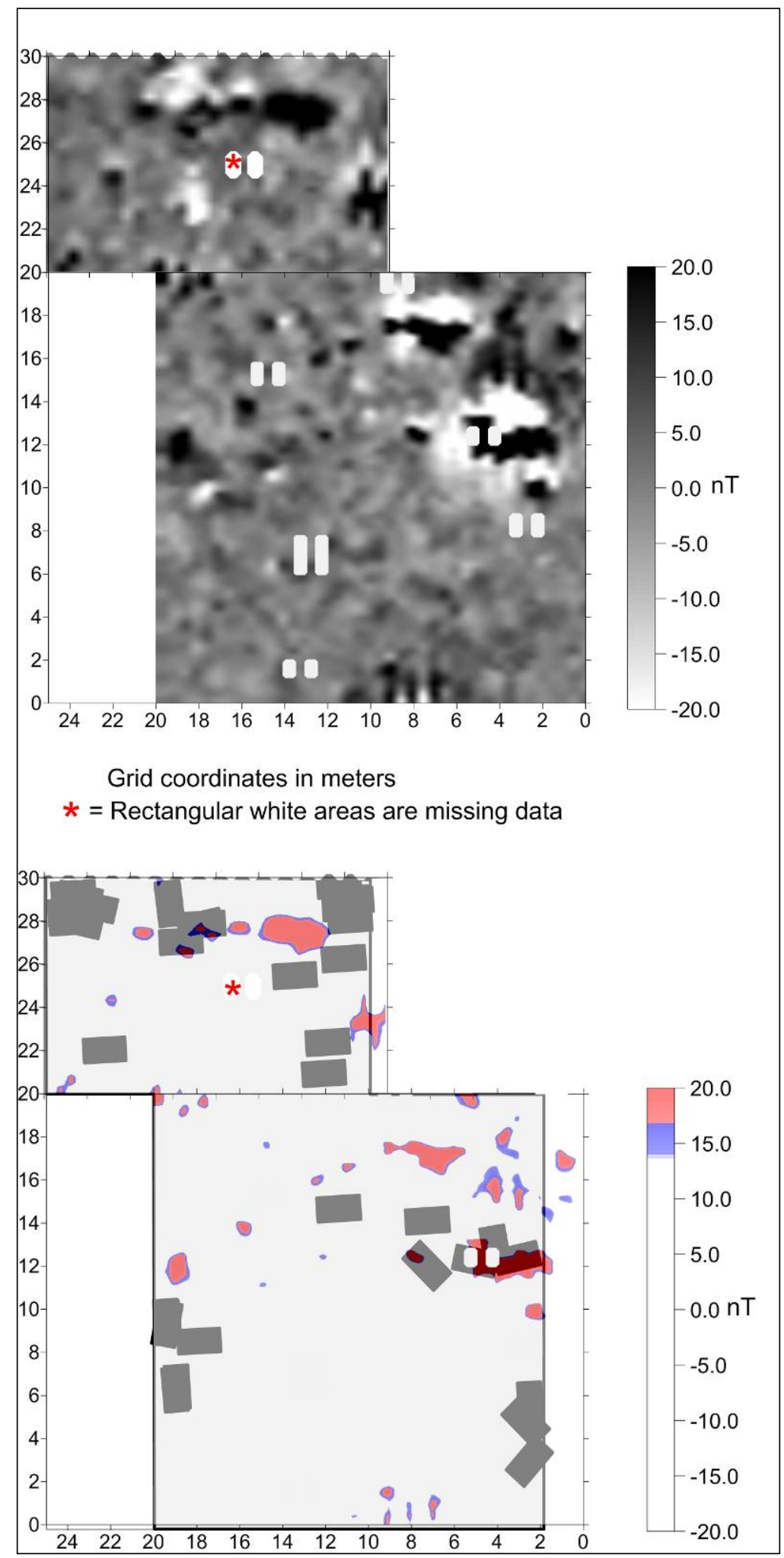


Figure 58. Results for Team AM survey of Cemetery 34, Fort Gordon.

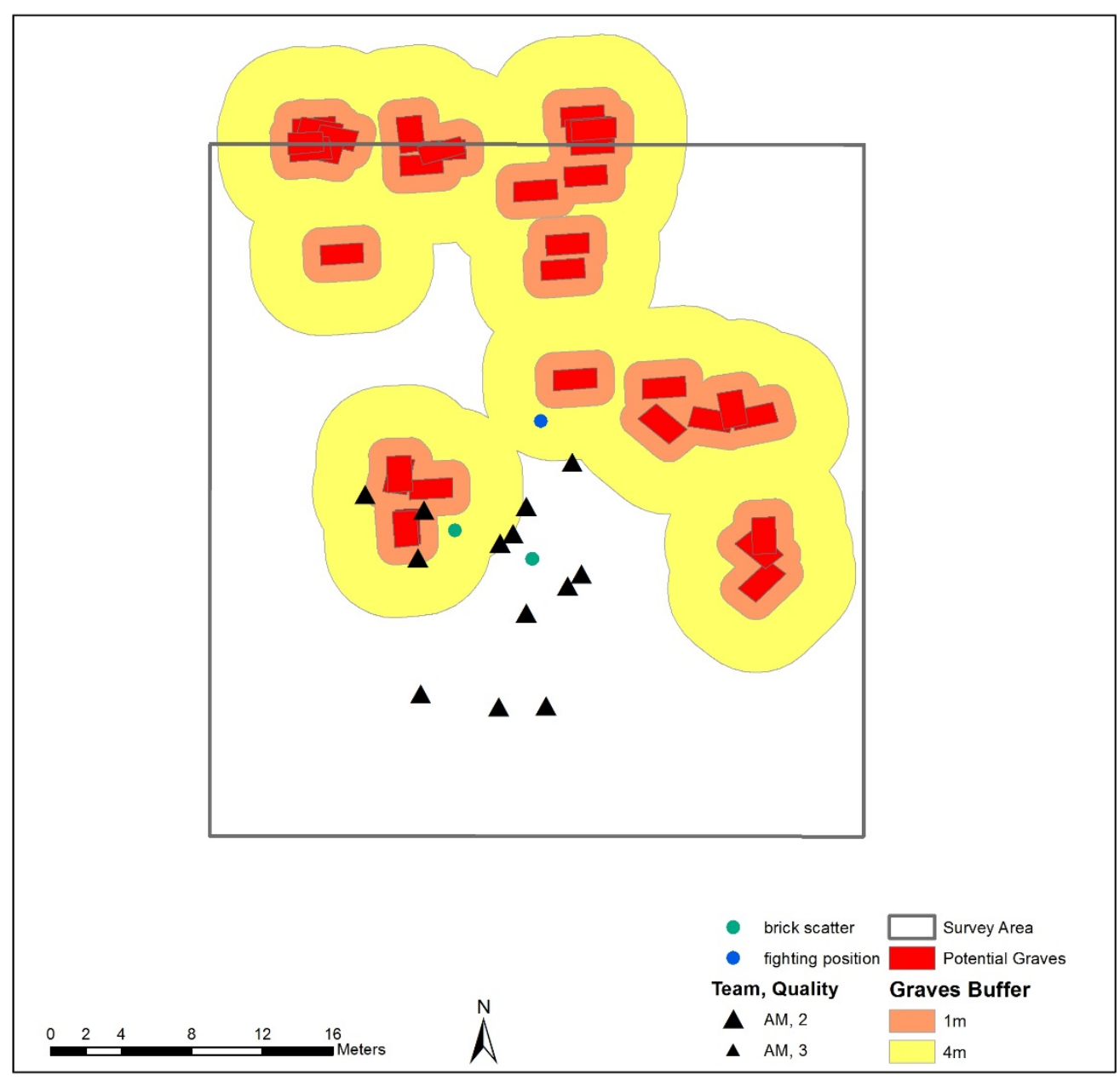


Figure 59. Results for Team BP survey of Cemetery 34, Fort Gordon.

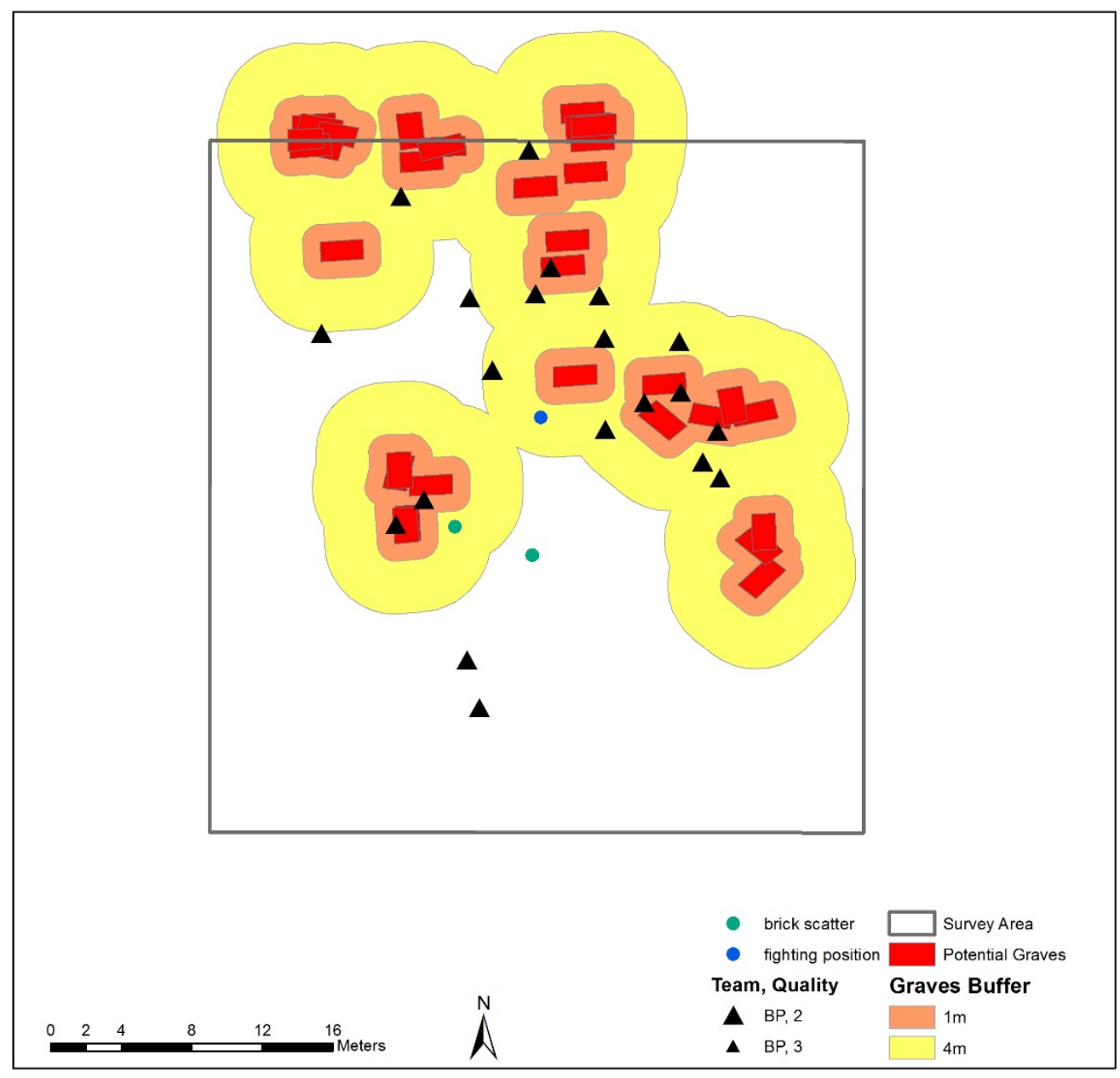


Figure 60. Results of Team JG survey of Cemetery 34, Fort Gordon.

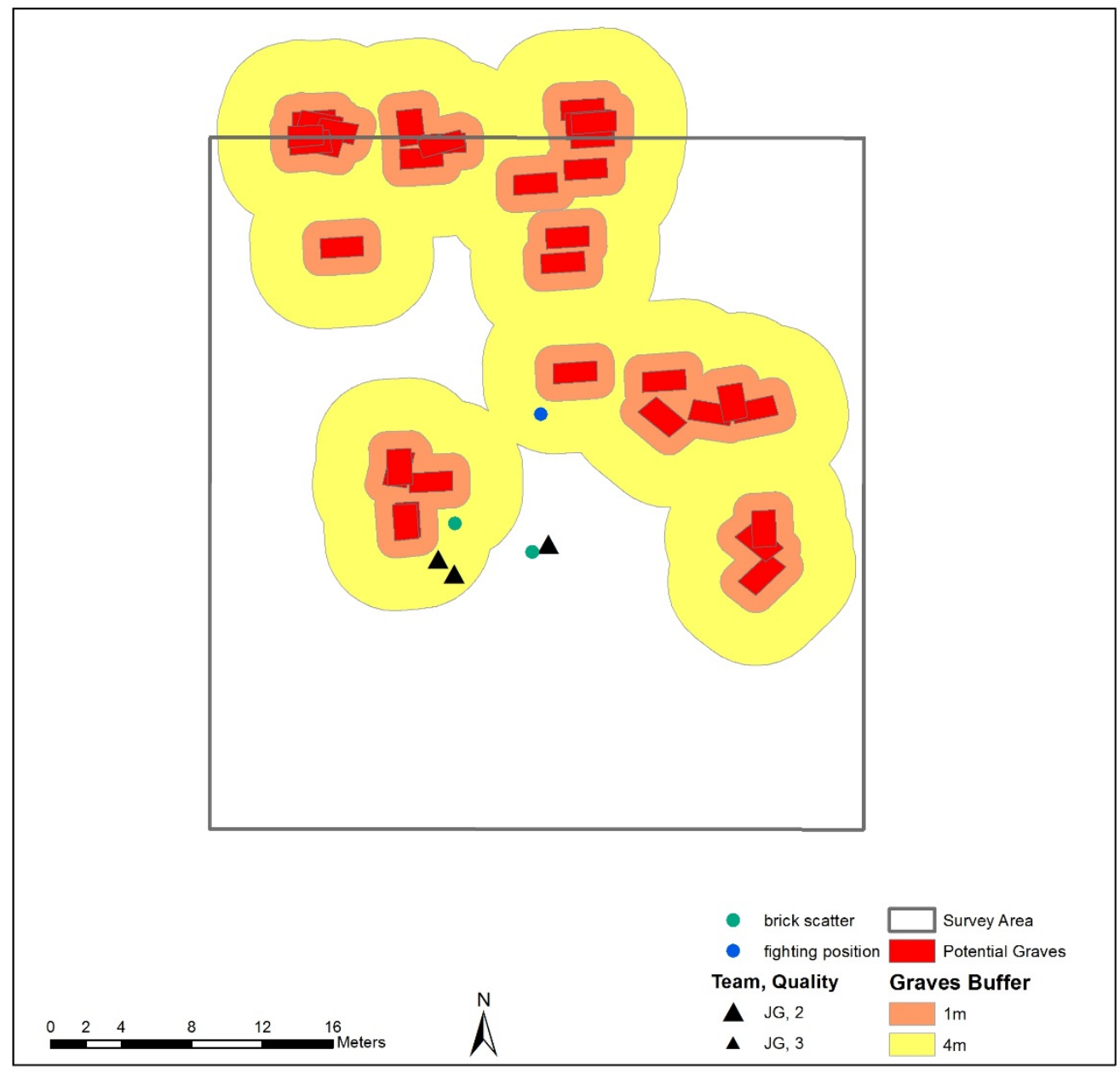


Figure 61. Results of Team LA survey of Cemetery 34, Fort Gordon.

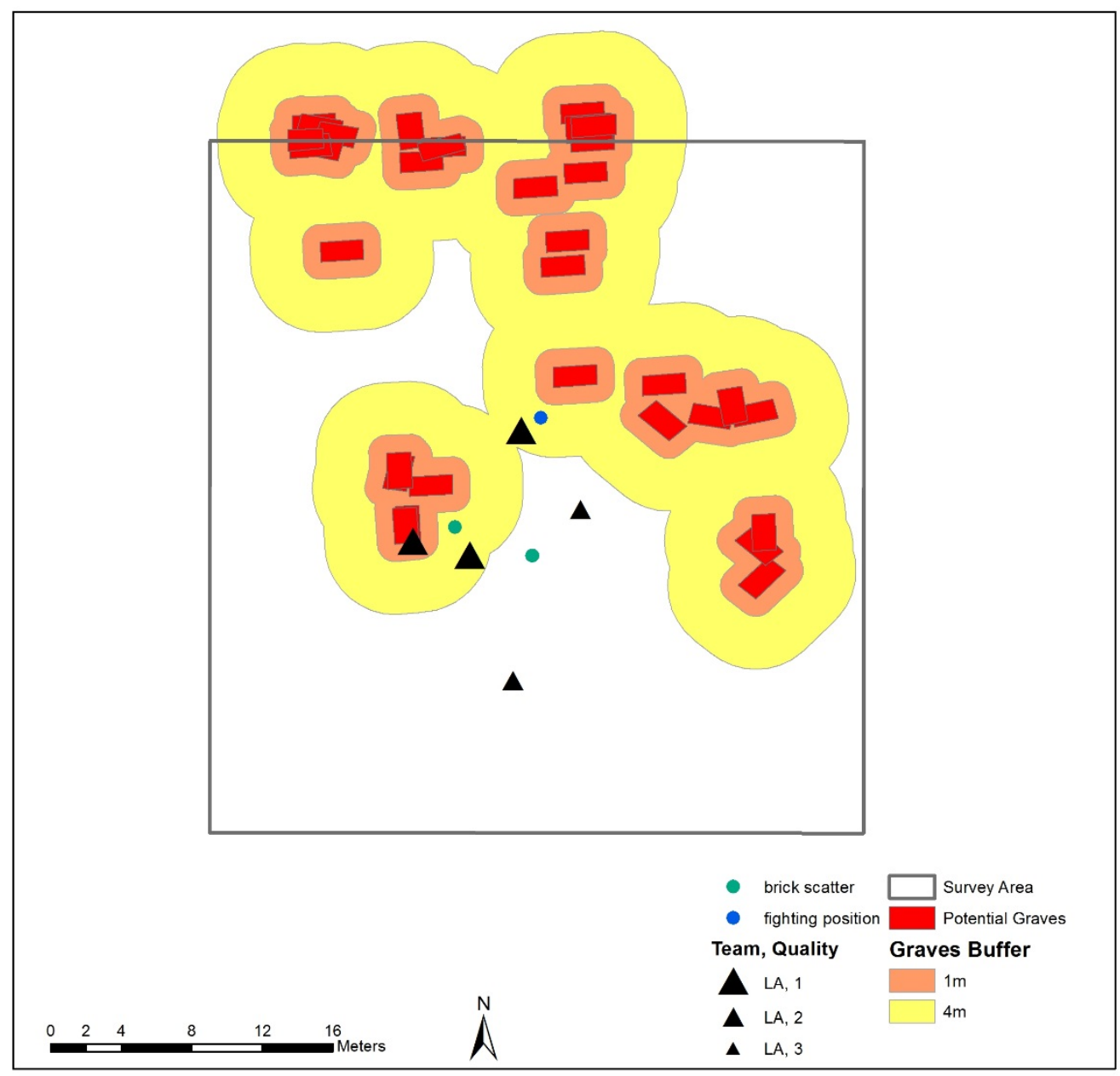

Table 11. Summary of HHRD dog survey, Cemetery 34, Fort Gordon.

\begin{tabular}{|c|c|c|c|c|}
\hline Dog Team & $\begin{array}{c}\text { Alerts over } \\
\text { Possible Graves }\end{array}$ & $\begin{array}{c}\text { Alerts within 1 m } \\
\text { of Possible Graves }\end{array}$ & $\begin{array}{c}\text { Alerts within 1-4 m } \\
\text { of Possible Graves }\end{array}$ & $\begin{array}{c}\text { Alerts more than } \\
4 \text { m from Possible } \\
\text { Graves }\end{array}$ \\
\hline AM & & 2 & 1 & 10 \\
\hline BP & 2 & 4 & 10 & 4 \\
\hline JG & & & 2 & 1 \\
\hline LA & 1 & & 2 & 2 \\
\hline
\end{tabular}




\subsection{Cost benefits comparison of HHRD and geophysical surveys.}

At Fort Gordon, both the geophysical and HHRD surveys were part of single effort trips, each cemetery was examined by every survey participant, and neither survey efforts were impacted by inclement weather. As a result, the Fort Gordon surveys are best suited to compare the relative expenditure of labor and funds. Travel expenses and per diem will not be considered as part of the analysis, as ICF's travel to Fort Gordon was interrupted by the stop in Champaign, Illinois, to conduct the first two portions of the study.

Two archeologists from ERDC-CERL conducted the geophysical survey in four days of fieldwork (10-13 May 2010). Nearly $30 \%$ of the time spent at each cemetery (with the exception of Cemetery 9 which was planted in mowed grass) was focused on clearing underbrush and ground debris from the survey areas to ensure high quality data collection. If the survey areas had not been wooded the underbrush clearing effort would not been necessary. ERDC-CERL archaeologists were able to provide verbal preliminary results for two of the cemeteries (9 and 31) while on site. Additional data processing and analysis occurred after the fieldwork was complete. The two archaeologists devoted approximately $380 \mathrm{hr}$ of combined labor on the project. A final report of all findings was submitted 7 months after the completion of fieldwork. Excluding travel and per diem expenses, the geophysical survey cost $\$ 60,200$.

ICF fielded four dog teams and one team coordinator. HHRD surveys on all give cemeteries were completed in two days of fieldwork (14-15 November 2013). The ground-clearing efforts conducted by ERDC-CERL did not have to be repeated, as the dog teams did not require as much open space to accommodate their survey. HHRD dog alerts were marked with pin flags and could be observed immediately after the survey was complete. GPS coordinates were collected for each alert and were available for analysis within days of the end of the survey. The five members of the ICF team devoted approximately $28 \mathrm{o} \mathrm{hr}$ of combined labor on the survey. ICF provided a written report detailing the alert locations 3 months after the 
completion of fieldwork. Excluding travel and per diem expenses 3 , the HHRD survey cost $\$ 7,000.4$

Geophysical survey time and report generation time was 200\% greater than HHRD survey time. The geophysical survey budget was 8.6 times greater than the HHRD budget (excluding travel expenses).

\subsection{Summary and conclusions on Fort Gordon cemetery surveys}

The results from this portion of the study were very promising (Table 12). The dogs alerted directly over the GPR anomalies described as potential graves at $60 \%$ of the cemeteries and alerted within $1 \mathrm{~m}$ of the anomalies at $100 \%$ of the cemeteries. More than half of all alerts (58.5\%) were located within $4 \mathrm{~m}$ of possible grave locations.

Table 12. Summary of all HHRD dog alerts at Fort Gordon cemeteries.

\begin{tabular}{|c|c|c|c|c|}
\hline Cemetery & $\begin{array}{l}\text { Alerts over } \\
\text { Possible Graves }\end{array}$ & $\begin{array}{l}\text { Alerts within 1 m } \\
\text { of Possible Graves }\end{array}$ & $\begin{array}{l}\text { Alerts within 1-4 m } \\
\text { of Possible Graves }\end{array}$ & $\begin{array}{l}\text { Alerts more than } \\
\text { 4 m from Possible } \\
\text { Graves }\end{array}$ \\
\hline 9 & 2 & 1 & 3 & 8 \\
\hline 20 & 1 & 4 & 6 & 3 \\
\hline 26 & 0 & 2 & 0 & 0 \\
\hline 31 & 0 & 6 & 12 & 11 \\
\hline 34 & 3 & 6 & 15 & 17 \\
\hline
\end{tabular}

The dogs also performed well at cemeteries where the visual cues were misleading. At Cemetery 9, 3 of the 4 teams alerted in the dirt tract outside of the cemetery fence line, which corresponds to the results of the geophysical survey that indicated the graves extended under and outside of the fence line. Geophysical survey also indicated that the broken stone slabs at Cemetery 26 had a very low probability of being a grave, and no dogs alerted on this feature. One handler stated that if she was the one generating alerts, she would have alerted on the slabs. Her dog, however, showed no interest in it and she trusted her dog.

\footnotetext{
3 While travel expenses were not included as part of this analysis, it should be noted that the cost of flying with four dogs was significant. ICF travel expenses comprised the majority of their budget and were more than double the expenses of the government team, despite the fact that their trip was of shorter duration.

${ }_{4}^{4}$ ICF is a nonprofit organization and did not include overhead expenses in their billing.
} 
The alerts that were more than $4 \mathrm{~m}$ away from the geophysical anomalies were often within the general areas of the grave anomaly clusters. An example would be that the anomalies at Cemetery 26 were clustered on the east side of the survey block and no alerts were generated in the western portion of the survey area.

HHRD dog teams consist of members who are interested in and being paid to find graves. It might be argued that the teams are predisposed to generating alerts at every survey site. Possible results of this predisposition may include the dogs alerting at every survey in order to get their reward or the handlers relaxing their criteria in the interpretation of alert behavior as the survey progresses without any strong alerts. In our survey, half of the teams generated no alerts at Cemetery 26. This finding indicates that the dogs and/or handlers are not conditioned to alert at every survey and do not claim to find graves at every location where graves are suspected. 


\section{Conclusions and Recommendations}

The study detailed in this report was intended to determine the effectiveness of HHRD dog teams in locating unmarked human burials. Human burial studies are problematic because investigations must be nonintrusive, and results cannot be verified through excavation. The study demonstrated that use of dog teams has some advantages over traditional geophysical survey techniques, but there are other scenarios where use of the dogs would not be advisable.

The first question of HHRD dog accuracy that should be addressed is whether the dogs can differentiate between human and nonhuman animal remains. Unmarked cemeteries are often located in areas that are overgrown or wooded, and there is a probability that naturally occurring decomposed faunal remains may be present in the study area. While the science of decomposition scent detection is not fully understood (see Section 2.1), it has been demonstrated in this study and others that trained dogs do appear to be able to differentiate between the scents of human and nonhuman skeletal remains. Chapter 4 details the controlled study portion of this experiment where human, nonhuman carnivorous (coyote), and nonhuman herbivorous (deer) bones were buried near preexisting domesticated nonhuman animal (pig) burials. The dogs performed well in this portion of the study, with alerts located within $10 \mathrm{~m}$ of buried nonhuman animal remains being the least common of all alert types.

The second question of accuracy concerns whether the dogs can pinpoint the exact location of a grave. The answer to this question would be that the dogs infrequently achieve this degree of accuracy. In the control study portion of this experiment (Chapter 4), where bones had been buried for 1 year, no dog alerts were recorded closer than $2 \mathrm{~m}$ of the burial location. Additionally, the presence of fence posts and a depressed area with broken sod in the general area of the burials created a conduit for the scent to rise to the surface at a spot some distance away from the burial locations, further reducing accuracy of the results. At the five Fort Gordon cemeteries (Chapter 6), where the remains had been in place for at least 50 years and in-situ decomposition had occurred, $5 \%$ of the dog alerts were located immediately over potential grave sites and $19 \%$ of the alerts were located 
within $1 \mathrm{~m}$ of the potential grave sites. The Fort Gordon survey demonstrated, however, that $61 \%$ of the dog alerts were located within $4 \mathrm{~m}$ of a geophysical anomaly described as a likely grave, and very few alerts were located more than $10 \mathrm{~m}$ away from suspected grave locations. The conclusion is that HHRD dogs do alert in the vicinity of graves but have difficulty pinpointing exact grave locations. It is recommended, therefore, that any HHRD dog alert not be interpreted as the location of a grave but as the center of a 4-5 $\mathrm{m}$ radius circle that may contain a grave.

Finally, the possibility that the dogs and/or handlers utilize visible cues to generate alerts was also examined in this study. In the control portion of the study, effort was taken to remove all visual cues from the test site. The HHRD survey occurred a year after sample burial, so the grass would have opportunity to regrow, and all excess soil generated in the burial process was removed from the site. At Fort Gordon cemeteries (Chapter 6), sites were selected where visual cues were deliberately misleading. At Cemetery 9, for example, potential graves were identified under and outside of the cemetery perimeter fence and not in the center of the fenced area. Three of the four dog teams successfully alerted outside of the fence line in the vicinity of the suspected grave locations. At Cemetery 26, there were broken limestone slabs that strongly resembled gravestones. Geophysical surveys indicated that the ground beneath the slabs had a low probability of containing graves. No HHRD dog team alerted in the vicinity of these stones despite the fact that one handler commented that the stones looked suspiciously grave-like. At Clements Cemetery (Chapter 5), where unmarked graves were interspersed with marked graves, one handler reported that his dog was not using her nose but instead alerting at tombstones. The handler did not record those alerts and did not continue the survey. This indicates that the dogs are smart enough to key in on visual cues, but that the handlers are aware of their dogs' working methods and can identify when their dogs are not working the study area properly. The conclusion is that while both the dogs and handlers are identifying visual cues at study locations, the teamwork between dog and handler tends to nullify the effects of visual observation of the study area.

The portion of the study where the dogs struggled was in the search for unmarked graves within a sizable cemetery (Chapter 5). The dogs appeared overwhelmed by the number of graves. The handlers reported that the large number of graves created a general aura of scent and made the identification of specific alert locations very difficult. Environmental con- 
ditions were problematic at this location with both the geophysical survey and the HHRD dog team survey. The archaeologists conducting the geophysical survey stated that better results might have been obtained with better conditions. The dog handlers, however, stated that it was unlikely that better results would have been obtained had the weather been different. Combined with the HHRD teams' low success rate in identifying the exact location of graves, it is not recommended that HHRD dogs be utilized to located exact grave locations within a larger cemetery.

The HHRD dog team surveys on Fort Gordon proved to be significantly faster and more cost effective than the geophysical survey of the same cemeteries. The dog team fieldwork was conducted in half the time of the geophysical survey. Four of the five cemeteries at Fort Gordon were located in overgrown and wooded areas, resulting in the geophysical survey team having to devote a significant portion of their field time to brush and ground clearing; however, it is doubtful that the geophysical survey could have been conducted as quickly as the dog team survey, even in ideal conditions. Preliminary results from the dogs were available immediately after the survey, and the ICF final report was completed in half the time of the geophysical report. Excluding travel expenses, the cost of the HHRD dog team field survey was $12 \%$ of the cost of the geophysical survey.

One aspect of the study where geophysical survey techniques proved superior to HHRD dog surveys was in the detail and transparency of the data analysis. As stated above, HHRD dog teams had a low degree of success in alerting immediately over suspected graves. Dog alerts resulted in a single GPS coordinate location (that might have been located several meters away from the potential grave) and a description on the strength of the dog alert. No other information about the potential grave could be provided. Geophysical survey techniques were not only able to pinpoint the exact location of anomalies, but they were also able to determine the size, shape and orientation of those anomalies. These characteristics were used to determine the likelihood that each one of the anomalies could or could not be described as a potential grave.

Geophysical survey data can be stored and/or disseminated, making it possible for the customer (or a third party) to evaluate the criteria used to identify grave-like anomalies and repeat or redo the data analysis. In the dog team surveys, the alerts result from a series of communications between the dog and the handler. Each dog has their own way of working the 
study area, interpreting the scents they are detecting, and reporting that information to their handler. HHRD dog teams are certified as a team; handlers cannot switch dogs with each other and expect to get accurate results. As a result, a third-party dog handler at the study location would not be able to observe a HHRD dog team working or a video of the survey and come up with an independent analysis of the dog's behavior. The only way to repeat or verify the analysis is to bring additional dog teams to the site and repeat the entire study.

Both geophysical and HHRD dog studies were improved by overlapping multiple data sets. The geophysical survey in this study utilized GPR and magnetic gradiometer technologies. The areas where graves were deemed most likely to be present were the areas where anomalies appeared in both sets of data. In the HHRD dog study, each survey area was worked independently by multiple dog teams; the data was most compelling when all or most of the dogs alerted in the same area. Additionally, dog team accuracy was not consistent by teams. The data demonstrated that at one cemetery a particular dog team could alert right over a potential grave and at the next site, that same team could generate alerts that were the farthest away from burial locations. It is strongly recommended, therefore, that regardless of what techniques are utilized, 5 multiple techniques or surveys be conducted whenever possible.

Both geophysical and HHRD dog surveys conducted as part of this study were affected adversely by environmental conditions. At the Clements Cemetery, GPR results were not conclusive, in part due to water saturation of the soil. At Cemetery 9 on Fort Gordon, the presence of a barbed wire fence in the survey area distorted the magnetic gradiometer data. At multiple cemeteries, a significant amount of underbrush and ground clearing had to occur prior to the geophysical survey to insure high-quality data. A couple of the HHRD dogs did not want to work at the Clements Cemetery due to the presence of snow. Several handlers commented that it took more time to get good alert locations at the control study site due to the high wind that was blowing that day. Finally, ICF requested that the surveys at Fort Gordon be conducted in the fall or spring so that the dogs were not working in the heat and humidity of the Georgia summer. Therefore, CRMs should provide descriptions of environmental and soil condi-

\footnotetext{
5 Additional geophysical techniques, such as electrical resistance, were not utilized due to soil types at the study locations used here, but they might be deployed elsewhere.
} 
tions to any survey team (regardless of survey type) and understand that the results of surveys may vary depending on field conditions.

The results of this study indicate that there is a scientific basis for the claims that HHRD dog teams can detect decomposing skeletal remains and differentiate between human and animal bones. At locations of in-situ decomposition, the dog teams consistently generated alerts in the proximity of suspected or known graves at a much higher statistical rate then if they were doing it by chance. The speed and reduced cost of HHRD dog team surveys make this a very attractive technique to land managers. It should be noted, however, that the dog teams perform some tasks better than others. They struggled in this study with identifying unmarked grave locations within cemeteries of a significant size. The difficulty the dogs had in pinpointing exact grave locations and the inability to provide any information on the characteristics of the potential graves is also problematic for generating a definitive understanding of the unmarked cemeteries being studied.

The authors have concluded that the best utilization of HHRD dog teams is in conjunction with, and not in place of, traditional geophysical survey techniques. Geophysical survey is expensive and time consuming, but it provides a great deal of information about potential cemetery sites. A CRM confronted with an area many hectares in size that is rumored to contain an unmarked cemetery may find that it is cost prohibitive to a conduct geophysical survey of the entire area. An HHRD dog team survey could be conducted at relatively little cost (compared to geophysical techniques) over the entire area and provide information about which portion to focus geophysical survey efforts on. By significantly reducing the area needed to be examined by geophysical survey techniques, HHRD dog team investigations can provide a meaningful cost benefit to CRMs at DoD installations. 


\section{References}

Baxter, Carey L., Michael L. Hargrave, and Carl G. Carlson-Drexler.2010. Archival and Geophysical Investigations to Locate a Civil War Cemetery and Railroad Station, Fort Lee, Virginia. Report submitted to Fort Lee Cultural Resource Management, Fort Lee, VA. Champaign, IL: Engineer Research and Development Center, Construction Engineering Research Laboratory.

Bevan, Bruce W. 1991. “The Search for Graves.” Geophysics 56(9):1310-1319.

The Bone Room. 2014. “The Bone Room FAQ - About Bones.” Accessed 1 March 2014 http://www.boneroom.com/store/c83/About_Our_Products.html

Burks, Jarrod. 2009a. Search for Unmarked Graves and Other Underground Features at the Franklinton Cemetery, Columbus, Ohio. OVAI Contract Report \#2009-41. Columbus, OH: Ohio Valley Archaeology, Inc. . 2009b. Geophysical Survey at the Holt Cemetery, Pike County, Ohio. OVAI Contract Report \#2009-22a. Columbus, OH: Ohio Valley Archaeology, Inc.

Cablk, Mary E. and John C. Sagebiel. 2011. "Field Capability of Dogs to Locate Individual Human Teeth.” Journal of Forensic Science; 56(4): 1018-1024.

Cablk, Mary E., Erin E. Szelagowski, and John C. Sagebiel. 2012. "Characterization of the Volatile Organic Compounds Present in the Headspace of Decomposing Animal Remains, and Compared with Human Remains." Forensic Science International 1(2): $16-24$.

Clark, Anthony. 2001. Seeing Beneath the Soil: Prospecting Methods in Archaeology. Revised paperback edition; originally published 1990 by B.T. Batsford Ltd. New York City: Routledge.

Clay, R. Berle. 2001. "Complementary Geophysical Survey Techniques: Why Two Ways are Always Better than One." Southeastern Archaeology 20(1):31-43.

Conyers, Lawrence B. 2004. Ground-Penetrating Radar for Archaeology. Walnut Creek, CA : Altamira Press. . 2006a. "Ground-Penetrating Radar Techniques to Discover and Map Historic Graves." Historical Archaeology 40(3):64-73. . 2006b. Developing an efficient and Cost Effective Ground-Penetrating Radar Field Methodology for Subsurface Exploration and Mapping of Cultural Resources on Public Lands. Final Report on SI-1261 to SERDP. Denver, CO: University of Denver, Department of Anthropology. . 2012. Interpreting Ground-Penetrating Radar for Archaeology. Walnut Creek, CA: Left Coast Press.

Crane, Breed, and Company. 1858. Fisk's and Crane's Patent Metallic Burial Cases and Caskets. Cincinnati, $\mathrm{OH}$. 
Ernenwein, Eileen G., and Michael L. Hargrave. 2009 (rev. from 2007). Archaeological Geophysics for DoD Field Use: A Guide for New and Novice Users. Report submitted to the Environmental Security Technology Certification Program for Project RC-200611: Streamlined Archaeo-geophysical Data Processing and Integration for DoD Field Use. Fayetteville, AR: Center for Advanced Spatial Technologies, University of Arkansas. Accessed 5 March 2014. https://wayback.archiveit.org/6471/20150825215604/http://cast.uark.edu/assets/files/PDF/ArchaeologicalGeophys icsforDoDFieldUse.pdf

France, D. L., T. J. Griffin, J. G. Swanburg, J. W Lindemann, G. C. Davenport, V. Trammell. 1997. NecroSearch Revisited: Further Multidisciplinary Approaches to the Detection of Clandestine Graves. In Forensic Taphonomy: the Post-Mortem Fate of Human Remains, 497-509. W. D. Haglund and M. H Sorg, ed. Boca Raton: CRC Press.

Gaffney, Chris, and John Gater. 2003. Revealing the Buried Past, Geophysics for Archaeologists. Gloucestershire, UK: Tempus Publishing, Ltd.

Geophysical Survey Systems, Inc. 2009. RADAN Version 6.6 (user manual). http://www.uvm.edu/ lewebb/CCLI/Manuals/

Hargrave, Michael L. 2010. "Geophysical Detection of Features and Community Plan at New Philadelphia.” Historical Archaeology 44 (1) 43-57.

. 2011. Geophysical Investigations of Five Historic Cemeteries at Fort Gordon, Georgia. Report on file at the Office of Environmental Division, DPW, Fort Gordon, GA. Champaign, IL: Engineer Research and Development Center, Construction Engineering Research Laboratory.

Hargrave, Michael L., with contributions by Robert Dunn. 2010. Geophysical Investigations in Search of the 1877-1878 Nez Perce Cemetery, Fort Leavenworth, Kansas. Report submitted to Fort Leavenworth Cultural Resource Management, Fort Leavenworth, KS. Champaign, IL: Engineer Research and Development Center, Construction Engineering Research Laboratory.

Hargrave, Michael L., Jarrod Burks, and Carey Baxter. 2010. Archival and Geophysical Investigations of the Fort Monroe Post Cemetery. Report submitted to Fort Monroe Cultural Resource Management, Fort Monroe, VA. Champaign, IL: Engineer Research and Development Center, Construction Engineering Research Laboratory.

ICF (Institute for Canine Forensics). 2013a. ICF Company Resume. Accessed 13 February 2014. www.HHRDD.org.

. 2013b. Using Historical Human Remains Detection Dogs Practices and Procedures. Accessed 13 February 2014. www.HHRDD.org.

Johnson, Jay K. 2006. Remote Sensing in Archaeology: An Explicitly North American Perspective. Tuscaloosa, AL: The University of Georgia Press.

Killam, W. Edward. 1990. The Detection of Human Remains. Springfield, IL: Charles C. Thomas Press. 
Komar, Debra. 1999. "The Use of Cadaver Dogs in Locating Scattered, Scavenged Human Remains: Preliminary Field Test Results.” Journal of Forensic Sciences 44(2): 405-408.

Kvamme, Kenneth L. 2003. "Geophysical Surveys as Landscape Archaeology." American Antiquity 68(3):435-457. . 2006. “Integrating Multidimensional Geophysical Data.” Archaeological Prospection 13(1): 57-72.

Lasseter, Alanna E., Keith P. Jacobi, Ricky Farley, and Lee Hensel. 2003. "Cadaver Dog and Handler Team Capabilities in the Recovery of Buried Human Remains in the Southeastern United States.” Journal of Forensic Sciences 48(3): 1-5.

Prowse, Tracy L. 2008. Burial Excavation and Recording Techniques. In Encyclopedia of Archaeology, 944-948. Deborah M. Pearsall, ed. New York: Academic Press.

Somers, Lewis E. 2006. "Resistivity Survey." In Remote Sensing in Archaeology: An Explicitly North American Perspective, 109-129; Jay K. Johnson, ed. Tuscaloosa, AL: University of Georgia Press.

Vass, Arpad A., Rob R. Smith, Cyril V. Thompson, Michael N. Burnett, Nishan Dulgerian, and Brian A. Eckenrode. 2008. "Odor Analysis of Decomposing Buried Human Remains.” Journal of Forensic Science 53(2): 384-391.

Vass, Arpad, A., Rob R. Smith, Cyril V. Thompson, Michael N. Burnett, Dennis A. Wolf, Jennifer A. Synstelien, and Nishan Dulgerian. 2004. "Decompositional Odor Analysis Database.” Journal of Forensic Science 49(4): 1-8.

Witten, Alan J. 2006. Handbook of Geophysics and Archaeology. Sheffield, UK: Equinox Publishing. 


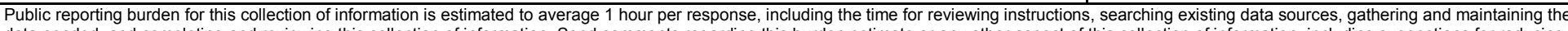

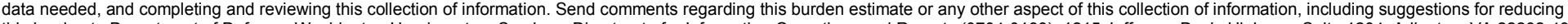

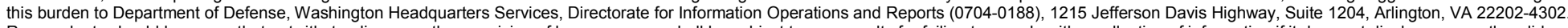

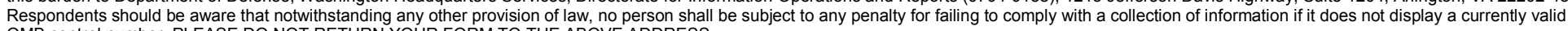
OMB control number. PLEASE DO NOT RETURN YOUR FORM TO THE ABOVE ADDRESS.
1. REPORT DATE (DD-MM-YYYY)
2. REPORT TYPE
Final
3. DATES COVERED (From - To)

31-12-2015

4. TITLE AND SUBTITLE

Guidance on the Use of Historic Human Remains Detection Dogs for Locating Unmarked Cemeteries

5a. CONTRACT NUMBER

5b. GRANT NUMBER

5c. PROGRAM ELEMENT NUMBER

6. AUTHOR(S)

Carey L. Baxter and Michael L. Hargrave

5d. PROJECT NUMBER

Project $12-510$

5e. TASK NUMBER

5f. WORK UNIT NUMBER

8. PERFORMING ORGANIZATION REPORT NUMBER

ERDC/CERL TR-15-36

\section{Construction Engineering Research Laboratory (CERL)}

U.S. Army Engineer Research and Development Center (ERDC)

PO Box 9005

Champaign, IL 61826-9005

\section{SPONSORING / MONITORING AGENCY NAME(S) AND ADDRESS(ES)}

DoD Legacy Resource Management Program

4800 Mark Center Drive, Ste 16G14

PO Box 56

Alexandria, VA 22202

10. SPONSOR/MONITOR'S ACRONYM(S) LRMP

11. SPONSOR/MONITOR'S REPORT NUMBER(S)

12. DISTRIBUTION / AVAILABILITY STATEMENT

Approved for public release. Distribution is unlimited.

\section{SUPPLEMENTARY NOTES}

\section{ABSTRACT}

Human burial sites form a unique class of archeological site. Local civilian populations tend to have strong emotional ties to historic cemeteries, and Native American cemeteries are given special protection under federal law. Standard operating procedures on most (if not all) government installations is to identify and protect (in situ) all known locations of human burials. The location of many cemeteries, however, is un-known due to a lack of recognizable visual cues such as grave markers. Because the sites must be investigated without excavation, archaeologists have traditionally used geophysical survey as a noninvasive technique to locate lost cemeteries.

A recent development in noninvasive grave location techniques is the use of Historic Human Remains Detection (HHRD) dogs. These dogs are specially trained to detect the scent of buried human bones. Proponents of this techniques claim the dogs can differentiate between human and animal bones and can detect graves exceeding 100 years of age and located up to 6 feet beneath the surface. Determining the effectiveness of HHRD dog surveys is problematic because ground truthing is rarely allowed. This report describes a scientific study testing the effectiveness of HHRD dogs and comparing HHRD dog results against geophysical survey results at multiple, unmarked, burial sites.

\section{SUBJECT TERMS}

archaeological research, historic archaeology, Native American cemeteries, historic human remains detection (HHRD) dogs, unmarked burial sites

\begin{tabular}{|c|c|c|c|c|c|}
\hline \multicolumn{3}{|c|}{ 16. SECURITY CLASSIFICATION OF: } & \multirow{2}{*}{$\begin{array}{l}\text { 17. LIMITATION } \\
\text { OF ABSTRACT } \\
\text { UU }\end{array}$} & \multirow{2}{*}{$\begin{array}{l}\text { 18. NUMBER } \\
\text { OF PAGES } \\
114\end{array}$} & 19a. NAME OF RESPONSIBLE PERSON \\
\hline $\begin{array}{l}\text { a. REPORT } \\
\text { Unclassified }\end{array}$ & $\begin{array}{l}\text { b. ABSTRACT } \\
\text { Unclassified }\end{array}$ & $\begin{array}{l}\text { c. THIS PAGE } \\
\text { Unclassified }\end{array}$ & & & $\begin{array}{l}\text { 19b. TELEPHONE NUMBER (in- } \\
\text { clude area code) }\end{array}$ \\
\hline
\end{tabular}

